Portland State University

PDXScholar

\title{
Temporal and phenomenological aspects of social behavior in captive wolves (Canis lupus L.)
}

Paul C. Paquet

Portland State University

Follow this and additional works at: https://pdxscholar.library.pdx.edu/open_access_etds

Part of the Animal Sciences Commons, and the Biology Commons Let us know how access to this document benefits you.

\section{Recommended Citation}

Paquet, Paul C., "Temporal and phenomenological aspects of social behavior in captive wolves (Canis lupus L.)" (1982). Dissertations and Theses. Paper 3222.

https://doi.org/10.15760/etd.3213

This Thesis is brought to you for free and open access. It has been accepted for inclusion in Dissertations and Theses by an authorized administrator of PDXScholar. Please contact us if we can make this document more accessible: pdxscholar@pdx.edu. 
AN ABSTRACT OF THE THESIS OF Paul C. Paquet for the Master of Science in Biology presented January 14, 1982.

Title: Temporal and Phenomenological Aspects of Social Behavior in Captive Wolves (Canis lupus L.).

APPROVED BY MEMBERS OF THE THESIS COMMITTEE:

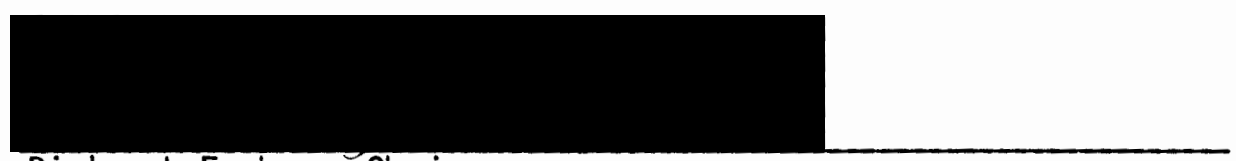

Richard Forbes, Chairman

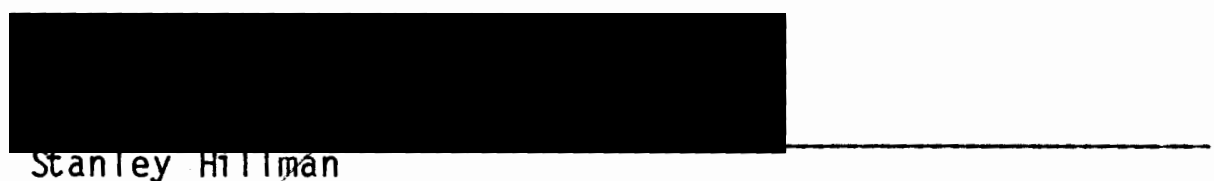

Stanley hinman

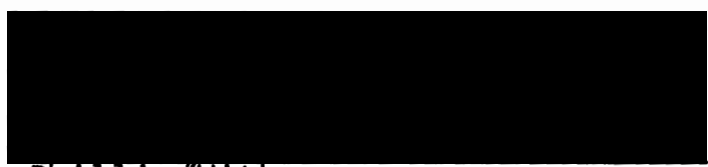

Phillip/withers

At though cooperative behavior is generally acknowledged to occur among wolves, there is a lack of systematically collected data confirming the extent of development. The objectives of this study were to collect long-term, detailed observations documenting the role of social structure, seasonal influences, and individual participation in wolf pack cooperative activities. Individual cooperative strategies were associated with age, sex, and social positions and critically compared with results of similar studies. Emphasis was placed on quantifying group and dyadic relationships, focusing on reproductive strategies and dominance structure. Additional data were collected on 
denning behavior, maternal care behavior, scent marking, and spontaneous individual and group howling.

Pack social activity fluctuated seasonally. It peaked during October-November and was lowest during June-July. Friendly behavior comprised the majority of activity throughout the year and, as such, had the most profound influence on general behavior. Changes in aggressive activity began and ended later than changes in general activity. High levels of aggression closely coincided with changes in the rank order. Fluctuations in submissive activity were of no apparent significance.

Assessment of social structure was conflicting, suggesting the presence of either a single social order composed of both sexes or two sexually distinct hierarchies. Rank order determined quantitatively (QRO) correlated with the Rank order determined by food acquisition (FRO) during winter months of two consecutive years for males and females. Rank order determined subjectively (SRO) closely agreed with QRO in all seasons, whereas FRO and SRO were comparable in winter months only.

Removal and reintroduction of wolves precipitated increases in aggressive behavior. The degree of aggression increased with the length of separation. Chorus howling fluctuated seasonally, remaining relativley constant during summer and fall, and gradually increasing in December to a peak in February and March. The number of chorus howls initiated by individual wolves appeared related to social rank. Solo howling followed a seasonal pattern similar to that observed for chorus howling. Again, social position influenced the degree of howling. 
The frequency of urine marking fluctuated seasonally with an increase beginning in November. A slight decrease was noted during the latter part of February when females were sexually receptive. Social position appeared to influence the rate of urine marking exhibited by individual wolves.

Courtship and mating involved only wolves 22 months and older. Younger animals showed no physical or behavioral signs of mating activty. With the exception of 1977, all matings were between alpha animals. Single litters were born in 1975 and 1976. Pup care during those years is compared with care of two concurrent litters born in 1977, which were cared for communally. 
TEMPORAL AND PHENOMENOLOGICAL ASPECTS OF SOCIAL BEHAVIOR

IN CAPTIVE WOLVES (Canis lupus L.)

by

PAUL CHARLES PAQUET

A thesis submitted in partial fulfillment of the requirements for the degree of

\author{
MASTER OF SCIENCE \\ in \\ BIOLOGY
}

Portland State University

1982 
TO THE OFFICE OF GRADUATE STUDIES AND RESEARCH:

The members of the Committee approve the thesis of Paul Charles Paquet presented January 14, 1982.

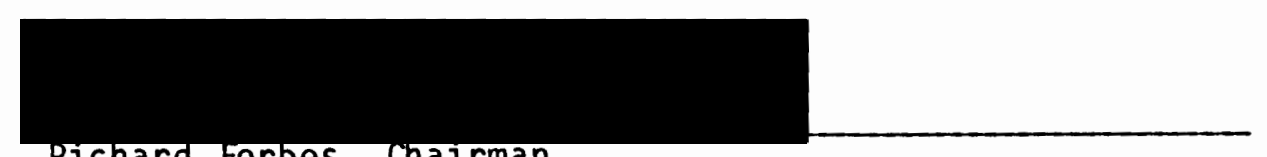

Richard Forbes, Chatrman

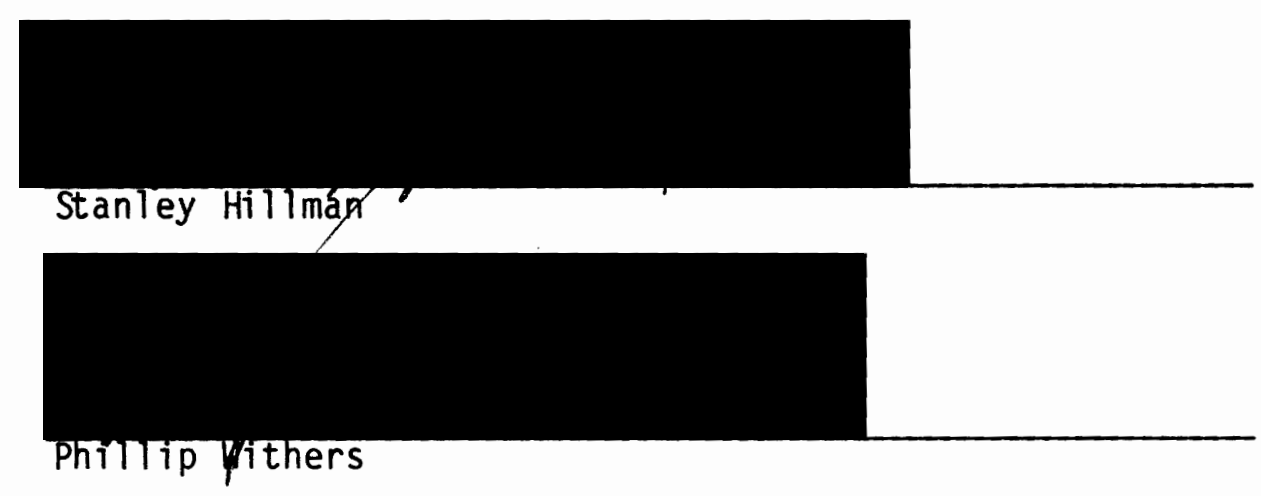

APPROVED :

W. Herman Taylor, Head, Department of Biology

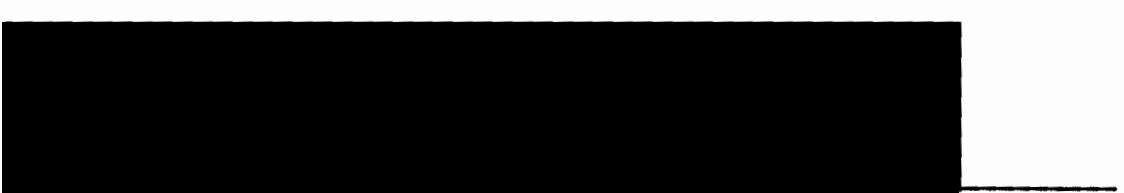

Stanley E. Rauch, Dean of Graduate Studies and Research 


\section{ACKNOWLEDGEMENTS}

I gratefully acknowledge the invaluable assistance of Washington Park Zoo staff and volunteers, especially Susan Bragdon, Dawn Gilkinson, Anne Mason, Brooke Friendly, Jill Mellin, Gordon Noyes and Dan Heath. I wish to thank Zoo Director, Warren Il iff, and General Curator Steve McCusker for their constant support throughout the project. Also, Richard Forbes, Stanley Hillman and Robert Tinnin for help in preparation of the manuscript and their friendly advisement and encouragement. I would like to extend a very special thanks to my wife Jennifer for her tolerance during all phases of the research, as well as her patience while typing the manuscript. Lastly, I thank my parents, Joseph and Evelyn Paquet, for financial and emotional support. 
ACKNOWLEDGMENTS..................................... ii

LIST OF TABLES......................................

LIST OF FIGURES.....................................

INTRODUCTION............................................

Social Organization.................................

Reproduction and Mating.............................

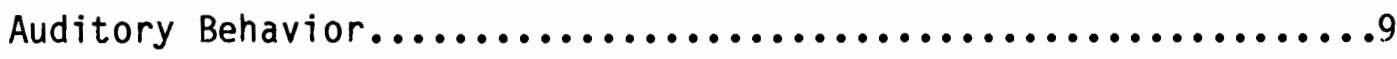

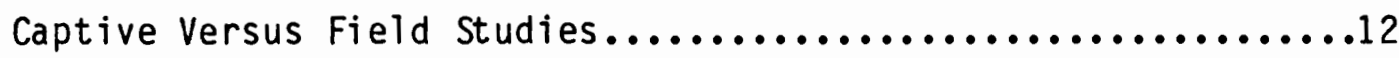

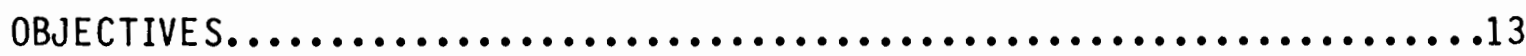

MATER IALS AND METHODS..................................14

Study Site........................................14

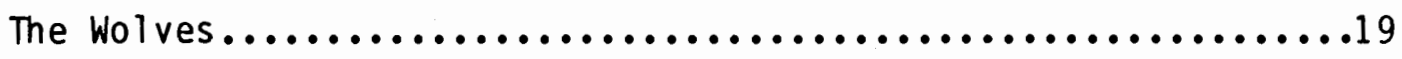

Behavioral Observations..............................24

Behavioral Measures.................................26

RESULTS............................................29

Pack Development and Behavioral Overview..................29

Activity Profile......................................

Dominance Relationships..................................

Rank Changes.........................................

Measures of Social Rank............................47

Effects of Removals \& Reintroductions on Aggressive Behavior....55

Howt ing. ........................................... 
Scent Marking....................................60

Mating Behavior.....................................63

In Utero Mortality...............................64

Pup Care.........................................65

Division of Maternal Care...........................66

Time Budget.....................................67

Cooperative Feeding During Denning........................1

DISCUSSION............................................

Variability in Wolves................................75

Social Behavior and Dominance Relationships...............77

Influence of Biosocial and Environmental Factors............81

Pack Composition................................81

Seasonality.....................................81

Time and Energy.................................81

Health of Individual Pack Members.....................82

Genetic Relatedness..............................82

Size of Enclosure...............................83

Environmental Conditions..........................83

Manipulation of Animals..........................83

Mating Relationships..............................84

Multiple Litters.................................84

Evolutionary Aspects of Multiple Litters.................88

In Utero Mortality $\ldots \ldots \ldots \ldots \ldots \ldots \ldots \ldots \ldots \ldots \ldots \ldots \ldots . \ldots . \ldots . \ldots$

Pup Preferences.....................................91

BIBLIOGRAPHY......................................93

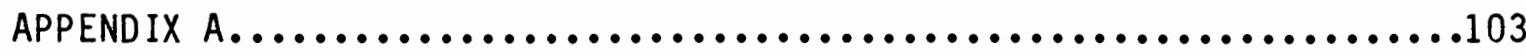

APPEND IX B................................................ 


\section{LIST OF TABLES}

TABLE

PAGE

I Yearly Distribution of of Observation Hours...............25

II Denning Observation Hours $\ldots \ldots \ldots \ldots \ldots \ldots \ldots \ldots \ldots \ldots \ldots \ldots$

III Correlational Relationships of Group Behavioral Categories....37

IV Dominance Matrix...................................

V Dominance Relationships During Winter Months, 1975-77........42

VI Statistical Comparison of Intrasexual and Intersexual

Behavioral Activity.........................43

VII Changes in Aggression Following Removal and Reintroduction

of Wolves..................................56

VIII Solo and Chorus Howls Recorded from June 1976 to 1978.........58

IX Relationship between Social Status and Chorus Howls for

the Periods, June $1976-77$ and June $1977-78 . \ldots \ldots \ldots \ldots . .58$

$X$ Relationship between Social Status and Solo Howls for the

Periods June 1976-77 and June 1977-78................59

$X I$ Scent Marking by Individual Wolves for the Period

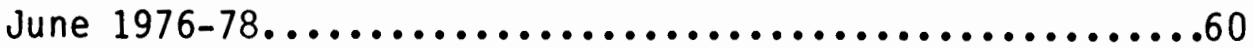

XII Social Status and Urine Marking for the Periods June

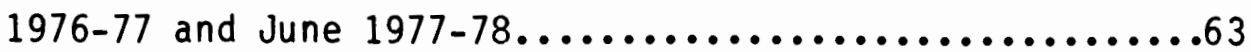

XIII Mating Behavior.................................64

XIV A Comparison of Care Behavior of Denning Mothers............67

XV Percentage of Time Females Present in Den with Pups..........70 
TABLE

PAGE

XVI Time Pups Left Alone.............................

XVII Feeding Distribution during Denning - 9 May-14 June, 1977.....72

XVIII Feeding Distribution during Denning - 23 April-7 June, 1976...73

XIX Feeding Distribution during Denning - 14 April-1 June, 1975...74 


\section{LIST OF FIGURES}

FIGURE

PAGE

1. Wolf Enclosure, September 1974 - June 1976, Washington

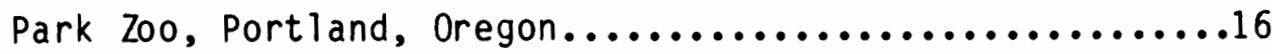

2. Wolf Enclosure, June 1976 to present, Washington Park

Zoo, Portland, Oregon..........................18

3. Chronology of Acquisitions, Births, Deaths and Transfers of

the Wolf Pack, Washington Park Zoo, Portland, Oregon......20

4. Wolf Pack Geneology from 1975 through 1978, Washington

Park Zoo, Portland, Oregon......................22

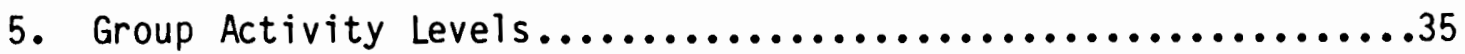

6. Total Number of Observed Interactions in which a Designated

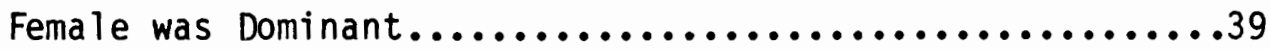

7. Total Number of Observed Interactions in which a Designated

Male was Dominant...............................41

8. Dominance Hierarchy as determined by Landau's Index of

Linearity................................43

9. Comparison of Intrasexual and Intersexual Aggressive

Behavior....................................44

10. Comparison of Intrasexual and Intersexual Friendly

Behavior.....................................45 
11. Comparison of Intrasexual and Intersexual Submissive Behavior .046

12. Percentage of Social Encounters in which Juneau Dominated Sitka compared to Percentage of Food Encounters in which Juneau Dominated Sitka for the Period 1 January5 May 1977. .49

13. Percentage of Social Encounters in which Zane Dominated Mowgli compared to Percentage of Food Encounters in which Zane Dominated Mowgli for the Period 1 January-

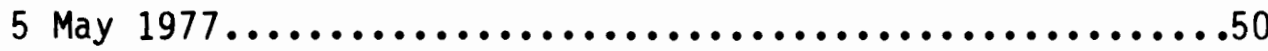

14. Percentage of Social Encounters in which Juneau Dominated Sitka compared to Percentage of Food Encounters in which Juneau Dominated Sitka for the Period 24 June-

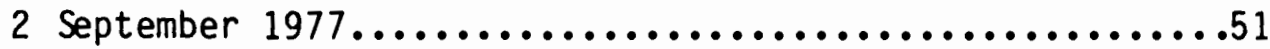

15. Percentage of Social Encounters in which Zane Dominated Mowgli compared to Percentage of Food Encounters in which Zane Dominated Mowgli for the Period 24 June-

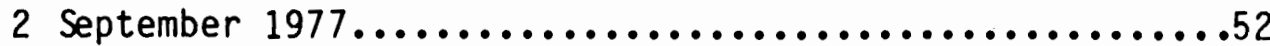

16. Percentage of Social Encounters in which Juneau Dominated Sitka compared to Percentage of Food Encounters in which Juneau Dominated Sitka for the Period 31 December31 March 1978...................................54 
17. Percentage of Social Encounters in which Zane Dominated Mowgli compared to Percentage of Food Encounters in which Zane Dominated Mowgli for the Period 31 December-

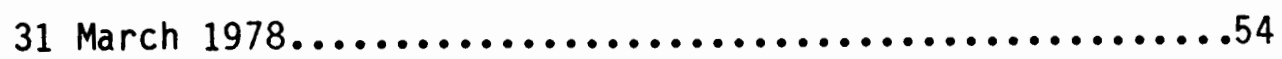

18. Seasonal Frequency of Chorus and Solo Howls..................57

19. Seasonal Frequency of Urine Marking....................62 20. Time Periods when Communally Denning Mothers were in Attendance................................68 
INTRODUCTION AND LITERATURE REVIEW

General Ecology

The wolf (Canis lupus L.) is a wide ranging, group hunting carnivore with a highly developed social organization. The advantages of group living include facilitation of male-female encounters, detection of prey, acquisition of resources, exchange of information, communal defense against rivals, protection of young from environmental extremes, division of labor, communal care of the young, and the shared benefits accrued through the individual experience of members (Wilson, 1975). Group living may have evolved primarily to enable wolves to exploit prey larger than themselves (Kleiman, 1967).

Wolves require extensive territory to provide for the nutritional needs of the pack. Home ranges vary with season, topography and available resources from a reported 36 square miles (Stenlund, 1955) to 5,000 square miles (Burkholder, 1959).

Pack activity alternates throughout the year between stationary and nomadic phases (Ognev, 1962; Harrington, 1975). The stationary period, beginning in late March or early April and lasting for five to six months, is centered around pup rearing and den site use. The pups remain in the sheltered den areas for seven to 10 weeks (Mech, 1970), after which most of their time is spent at "rendezvous sites" (Murie, 1944; Joslin, 1967; Harrington, 1975).

The nomadic phase begins, with considerable variation, in late September, at which time the pups are mature enough to travel (Van 
Ballenberghe and Mech, 1975). Movement of the pack during this phase is related primarily to hunting (Mech, 1970; Carbyn, 1974) with no one site being used regularly as a staging area. Breeding season occurs near the end of the nomadic period, starting in mid-February and extending into early March. Successful mating usually occurs only among the pack leaders (Rabb et al., 1967; Woolpy, 1968; Fox, 1971; Zimen, 1975). A pregnant female stops traveling with the pack three to five weeks prior to parturition, at which time she selects and prepares a den site (Murie, 1944; Mech, 1970). Most often only one litter of pups is born within a pack (Mech, 1970).

The pack is the basic social unit of wolf society, varying in size from two members to more than twenty (Rausch, 1967; Mech, 1970), with an average size of seven (0lson, 1938; Rausch, 1967; Mech, 1970). Pack size appears to be affected by a variety of factors including food supply, size of prey, prey density and wolf density (Zimen, 1976; Packard and Mech, 1980). The pack is commonly defined as a group of related individuals "travelling, hunting, feeding and resting together in a loose association; with bonds of attachments among all animals" (Mech, 1970). Al though packs have often been described as consisting of only a breeding pair and the young of the year (01son, 1938; Murie, 1944), numerous packs have been observed which include members beyond this immediate group (Mech, 1970). It is thought that consanguinous relationships within the pack help strengthen social cohesiveness and contribute to overall pack efficiency (Fox, 1971). 
Social Organization

The social organization of wolf packs has most often been described in terms of dominance theory (Murie, 1944; Schenke1, 1947, 1967; Rabb et al, 1967; Mech, 1970; Zimen, 1975), although recent dissatisfaction with this concept has prompted consideration of other models (Lockwood, 1976; Sharp, in press). Current researchers employ the dominance concept in a form modified from that described in early studies of social insects (Huber, 1802; Hoffer, 1882 cited in Wilson, 1975) and later popularized by Schjelderup-Ebbe $(1922,1935)$ while studying peck orders in domestic chickens. Successful application of the theory is dependent upon accurate assessment of social relationships among individual pack members.

Since the theory assumes that individual differences in competitive abilities result in unequal distribution of resources, it has been suggested that wolves may be ranked according to their access to various essential resources such as food (Fox, 1971). However, in practice, dominance, and thereby rank position, has most often been determined by qualitative evaluation of well described social behaviors, primarily body postures (Schenkel, 1947, 1967; Murie, 1944; Mech, 1966, 1970; Rabb et al., 1967; Haber, 1977; Woolpy, 1968; Zimen, 1975). The usefulness of food for elucidating social rank has been criticized as registering only food aggression, which may differ from the actual dominance order (Zimen, 1975). Support for this objection has been provided by observations in the field and in captivity which have failed to indicate any priority in feeding (Burkholder, 1959; Mech, 1970; Haber, 1973; Foster, pers. comm.). Moreover, Mech (1970) has described 
an "ownership zone," an area near an eating wolf's mouth into which no other wolf will tresspass, regardless of rank. However, conflicting information clearly suggesting feeding priority is provided from field observations by Allen (1979), who states that "there appear to be adults that regularly associate (with the rest of the pack) but are not allowed to eat at the first table." Rutter and Pimlott (1968) and Fox (1971) also imply that there is a correlation between food competition and postures and displays, although no quantified data are provided. Finally Lockwood (1976), as the result of a quantified study, concluded that food competition tests could be considered reliable and valid measures of social status and therefore of pack organization. However, the investigation was exclusively conducted in summer months and therefore did not account for changes in seasonal activity. Behavioral studies which neglect to consider the temporal aspects of wolf social behavior can be misleading (Zimen, pers. comm.).

Wolf social organization has been described as having separate male and female rank orders or hierarchies, with most males dominant over females (Mech, 1970; Zimen, 1975; Rabb et al.., 1967; Woolpy, 1968, Shotte and Ginsburg, 1978). An alternative view maintains that the dominance hierarchy is a single linear relationship composed of both males and females with a male always as pack leader. In this model, a separate dominance hierarchy may, at times, be seen among females, especially during breeding season (Fox, 1971). Most evidence suggests that separate hierarchies exist for both sexes throughout the year, becoming most obvious with the onset of estrus (Zimen, 1975). Additionally, each sexual order appears to be headed by a separate 
leader or alpha animal, one of which is also the alpha for the entire pack (Zimen, 1975; Haber, 1978; Allen, 1979).

Ranking directly beneath the two alpha wolves is a group of subdominant males and females. This group is typically composed of younger animals who have reached sexual maturity and former alpha wolves who have lost their position. Among the males in this group there exists minimal rank differences (Rabb et al., 1967; Mech, 1970; Zimen, 1975). Distinctions which do exist are the result of varying degrees of social suppression imposed by the alpha male on these lower ranking animals (Rabb et al., 1967; Zimen, 1975). Among the more aggressive females (Schenke1, 1947; Rabb, 1967; Woolpy, 1968; Mech, 1970; Zimen, 1975), the social rank order is more obviously linear. Increases in aggressive behavior prior to the onset of estrus play an important role in establishing the female rank order. During this time, the alpha female will often attempt to solidify her position by suppressing the activities of subdominant females. In turn, she is subject to challenges by lesser females intent on securing the dominant position (Schenkel, 1947; Rabb et al.., 1967; Woolpy, 1968; Zimen, 1975; Shotte, 1978).

Following this group of higher ranking, sexually mature wolves is a subgroup of low status juveniles. These immature wolves do not become fully integrated into the adult social organization until their second or third year (Woolpy, 1968; Fox, 1971; Zimen, 1975). Zimen (1975) maintains that within this subgroup, if it contains enough wolves, there exists another social order essentially duplicating that of the older pack members. He contends that high ranking wolves within this 
subgroup, when together with others of equal stature, behave much 1 ike the alpha wolves do within the entire pack. They mimic social displays and show increased alertness and aggressiveness during times of threat or danger. This conflicts with Ginsburg's (1968) observation that prior to integration into the adult social structure, the interactions of juveniles are generally inconsistent with adult behaviors.. He believes this to be less true as juveniles mature, with the process of integration being progressive. It is generally agreed that upon reaching sexual maturity, usually at two years of age, these wolves become part of the pack's primary social structure (Rabb et al., 1967; Woolpy, 1968; Zimen, 1975).

Independent of the social rank order are the pups. They never participate in rank order disputes and are commonly allowed social privileges not extended to adult or juvenile wolves (Schenke1, 1947; Rabb et al., 1967; Woolpy, 1968; Zimen, 1975). Dominance orders cross sexual lines in pups and do not divide into male and female orders until sexual maturity (Mech, 1970). Pups begin to lose social privileges as they approach the adults in physical stature, usually around six months.

At the very bottom of the dominance hierarchy is the pack "scapegoat," an ostracized and outcast wolf (Schenkel, 1947; Rabb et al., 1967; Zimen, 1975). This wolf, depending upon the position previously held, is continually assailed by the rest of the pack (Zimen, 1975). Joint attacks upon the scapegoat infrequently occur, but when they do the wolf may withdraw from the pack or, in extreme cases, may actually be killed (Zimen, 1975). At the very least, these wolves will become peripheral to the rest of the pack, being denied any form of 
social interaction. Ostracized wolves may be of either sex, but are frequently females (Zimen, 1975, 1976; Mal1, 1980). The wolf identified as the primary protaganist in ejecting the outcast is usually of the same sex, although not necessarily an alpha animal (Mall, pers. comm.).

Within the same pack, aggressive interactions between adult wolves of different sexes rarely occur, and when they do they are seldom severe (Rabb et al., 1967; Woolpy, 1968; Zimen, 1975). In spite of this, the alpha female is dominant over the subdominant males, and the subdominant males over the lower ranking females (Zimen, 1975). In other words, the two social rank orders are not fully independent, but show some interaction. Severe social altercations, which almost always involve rank disputes, are limited to wolves of the same sex.

Reproduction And Mating

Wolf populations seldom realize their potential rate of increase (Rausch, 1967; Zimen, 1976; Packard and Mech, 1980). Several mechanisms which could limit reproductive potential have been suggested, including post-natal mortality, failure of females to breed due to social restrictions, and various environmental contingencies affecting litter size and sex ratios (Rausch, 1967; Mech, 1970, 1975, 1978; Haber, 1974; Zimen, 1975, 1976). It has most recently been argued that wolf populations are regulated by an interaction of biological and social factors, with nutrition as the proximate control (Packard and Mech, 1980).

Rausch (1967) concluded "...(that) the observed variation in the abundance of young of the year is a function of in utero and post-natal mortality." Post-natal mortality has been documented by several 
investigators (Kelsall, 1968; Kuyt, 1972; Mech, 1975, 1977; Packard and Mech, 1978). Disproportionate sex ratios in litters has also been confirmed (Mech, 1975, 1978), as has loss of ova between ovulation and implantation (Rausch, 1967). Information on number of pups delivered versus number of fetuses implanted, however, is lacking (Mech, pers. comm.; Packard, pers. comm.).

Captive studies have confirmed that often, only the dominant female within a pack produces pups. This has been attributed, in part, to reproductive limitations imposed by pack social organization which prevents some sexually mature females from breeding (Fox, 1971; Zimen, 1975, 1976; Packard and Mech, 1980). However, claims that most matings are monogamous pairings between dominant animals are unsupported (Schenkel, 1947; Fox, 1971). Reports of multiple pregnancies within packs (Rabb et al., 1967; Rausch, 1967; Haber, in Fox, 1971), lack of courtship activity and breeding in alpha males (Murie, 1944; Rabb, 1967; Woolpy, 1968; Haber, 1978) and polygamy (Rabb et al., 1967) prompted a re-evaluation of this concept (Harrington et al., in press).

It now appears that in packs with well established and stable hierarchies, successful copulation may be limited to certain wolves. If the pack contains only a single mature pair, mating is of course restricted to these animals. In packs which include several mature wolves, mating commonly occurs between the alpha female and the beta male (Murie, 1944; Rabb et al., 1967; Woolpy, 1968; Haber, in Fox, 1971), although in some packs the alpha male may do all the mating (Zimen, 1975 and 1976). It may be that the alpha male only contributes to a pack's reproduction when it is first established (Mech, 1970) or 
when no other adult males are in the pack. This restrictive mating system is maintained through physical interference and by intimidation of lower ranking wolves by dominant animals (Rabb, 1967; Woolpy, 1968; Zimen, 1975). In packs which have not been long established and/or there has been a breakdown in social organization, restrictions on mating may not be present. In this situation, any sexually mature wolf may exercise the opportunity to mate, and several females may simultaneously produce litters (Rabb et al., 1967; Woolpy, 1968)

A recent review of wolf matings indicated that monogamy is only one of several mating systems (Harrington et al, in press). Three forms of monogamy were distinguished: 1) de facto monogamy, when only one adult pair is present in a pack; 2) forced monogamy, when intrasexual aggression limits mating opportunities to one partner despite the presence of other potential mates; and 3) preference monogamy, when individuals, by choice, limit their courtship and mating to one partner. The latter did not appear to adequately describe wolf mating patterns, as unequivocal evidence for it does not exist. Patterns of courtship and mating suggest that polygamy, constrained by intrasexual aggression in both sexes, more adequately describes wolf mating systems. Males exhibit a female defense polygyny and females display a female access polyandry (see Appendix A).

\section{Auditory Behavior}

It is generally recognized that auditory activity, like other animal behavior, is influenced by the time of day, seasonality, weather conditions and related environmental and biological conditions. Spontaneous group howling in wild wolves (howls not stimulated by known 
external factors) follows both daily and seasonal trends in frequency (Harrington, 1975). Studies with both captive and wild wolves have shown peaks in howling during evening and morning (Rutter and Pimlott, 1968; Zimen, 1972; Kl inghammer and Laidlaw, 1979). Al though the majority of howling may occur between dusk and dawn (Carbyn, 1974), howling has been heard at all times of day (Joslin, 1966; Harrington, 1975; Harrington and Mech, 1979).

There is an increase of howling in captive wolves beginning in fall, and peaking around breeding season in mid-February (Zimen, 1972, 1975; Klinghammer and Laidlaw, 1979). Elicited howling from wild wolves shows similar trends, with the increase in response rate being correlated with the breeding season. After the breeding season, the response rate drops both in captivity and the wild (Harrington and Mech, 1979). From a low rate in early summer, the response of wild wolves begins to rise in July and increases throughout the summer.

Joslin (1966) felt that the low early summer response rate was due to the presence of pups, suggesting that howling would jeopardize their safety by indicating their location. However, Voigt (1973), studying the same wolf pack as Joslin, found no increase in adult howling after denning, but attributed the increased July rate to the howling of pups.

Howling is also influenced by pack size. Generally, the larger the pack, the higher the response rate. It is thought that each individual has a finite probability of replying to a strange howl, and that the probability of a pack reply is simply the sum of individual probabilities (Harrington and Mech, 1979). Therefore, larger packs show increased rates of response. Alternatively, it has been hypothesized 
that select pack members initiate howling, with their response threshold being determined by the presence of other pack members (Harrington and Mech, 1979).

The frequency of induced howling also increases in the presence of new kills, gradually declining as the prey is consumed. The high response rate near kills is probably associated with defense of a valuable resource (Harrington, 1975). Additionally, the response rate of single animals varies according to social position, with high ranking adult males most responsive (Harrington, 1975).

Howling is thought to serve in long-distance communication, useful in reassembling separated members. It may also advertise territorial boundaries by communicating the location of packs or individuals, thereby reducing the chance of contact between them (Joslin, 1967; Theberge and Falls, 1967). Al though direct evidence of the territorial role of howling is lacking, circumstantial evidence does exist. Adjacent wolf packs often move apart after interpack howling, and separated pack members frequently return to the pack following howls by strangers (Harrington, 1975). Both behaviors suggest howling occurs in an agonistic context. In addition, three of the five major factors influencing the reply rate of elicited howling, pack size, social role and breeding season are closely associated with the degree of agonism displayed toward pack strangers. The other two factors - kills and pups - are important pack investments which necessitate protection (Harrington and Mech, 1979). 
Captive Versus Field Studies

Details of social organization within wolf packs have, to a large extent, been inferred from studies of captive wolves. Although the artificial environment may accentuate and alter the frequency of some behaviors (Hediger, 1950; Rutter and Pimlott, 1968; Fox, 1971; Sullivan and Paquet, 1977), captive studies permit close observations of animals in a group and environment which can be controlled (Fentress and Ryon, in press). By limiting the context in which animals can perform, we reduce the variables which may influence their activity, allowing for easier analysis of data. We also gain the advantage of observing animals with documented histories. Studies of social behavior in captive subjects may provide data which are highly relevant to behavior observed in the field (Bekoff, 1975). Furthermore, behavior observed in captivity may be of great importance, even though not yet described by field workers (Chance, 1962).

The limitations of captive studies are numerous, the foremost of which is the applicability of derived information to wild populations. Kleiman (1977) cautions that generalizations about social systems and social structure derived from observations of captive animals are unwise unless supportive field observations of wolves in undisturbed habitats are available. Important social factors such as hunting activity and freedom of movement are lacking, as are specific environmental influences such as topography. Nevertheless, most researchers believe observations of captives to be accurate descriptions of wolf behavior in the wild (Mech, 1970; Zimen, 1975; Allen, 1979). 


\section{OBJECTIVES}

Identifying variations in the same species adapted to different environments may show evolutionary trends which, in the absence of comparative analysis, might not otherwise be revealed (Fox, 1975; Moran and Fentress, 1979). Bekoff (1975) notes phylogenetic relationships may be determined based on comparative behavioral data (e.g. Kleiman, 1967) as well as on anatomical similarities and differences (e.g. Atkins and Dillon, 1971). Understanding of wolf behavior under different environmental contingencies can help separate those behaviors which are common to all wolves under all conditions from those which are modified by proximate or immediate factors. It can also provide important background for management of wolves in the wild and captivity, and for the eventual reintroduciton of wolves into previously occupied habitat.

Although cooperative behavior is generally acknowledged to exist among wolves, there remains a lack of systematically collected data confirming the extent of its development. Accordingly, Fentress and Ryon (in press) and Harrington and Mech (in press) have pointed to the need for long-term, detailed observations documenting the role of social structure and the degree of individual participation in cooperative pack activities. Individual cooperative strategies can then be associated with age, sex, and social position and critically compared with analagous behaviors in other canine species.

The objectives of this study were to observe a captive pack of wolves for a sufficient time period to quantify and assess previously 
categorized social behaviors (Schenkel, 1947, 1967; Rabb et al., 1967; Mech, 1970). Emphasis was placed on quantifying group and dyadic relationships, focusing on reproductive strategies and dominance structure. Data were collected on denning behavior, maternal care behavior, scent marking, and spontaneous individual and group howling. An effort was made to identify conditions which precipitated change in social relationships. It was hypothesized that variability exists within and between wolf packs, both captive and wild, due to differences in pack genetics and environmental experiences, and that differences should be evident when contrasting social behavior of various packs. Data collected during this study was compared with that of similarly directed studies with the intent of identifying similarities and differences.

It was felt, however, that a valid comparison could not be made without evaluating the compatibility of methods employed in this study for assessing social behavior with those employed in other studies. Therefore, the question was posed whether social relationship, as determined by quantification of postural displays, correlated with relationships determined in the following manner: 1) food rank order, or 2) subjective assignment of rank. 


\section{MATERIALS AND METHODS}

\section{Study Site}

From September 1973 until June 1976 the wolves were housed in a .006 ha (53 sq. m.) caged enclosure (Figure 1). The floor was composed of three gravel pits separated by areas of flat concrete. Centrally located on the south wall was a hollow concrete log, which at times was used as a den. A small drinking pool was located along the same wall. Holding cages, with sliding doors providing access to the main enclosure, were located in the southeast corner. The keeper entrance was provided by a swinging door near the hollow concrete log. 


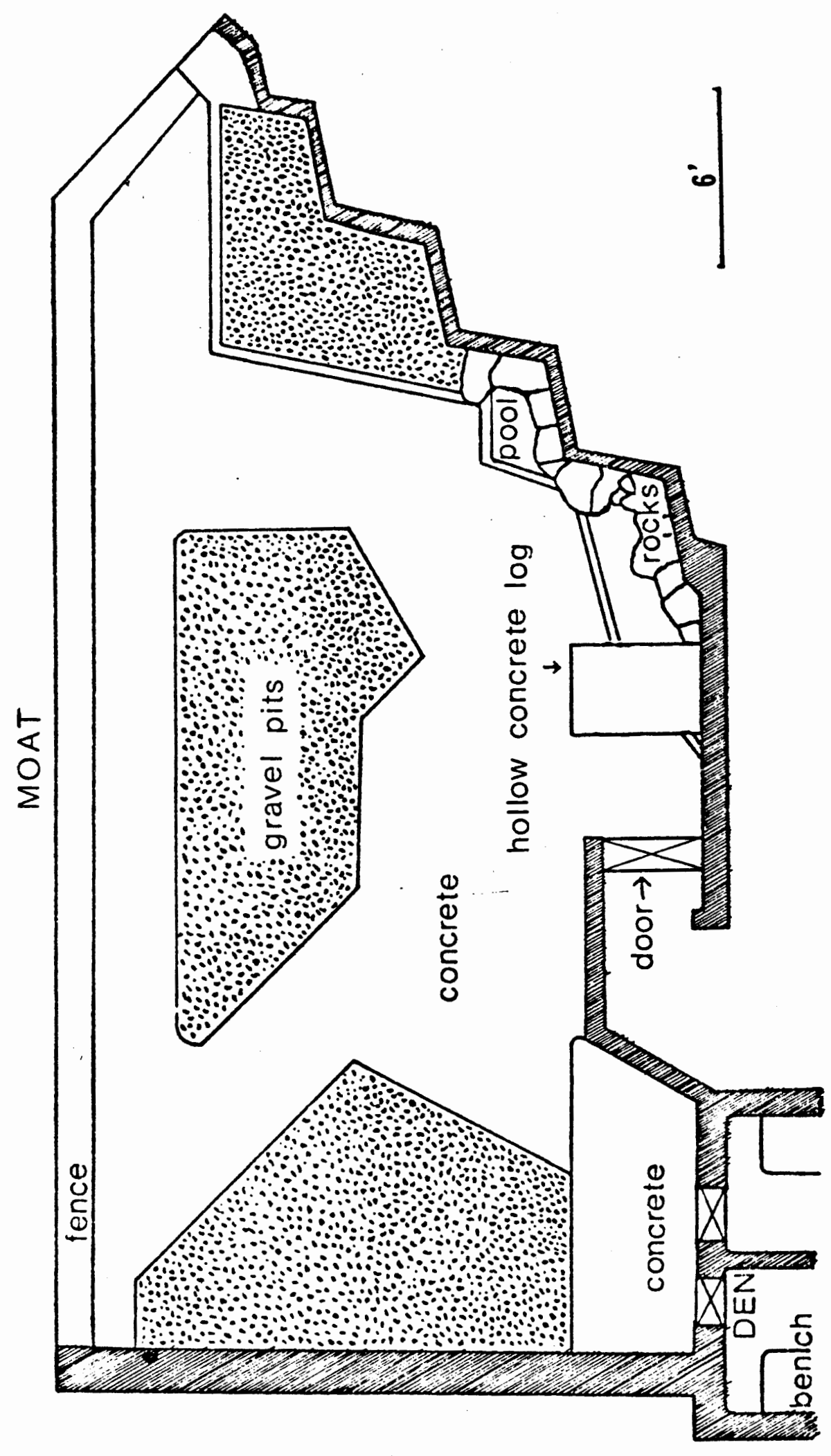

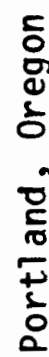

웅

紊

둥

일

兵

$\frac{\pi}{3}$

$\frac{6}{\sigma}$

독

1

守

बे

00
$\frac{5}{5}$
0
$\frac{0}{0}$
$\frac{0}{0}$
$\frac{4}{3}$

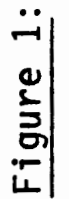


In June of 1976, the wolves were transferred to a cement grotto (Figure 2). The grotto consisted of three tiered, semi-circular platforms leading down into a dry moat. A small gravelled area, a pool and a cement shelter were provided. The back of the enclosure was surrounded by high cement walls. No dirt or grass were available. Total area was approximately .03 ha (265 sq. m.). 


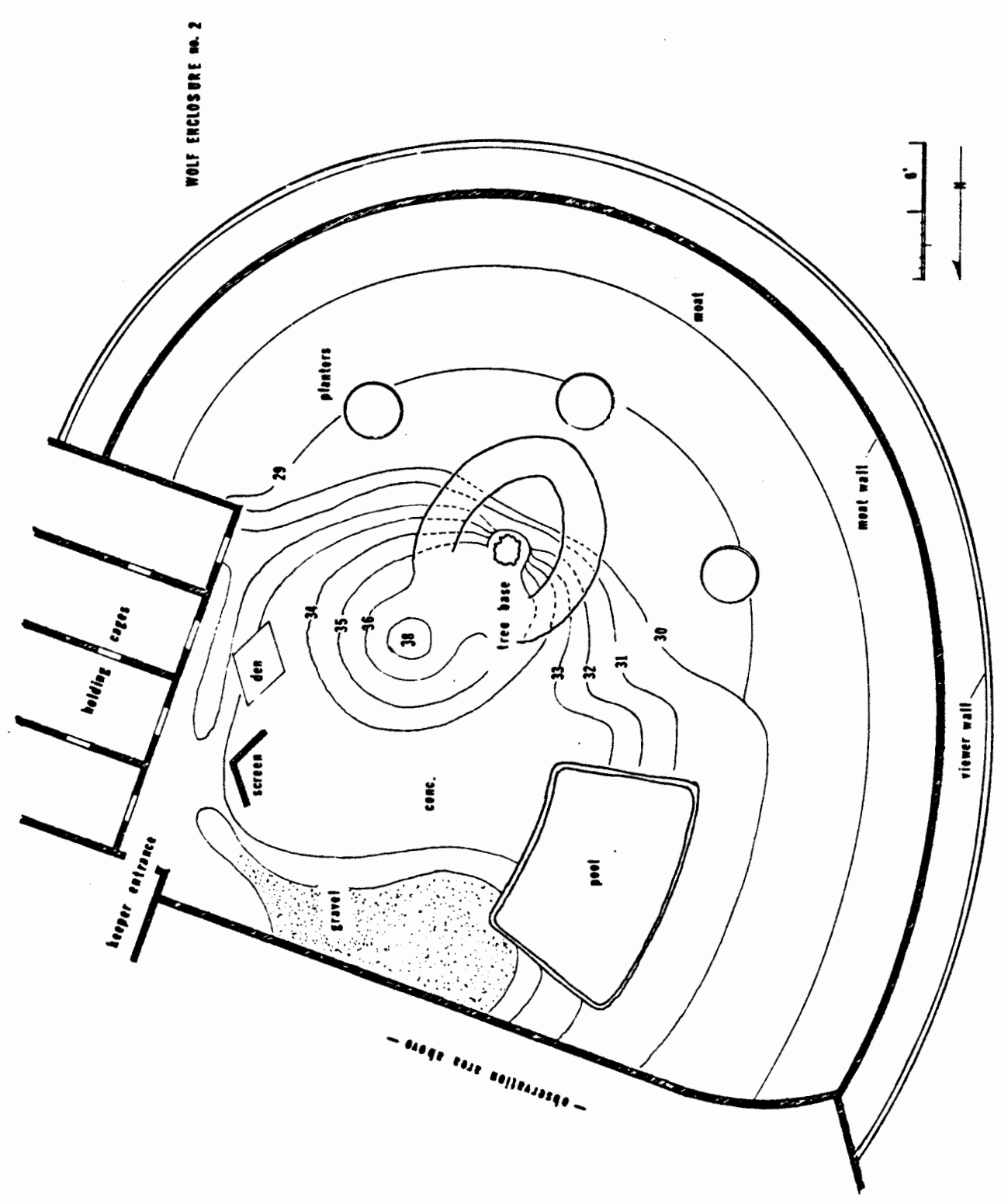

동
엉

$\frac{0}{0}$

옹

$\frac{1}{2}$

实

동

$\frac{9}{0}$
$\frac{1}{5}$
$\frac{1}{4}$
$\frac{0}{3}$

ثै

아

$\frac{0}{\sigma}$

号

$\frac{0}{5}$

$\frac{4}{3}$

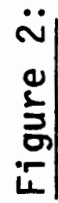


Contiguous with the grotto were four adjacent concrete holding rooms. Each room was approximately $2 \times 4 \times 3 \mathrm{~m}$. Three of the four rooms were provided with sliding guillotine-style doors opening into the main enclosure. Three similar doors connected the four rooms. At the rear of each holding cage was an access door. Each door was provided with a slanted feeding funnel and viewing window $(12 \times 30 \mathrm{~cm}$. $)$. Water troughs fillable from the outside were in each of the four cages. Il lumination for each holding cage was provided by a single 60 watt lightbulb controlled by the keepers. Indirect light was available from the keeper's hallway which ran along the rear of the holding cages. There was no natural illumination.

In both locations, the wolves were fed daily except Sunday, a commercially prepared meat substitute (Zupreme ${ }^{\mathrm{m}}$ ) supplemented by dry dog kibbles (Blue Mountainm). Frozen salmon was provided once weekly when in season. Water was available ad lib.

The Wolves

All wolves were of the subspecies C. 1. pambasileus. None were socialized to humans although they habituated quickly to observers and zoo staff. At the onset of this study the pack consisted of two wolves, a 15 month old male (house name, Zane) and a 15 month old female (house name, Taquish). During the course of the study, pack membership varied from two to nine wolves. In total, 21 wolves were involved in the study. Two were killed by other wolves, three died for various reasons as pups, and one adult female succumbed to salmon poisoning. Thirteen wolves were surplussed to other zoos and animal dealers (Figure 3 ). 


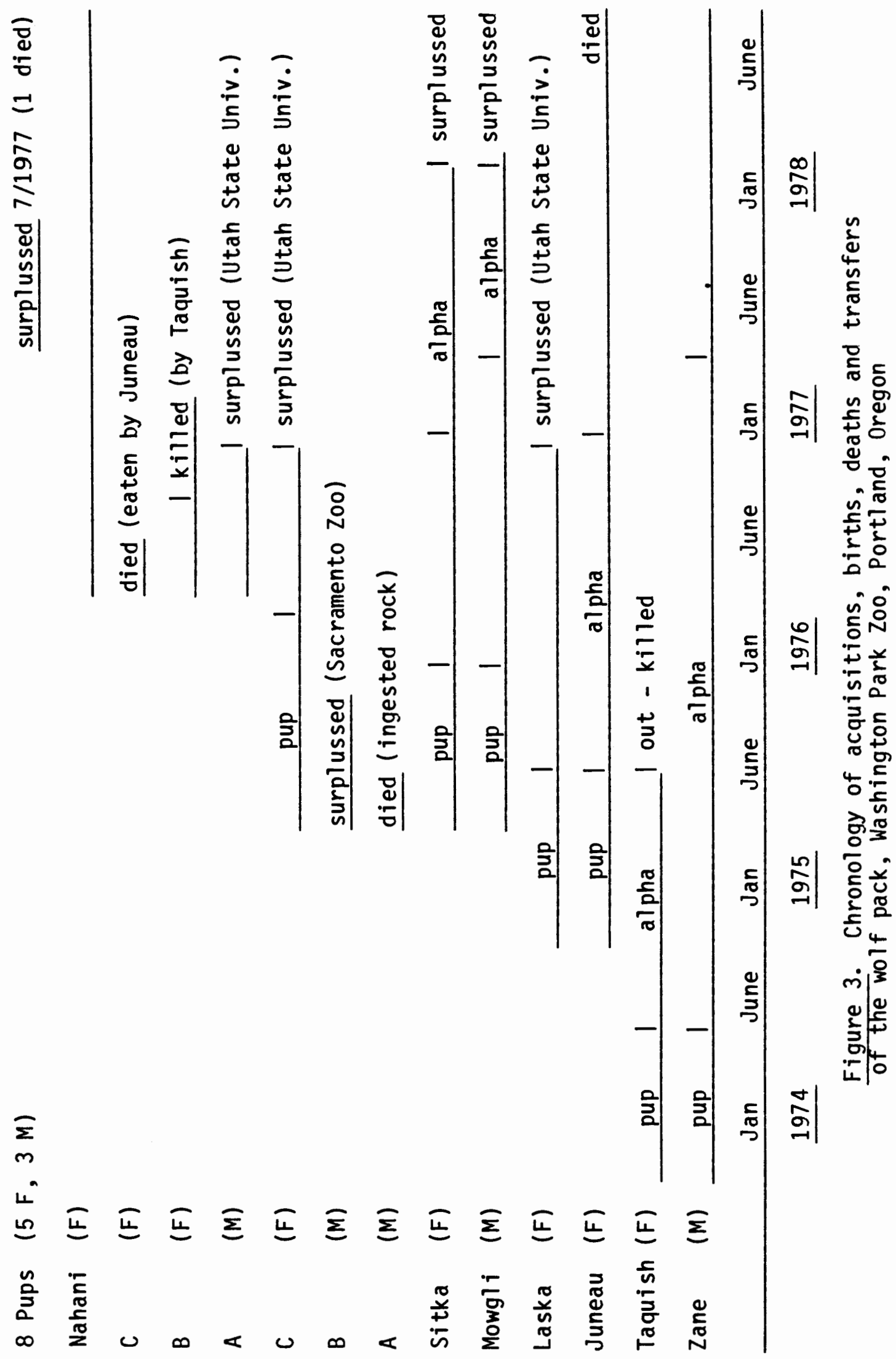


The following text is a chronological listing of acquisitions, births, deaths and selling of wolves at the Washington Park Zoo. It is summarized in Figure 3 and presented for reference and clarification while reading the manuscript. Pack geneology is presented in Figure 4. 


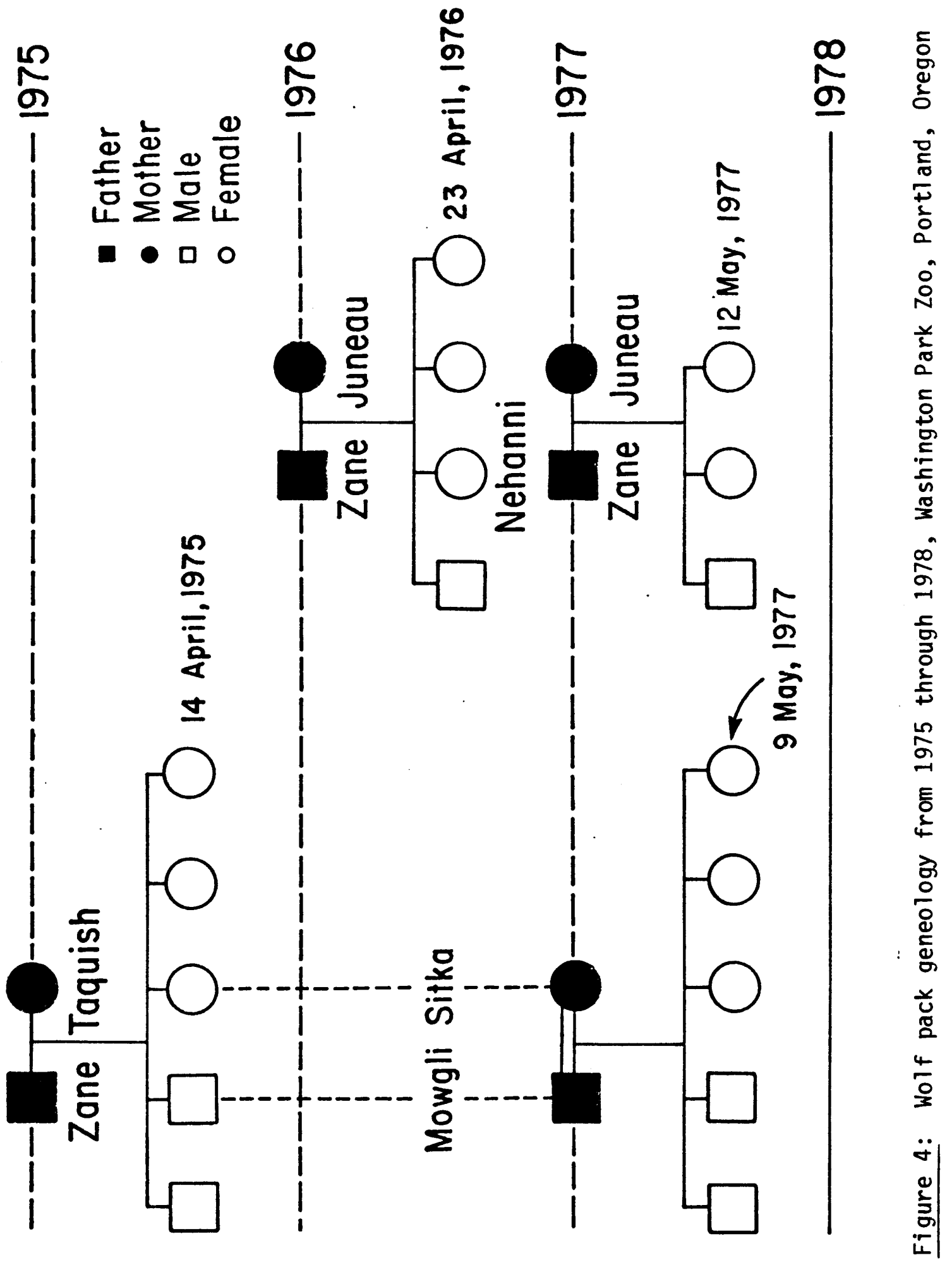


The original pair, Zane (male) and Taquish (female), were received by the Washington Park Zoo, Portland, Oregon, as a gift from the Alaskan Department of Fish and Game (ADFG) in September of 1973. They were four months of age and unrelated. Both had been removed from dens near Mt. Mckinley, Alaska, at an estimated age of six weeks. Subspecific identification was listed as C. 1. pambasileus.

In September 1974, two wild born females, also from the Mt. Mckinley area, were introduced with the yearling pair acquired the previous year. The two pups (house names, Juneau and Laska), approximately four and a half months old, were from two separate litters, also of the subspecies C. 1. pambasileus. Neither the yearlings nor the pups were interrelated.

In April 1975, Taquish gave birth to five pups ( 3 females, 2 males) sired by Zane. One male pup suffered a broken leg, was removed from the enclosure and later sold to the Sacramento Zoo, Sacramento, California. In June of the same year, a female pup died of an intestinal obstruction caused by an ingested rock (Michael Schmidt, D.V.M., personal communication). The three surviving pups remained with the pack.

In May 1976 Juneau produced a litter of four pups ( 3 female, 1 male), also sired by Zane. One female pup died two days after being born and was consumed by Juneau. In June of the same year, another female pup was killed by Taquish. Taquish was, in turn, killed by Juneau, either during the evening of the same day or the following morning. 
In December of 1976, Laska, a female yearling from the 1975 Zane and Taquish mating, and a male pup from the 1976 Zane and Juneau mating were surplussed to Utah State University, Logan, Utah.

In May 1977, two litters were born to the pack. The parents of one of the litters were siblings, Sitka and Mowgli, the result of the 1975 mating between Zane and the deceased female, Taquish. Their father, Zane, sired the other litter in a mating with Juneau. Juneau was unrelated to Sitka and Mowgli. Both litters were surplussed to an animal dealer in September 1977.

In May 1978, the pack was divided into two separate groups. Sitka and Mowgli were removed from the main enclosure and housed in an adjacent compound. Zane, Juneau and Nahani remained together. In October 1978 Juneau died of salmon poisoning and Mowgli and Sitka were sent to an Indiana zoo.

Behavioral observations

Behavioral observations were recorded in field notebooks and on data sheets and were later transcribed onto computer cards for analysis. Observations were made primarily during daylight hours, anytime from sunrise to sunset. Night observations were conducted during breeding season and when newborn pups were present. Observations of the wolves in enclosure \#1 (Figure 1) were made from the east-west walkway that traverses the north side of the compound. Observations of wolves in the grotto were generally made from a maintenance ramp overlooking the entire grotto. Observations of wolves in holding cages were made through viewing windows in the keeper access doors. 
Binocculars $(9 \times 36$ or $8 \times 35)$ were used as needed. Time contingent data were recorded using watches with sweep second-hands.

The study was conducted during a five year period (1974-1979). Total observation time of pack activity from September 1974 until June 1978 was approximately 2,000 hours (Table I). Total observation time of denning behavior was 225 hours (Table II). Personal observation time was approximately 1,500 hours with 700 hours provided by volunteer workers and zoo staff. Quantified data is the result of information collected during the period beginning December 1975 and ending June 1978. Data collected prior to and after that time are included for background reference and chronological continuity. Interobserver reliability averaged over 94 percent, as determined twice monthly throughout the study.

\section{TABLE I}

YEARLY DISTRIBUTION OF OBSERVATION HOURS

Observation Period

September 1974 - June 1975

June 1975 - June 1976

June 1976 - June 1977

June 1977 - June 1978
Observation Hours

230

671

720 
TABLE II

DENNING OBSERVATION HOURS

Year

Female

Observation Hours

$\underline{\text { Dates }}$

1975 Taquish

1976 Juneau

1977 Isolated pregnant females

1977 Sitka with solitary litter

1977 Communally denning females
51

47

13

15

99
14 April-29 April

23 Apri1- 7 May

5 May - 9 May

9 May - 13 May

13 May - 25 May

Behavioral Measures

Social relationships within the pack were assessed by quantifying the relative frequencies of designated behaviors, primarily body postures (Schenke1, 1947, 1967; Mech, 1970; Fox, 1971), during dyadic or group interactions. Other behaviors recognized as typical of dominant animals were also taken into account (Mech, 1970). Courtship and mating behaviors were initially classified according to descriptions by Schenkel (1947) and Rabb et al. (1967). They were later re-evaluated to conform with classifications employed by Shotte and Rabb (1977, 1978).

Behavioral events were tabulated during each observation session, providing summed scores and mean scores for each major and component behavioral category. A set of three general categories was constructed for group and dyadic social interactions (see Appendix B). Behaviors were distinguished as friendly, aggressive or submissive. Friendly behavior was categorized as all activity considered behaviorally neutral ((Zimen, 1975, pers comm.) Included in this grouping were play, sniffing, some allogrooming and most sexual behavior. Aggressive behaviors included all agonistic interactions (Schenkel, 1947, 1967; 
Zimen, 1975) such as biting, attacking, displacement activity, fighting, visual threat and subordination. Submissive behavior comprised all active and passive submission (Schenke1, 1947; Zimen, 1975). Also tabulated were the direction of interactions among pack members, individual scent marking, categorized as raised leg urination (RLU) and squat urination (SQU) (Peters and Mech, 1975; Rothman and Mech, 1979), and spontaneous individual and group howling ( $K$ linghammer and Laidlaw, 1979). If there was difficulty in assigning a behavior to one of the designated categories, the event was recorded but not used in analysis.

A total of 20,616 dyadic or group events was recorded for seven wolves over a period of two years. All occurred in a pack environment. Solitary behaviors, such as scent marking and howling, were tabulated separately. Behavioral correlations were determined using the Pearson Product Moment Correlation Test.

Beginning June 1976, three separate methods of assessing individual rank and social order were employed simultaneously. Rank was determined by qualitative evaluation, quantitative evaluation and access to food. Qualitative ranking relied upon subjective interpretation of well described behaviors (Schenke1, 1947; Mech, 1970; Zimen, 1975) by trained observers. Quantified ranking was accomplished by cataloging the same behaviors into predetermined categories designated as aggressive, submissive and friendly. The categories were then placed in a computer matrix programmed to numerically rank the five wolves according to sexually separate dominance relationships. Lastly, in assigning food ranking, a wolf that obtained and ate any food item equally accessible to all pack members was considered dominant. If a 
wolf ate until satiated and left the remaining food, or secured only a portion of available food and ate elsewhere, the wolves were rated according to the order in which they ate. All observations were made during regularly scheduled zoo feedings and special feedings of whole salmon. All pack members were present at each feeding.

Five observers were employed during the two year period, each utilizing one method of ranking. Data from each method were compiled separately and then grouped into identical summer and winter periods for evaluation. Relationships between food ranking and quantified ranking were determined using the Pearson Product Correlation Moment Test. All other relationships were determined by comparison of weekly rankings providing a percentage of similarity. For example, if qualitative ranking and food ranking agreed in placement of four of five wolves, the weekly rating would be 80 percent. The average for the total number of test weeks provided the percentage of similarity. 


\section{RESULTS}

\section{Pack Development And Behavioral Overview}

The Washington Park Zoo wolf pack was established September 1973 with the acquisition of two wild-born, unrelated pups - a male, housenamed Zane and a female, house-named Taquish. An additional two wildborn female pups, Juneau and Laska, were acquired the following September, 1974. None of the wolves were related and all were of the subspecies C. 1. pambasileus.

Initial attempts to integrate the pups with the original pair were unsuccessful. Juneau was threatened and attacked by Taquish and it was necessary, after four days, to remove her from the enclosure. With the exception of preliminary sniffing, Laska was virtually ignored by both yearlings. Since no aggression had been directed toward her, it was anticipated that she would be accepted by the yearling pair. However, in the absence of Juneau, Laska became the subject of Taquish's attacks. To prevent serious injury, Laska was also removed from the enclosure.

Integration of the pups and yearlings was eventually accomplished by gradually extending periods of exposure. It is noteworthy that during this period of acclimation, Taquish seldom interacted with Laska, but used every opportunity to subordinate Juneau. Conversely, Zane attempted to groom and play with both pups, although Taquish tried to prevent these interactions by interjecting herself between Zane and the pups. These relationships remained consistent throughout the period of socialization. 
During winter of 1974-75, Taquish was the only female to show signs of estrus, and mating was restricted to Taquish and Zane. Again, relationships among the females showed no changes over previous months. On 27 April 1975, Taquish delivered five pups (2 male, 3 female).

Movement near or toward the den by either Juneau or Laska elicited uninhibited attacks by Taquish. Zane was allowed free access to the den and the pups. Few aggressive encounters were observed among the females after the pups emerged from the den. Taquish seldom associated with either of the two younger females until the latter part of september. Although the frequency of encounters increased during this period, they were mostly neutral or nonaggressive. The few aggressive encounters observed were of low intensity and did not involve biting. No injuries were observed.

In November, Taquish began asserting herself with frequent attacks upon Juneau. Toward Laska, she displayed only imposition behavior, blocking all social activities. Laska behaved subordinately even to Taquish's pups. On 9 December, in a fight with Juneau, Taquish received a severe gash across the muzzle and was removed from the enclosure for treatment by the Zoo veterinarian. At this time she may have relinquished her role as alpha female to Juneau; at least in her absence Juneau, by default, became dominant female. Laska did not contest the new order and remained friendly with Juneau. She no longer behaved subordinately to Taquish's pups and frequently was observed playing with them. 
Taquish was not immediately reintroduced to the pack because it was anticipated that intense and violent rank fighting would ensue, possibly enhanced by pre-estrus aggression. Additionally, enclosure space was limited, compounded by the continuous maturation of Taquish's pups .

Juneau was confirmed to be pregnant in April 1976. She was transferred, together with Laska, to a holding cage adjacent to a larger enclosure being prepared as a new wolf exhibit. Taquish was then reunited with the remaining pack, which included her mate of the previous year, Zane, and their yearling pups. As the only adult female, she resumed her alpha role unchallenged.

On 23 April, Juneau delivered four pups $(1,3)$, three of which survived $(1,2)$. Upon completion of the new enclosure, it was decided to reunite the entire pack. Zane, Taquish and the three yearlings were transferred to a holding cage adjacent to Laska, Juneau and the three pups. The two adults and yearling wolves were released from there into the main enclosure (see Figure 2). Juneau and Laska were simultaneously allowed acces to the enclosure, and the pups were placed by keepers into the new denning area. All wolves appeared agitated and apprehensive.

In Juneau's first encounter with Taquish since December 1975, she actively submitted to Taquish. Taquish stood over Juneau but did not bite her. The encounter lasted less than 30 seconds. Taquish then began to sniff and 1ick the new pups. Juneau made no attempt to interfere. Suddenly, Taquish attacked one female pup, shaking and tossing it into the air. The pup died of the resulting injuries. The two other pups were removed from the enclosure. 
Throughout the remainder of the day, Taquish continuously assaulted Juneau, forcing her into the pool and not allowing her out. During one such attack, Juneau bit Taquish in the chest. Taquish was thrown over backwards. Together, Juneau and Laska attacked Taquish. She quickly submitted and retreated to the cement shelter. At 0700 the following day, Taquish was found dead. There was an additional bite on her throat and I suspect Juneau killed Taquish.

Laska was uninjured but, for the first time, behaved submissively toward Juneau. Juneau was removed from the enclosure for treatment of injuries. Laska assumed the dominant position, unchallenged by the yearling females.

The pack remained separated until June 30 , at which time Juneau and her two remaining pups were allowed access to the main enclosure. The pups were enthusiastically greeted by all pack members. Juneau briefly greeted Zane and then turned and attacked Laska. Both females were inhibited in their biting and the altercation was settled quickly with Juneau emerging dominant. Subsequently, no serious aggressive encounters were observed between these two females, although Juneau on occasion threatened Laska. There was no evident rank difference among the low-ranking females until september 1976. At that time, Sitka (Taquish's pup) began challenging Laska for beta position. By the middle of October, Laska was subordinate to all Taquish's pups (now 1$1 / 2$ years $01 d$ ), although still tolerated by Juneau and Zane.

In November, there was an increase in aggressive altercations between Juneau and Sitka, although no severe fighting was observed. However, the intensity of the interactions was more pronounced with 
Sitka displaying frequent minor wounds on her hindquarters and muzzle. By the end of December, Sitka was showing intense protest behavior to any attempted imposition by Juneau. By early January, it was unclear as to which female was dominant. In the latter part of January, Sitka effectively established herself as the dominant female. No decisive battle was observed and the transition appeared gradual rather than sudden. Sitka now initiated most interactions and deprived Juneau of all social and most sexual activities. Juneau withdrew to the confines of the holding cages.

Throughout these disputes, the two males, Zane and Mowgli, were never observed to interfere. Mowgli never displayed any aggression toward Zane and their relationship appeared stable. In early February, Sitka became very solicitous of Zane, displaying behavior commonly associated with courtship (Schotte and Ginsburg, 1978). Juneau made no attempt to interfere, but Zane remained unresponsive to Sitka and would often threaten and occasionally attack her. Several times Zane was observed defending Juneau from Sitka's attacks.

Mowgli began to show interest in Sitka and, in her presence only, would threaten Zane. The deteriorating relationship between the two males was characterized by frequent imposition behavior by Zane and a noticeable lack of mutual play.

Zane remained dominant throughout the month of March. By the first week of April, it was difficult to discern whether Zane or Mowgli was dominant as both displayed socially dominant signs. However, on 3 April, Zane retreated to the confines of the holding cages. He ceased to interact with the other wolves. During the month of March, I had the 
impression Zane was not healthy. He also appeared unhealthy during the period when he was isolated from the pack. Subsequent discussion with Mike Schmidt, the Zoo veterinarian, revealed that he also had the impression Zane was unwell at the time.

Although the newly established hierarchy remained unchanged until the pack was disbanded in June 1978, it never appeared to stabilize. Continual seasonal harrassment by Sitka of Juneau, and eventually Nahani, necessitated frequent separation of the females. Sitka's attacks became so frequent and severe during the winter of 1978 that she was regularly separated from the pack.

\section{Activity Profile}

Pack social behavior fluctuated seasonally with increased activity in fall and winter months. All activity levels were highest during October-November and lowest during June-July (Figure 5). Friendly behavior occurred with the highest relative frequency, comprising 55 percent of all observed activity. This was followed by aggressive behavior $(31 \%)$, and submissive behavior $(14 \%)$. 


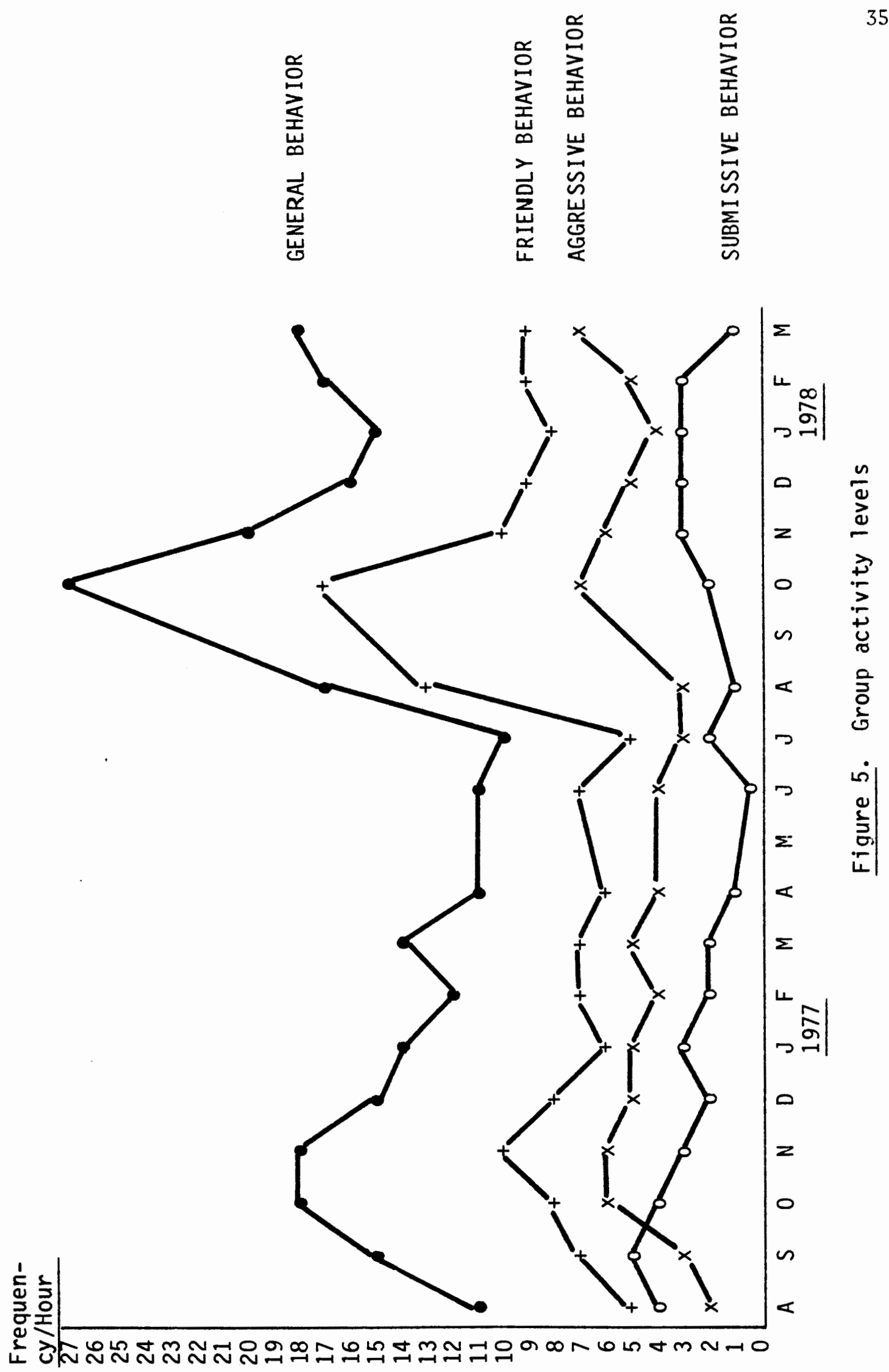


Fluctuations in aggressive behavior closely paralleled those of all combined behavior (hereafter referred to as general behaviors), $(r=0.77, p<.001)$ (Figure 5). The months December through April were above average for relative percentage of aggression and coincided closely with the period during which all rank changes occurred (Table III: see next section - Dominance Relationships). Al though changes in general activity levels were closely related to changes in aggressive behavior, increases and decreases in the frequency of aggressive behavior began and ended later than other activities (Figure 5). The frequency of friendly behavior closely paralleled fluctuations in general activity levels (Figure 5$)(r=0.90, p<.001)$. A relative yearly mean of 55 percent strongly suggests that changes in overall activity profiles were largely dictated by levels of friendly behavior. Friendly behavior increased in August and peaked in OctoberNovember. This was loosely associated with changes in aggressive behavior $(r=0.55, p<.001)$ and unrelated to levels of submissive behavior $(r=0.174, n=51)$ (Table III).

Fluctuations in submissive behavior showed no correltion with changes in general behavior $(r=0.17, n=51)$. Submissive behavior comprised only 14 percent of all observed behavior. The only month with annually consistent levels was January. Submissive behaviors showed no correlation with aggressive behavior $(r=-0.02 ; n=51)$ (Table III). 
TABLE III

CORRELATIONAL RELATIONSHIPS OF GROUP BEHAVIORAL CATEGORIES

\begin{tabular}{lr}
\multicolumn{1}{c}{ Categories } & Correlational Value \\
\cline { 2 - 2 } Aggressive versus friendly & $r=0.55, p<.001$ \\
Aggressive versus general & $r=0.77, p<.001$ \\
Aggressive versus submissive & $r=-0.02, n=51$ \\
Submissive versus general & $r=0.17, n=51$ \\
Friendly versus submissive & $r=0.17, n=51$ \\
Friendly versus general & $r=0.90, p<.001$
\end{tabular}

The winter months of 1976 (January-March) were unique in that pack activity levels were similar to summer levels observed during other years. There was no increase in agonistic behavior among the adult wolves. Of all behaviors recorded, only group howling (up 352\%) and scent marking (up 671\%) showed significant increases. Although increased sexual behavior was observed between Zane and Juneau, this did not affect group activity levels. An increase in neutral behaviors over previous months apparently offset decreases in agonistic encounters.

Dominance Relationships

A dominance matrix composed of adult wolves and constructed from data collected from April 1977 thru April 1978 (Brown, 1975) (Table IV) determined the following unisexual hierarchy. Mowgli emerged as the dominant pack member, followed equally by his father Zane and his sister Sitka. Juneau was subordinate to all pack members except her daughter, Nahani. 
TABLE IV

DOMINANCE MATRIX

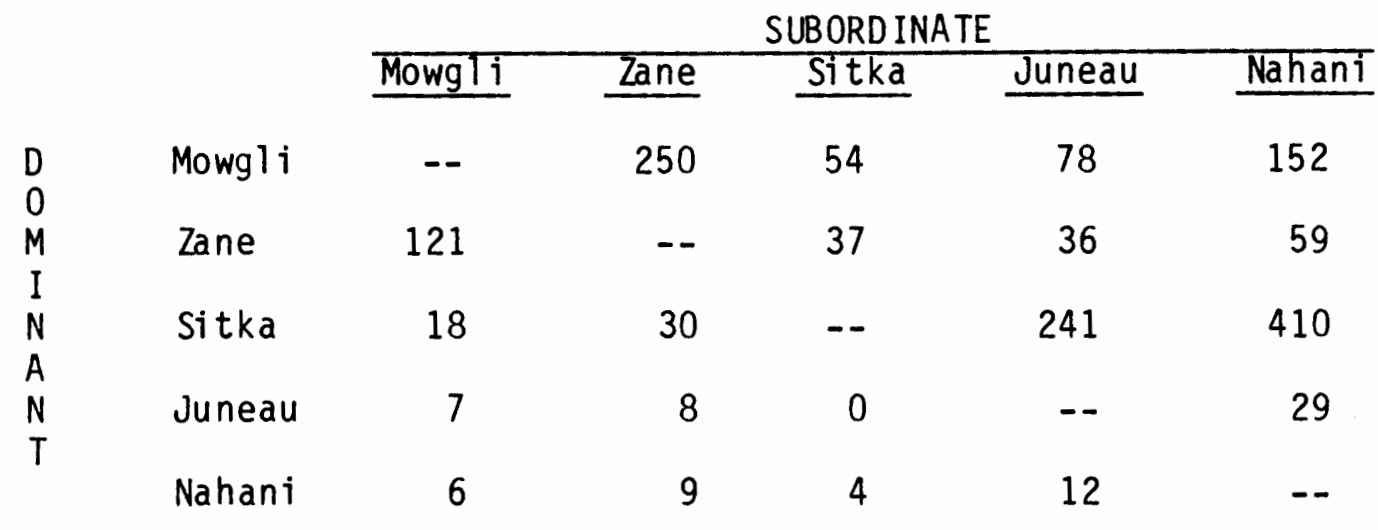

Rank Changes

A total of three rank order changes were observed, two among the females and one between the males (Table 5). All social changes occurred during the months December through April. Taquish, dominant female from the pack's inception in 1974, was displaced by Juneau in either December 1975 or May 1976. It is unclear whether Juneau was dominant when Taquish was removed from the enclosure in December 1975, although it was assumed at the time that she was. However, when Taquish was reintroduced in June 1976, she immediately dominated Juneau. Nevertheless, Taquish was subsequentiy killed, probably by Juneau.

Sitka became established as dominant female in the latter part of January 1977 when she displaced Juneau. A reversal in the outcome of agonistic encounters between the two females was apparent at the time (Figure 6). During the same period, numerous aggressive encounters were also observed between Sitka and Zane. Sitka, however, failed to dominate Zane. These were the only consistent intersexual aggressive encounters recorded throughout the entire study. 


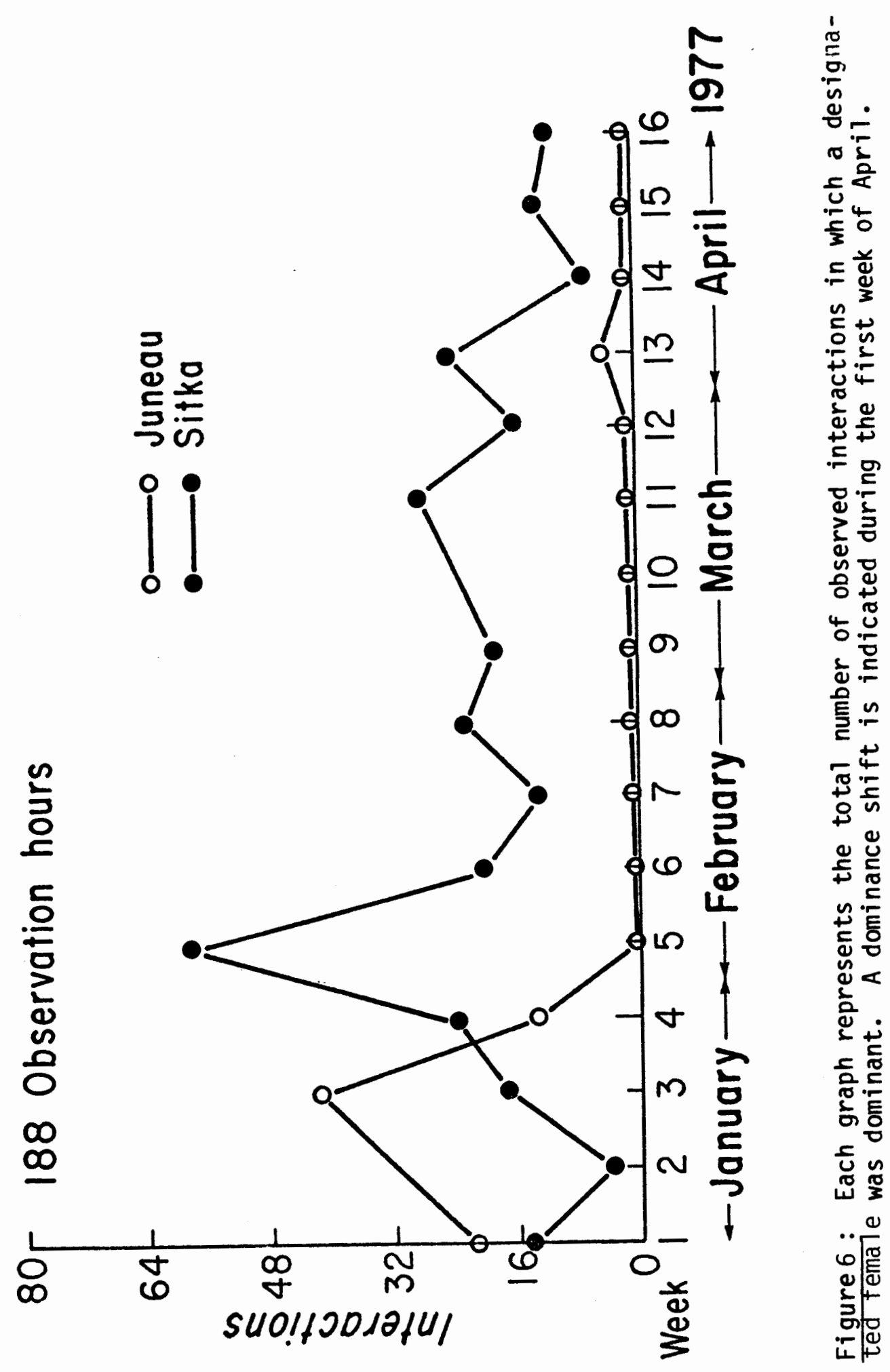


Finally, Zane was replaced by his son Mowgli as dominant male in the latter part of April (Figure 7). As noted in the pack overview, there were indications that Zane was in poor health when he was displaced. Although a reversal of roles was readily apparent immediately following the dominance shift, it was difficult in later months to discern which male was dominant as both males displayed dominant signs. One notable change was that Mowgli frequently mounted Zane. 


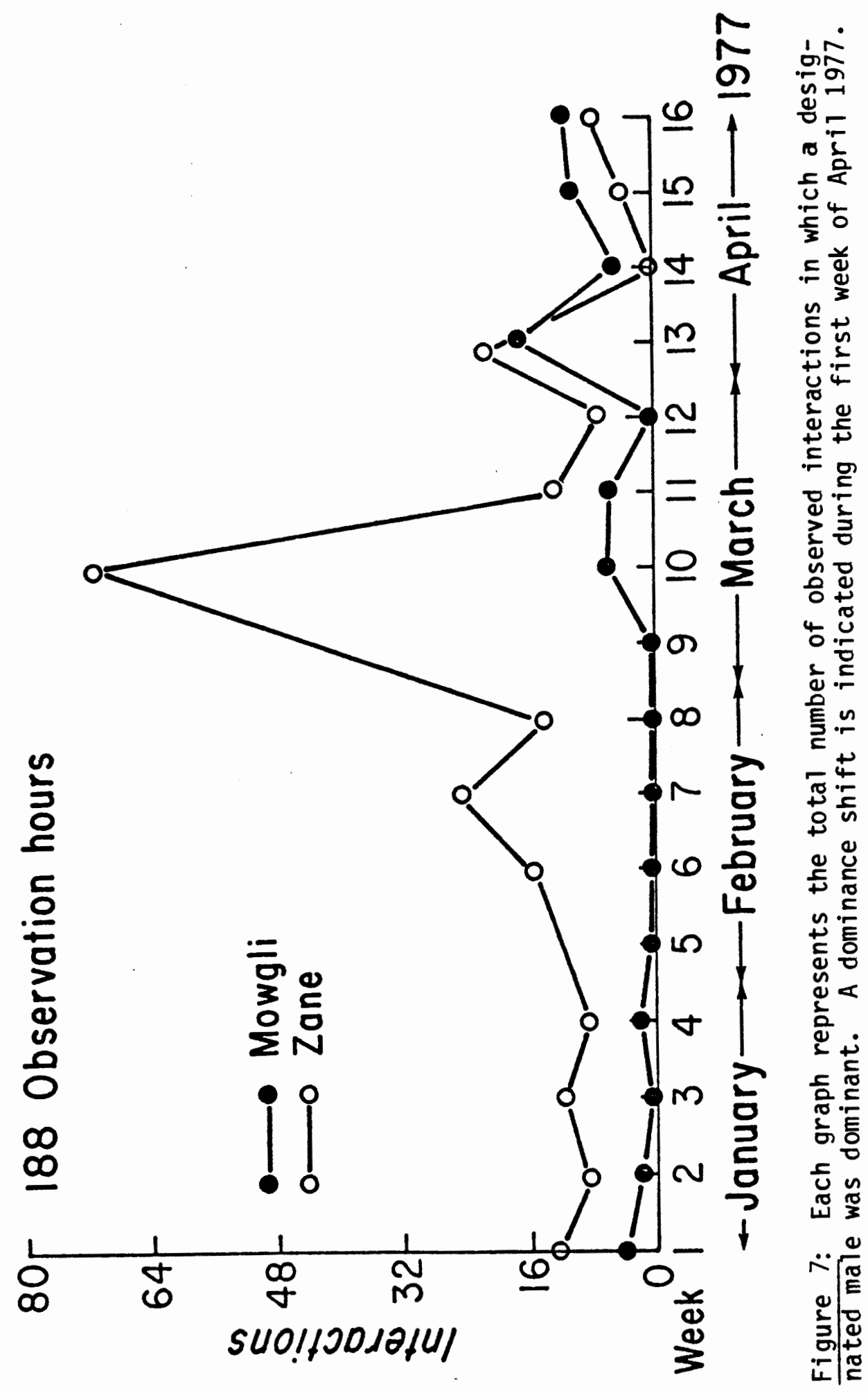


TABLE $V$

DOMINANCE RELATIONSHIP DURING WINTER MONTHS, 1975-77

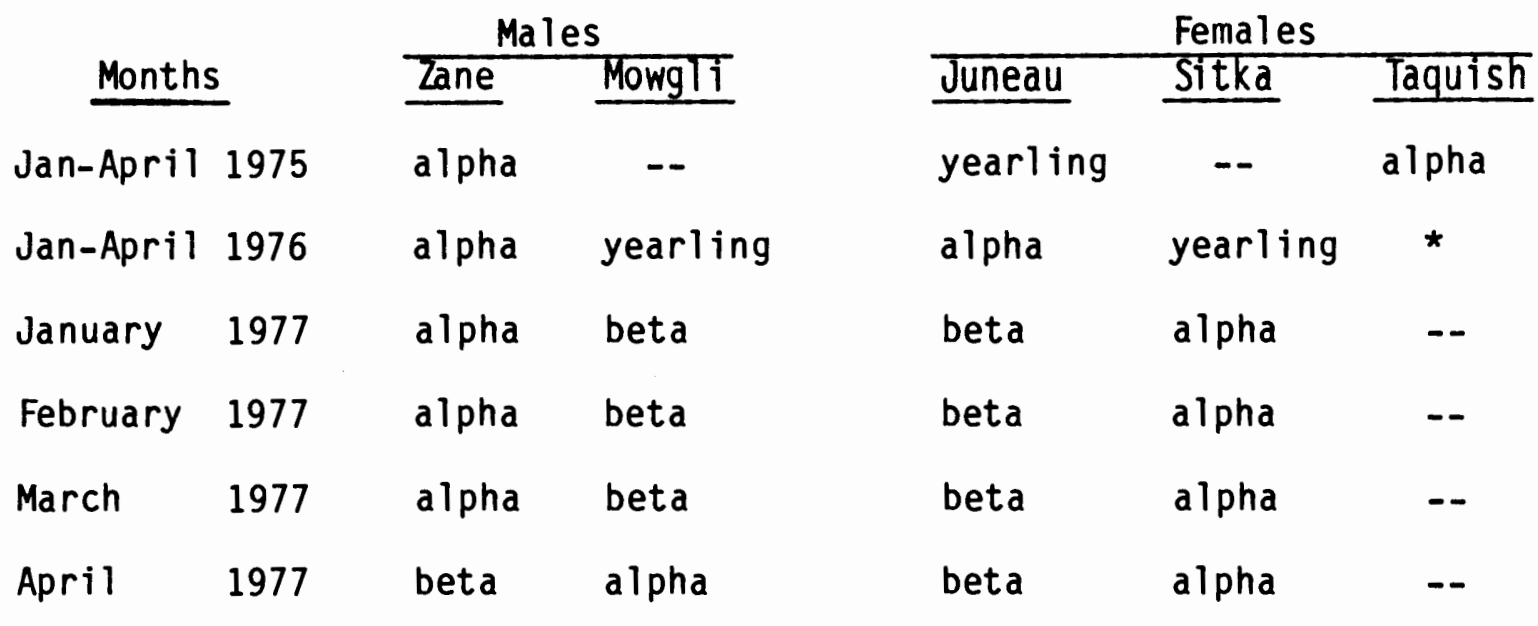

*Isolated from pack December 1975 - May 1976, during which time Juneau mated with Zane

Despite occasional observations of subordinates winning encounters with dominant individuals and the equal status of Zane and Sitka, Landau's index of linearity for dominance hierarchies $(h=.95$; perfect linearity is $h=1.00$ ) (Bekoff, 1977; Chase, 1974; Lehner, 1979) indicated a high degree of structural linearity for the pack including males and females in a single sexual order (Figure 6). Although Landau's Index reflects a unisexually linear social structure, other data conflict with this assessment, indicating the presence of separate sexual hierarchies. For example, levels of intrasexual and intersexual behaviors differed significantly in all categories. The intrasexual groups displayed significantly more aggression than the intersexual groups. Additionally, intrasexual groups showed no significant difference in levels of aggression, neutral behavior or submissive behavior (Table VI). 
Finally, seasonal changes in intersexual and intrasexual behaviors failed to show any correlation (Table VI, Figures 9-11).

\section{Mowgli}

Sitka $=$ Zane

Juneau

Nahani

Figure 8. Dominance hierarchy as

determined by Landau's Index of Linearity

TABLE V I

STATISTICAL COMPARISON OF INTRASEXUAL

AND INTER SEXUAL BEHAV IORAL

ACTIVITY

Sample Groups

Aggressive

Friendly Submissive

Male vs. male + female $t=10.02(p>.005) \quad t=8.23(p>.005) t=2.47(p>.01)$

$$
r=-0.12(n=51) \quad r=.45(n=51) \quad r=-.135 \quad(n=51)
$$

Female vs. male + female $t=11.79(p>.003) t=9.35(p>.005) \quad t=3.70(p>.005)$

$$
r=-.257(n=51) \quad r=.096(n=51) \quad r=.388 \quad(n=51)
$$

Male vs. female

$$
\begin{array}{lllll}
t=1.31 & (n=51) & t=.854 & (n=51) & t=1.07 \quad(n=51) \\
r=.262 & (n=51) & r=.216 \quad(n=51) & r=.051 \quad(n=51)
\end{array}
$$



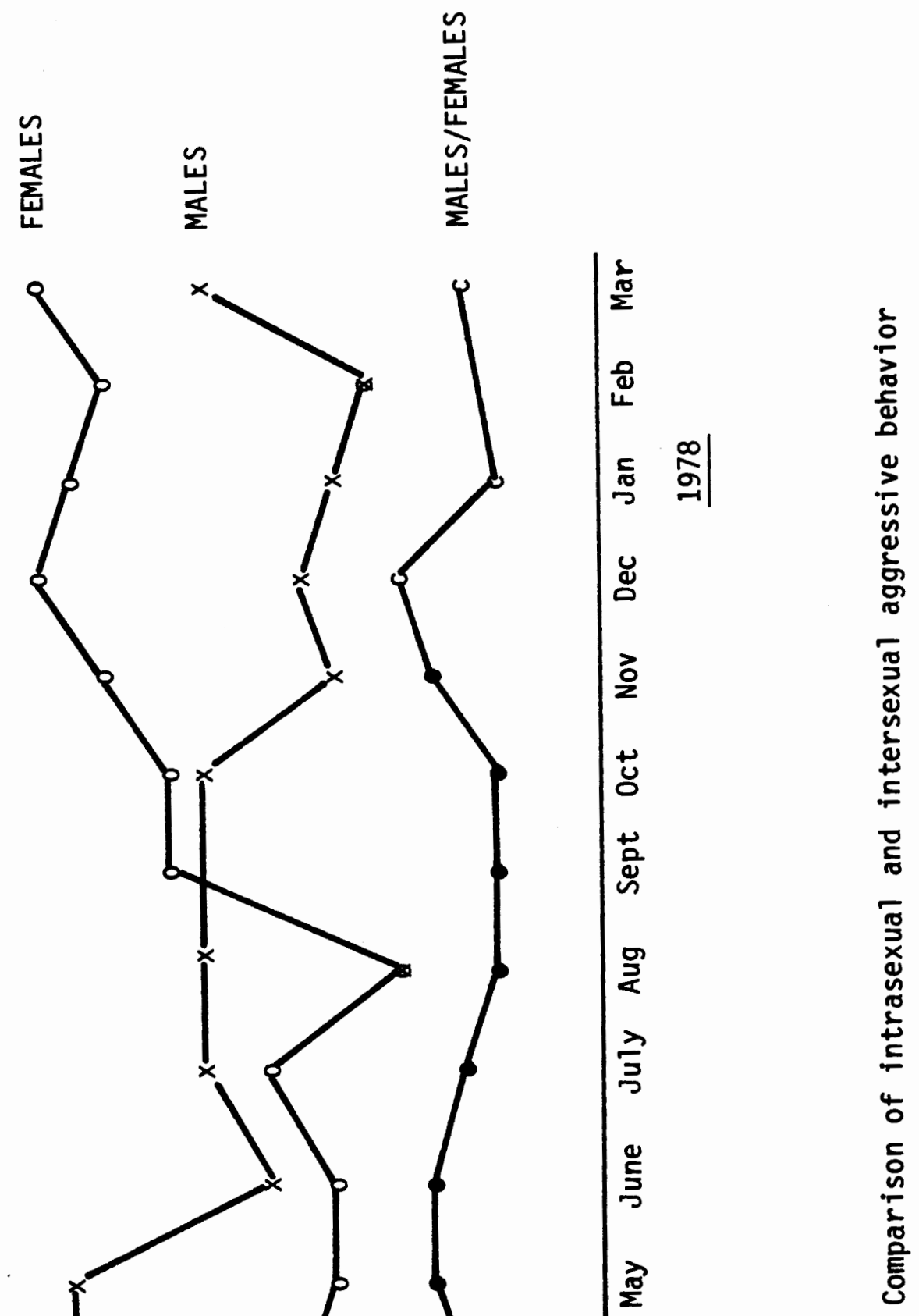

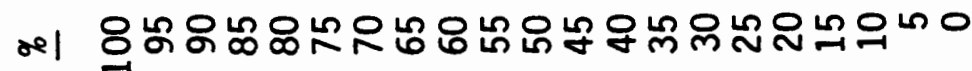

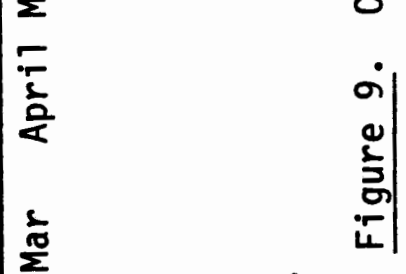



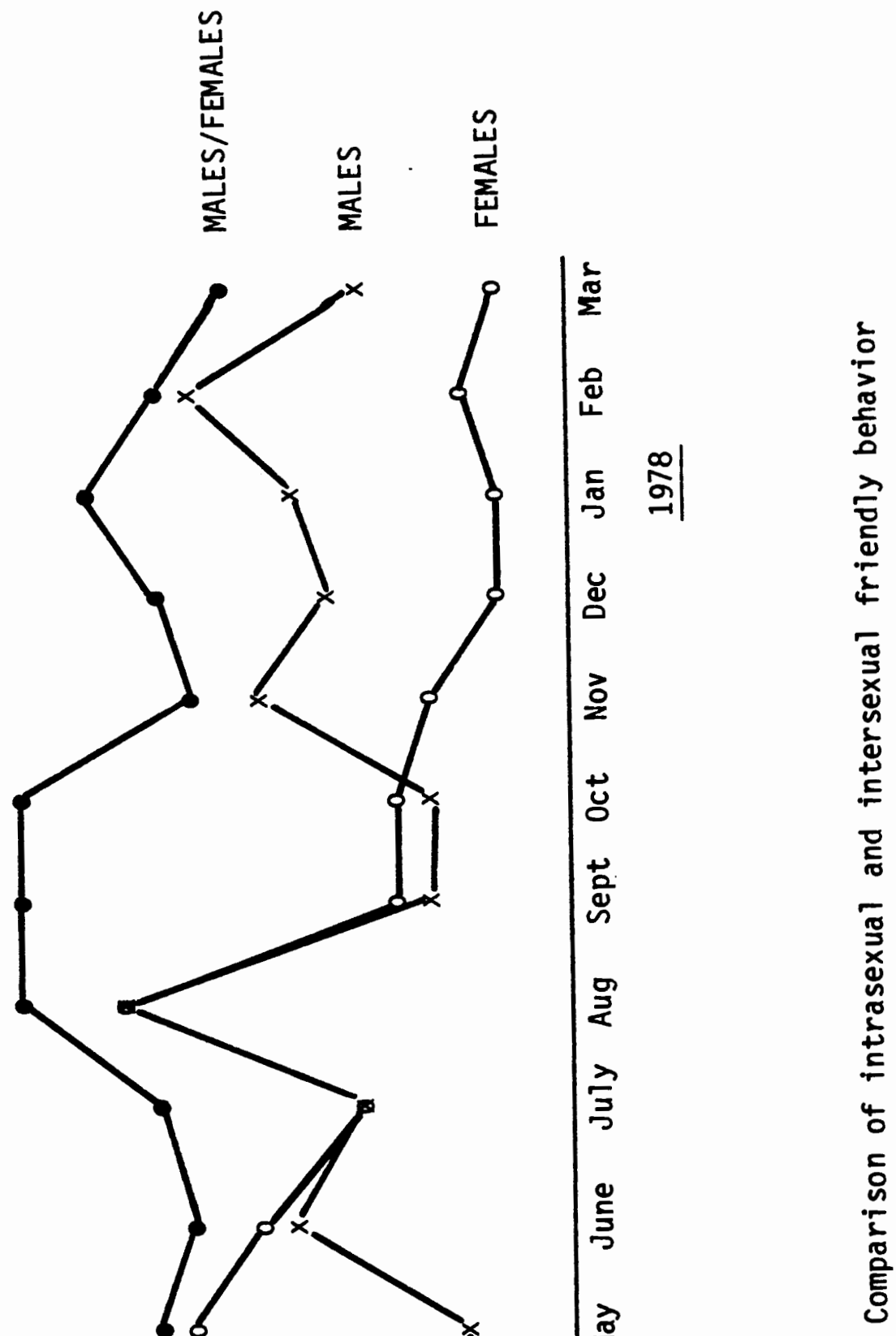

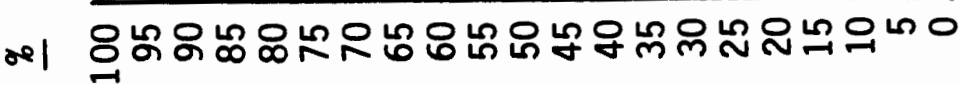

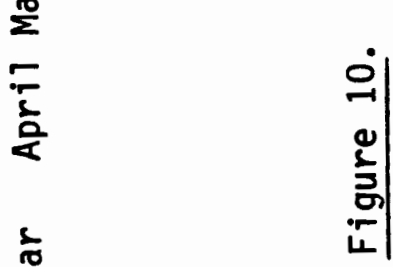




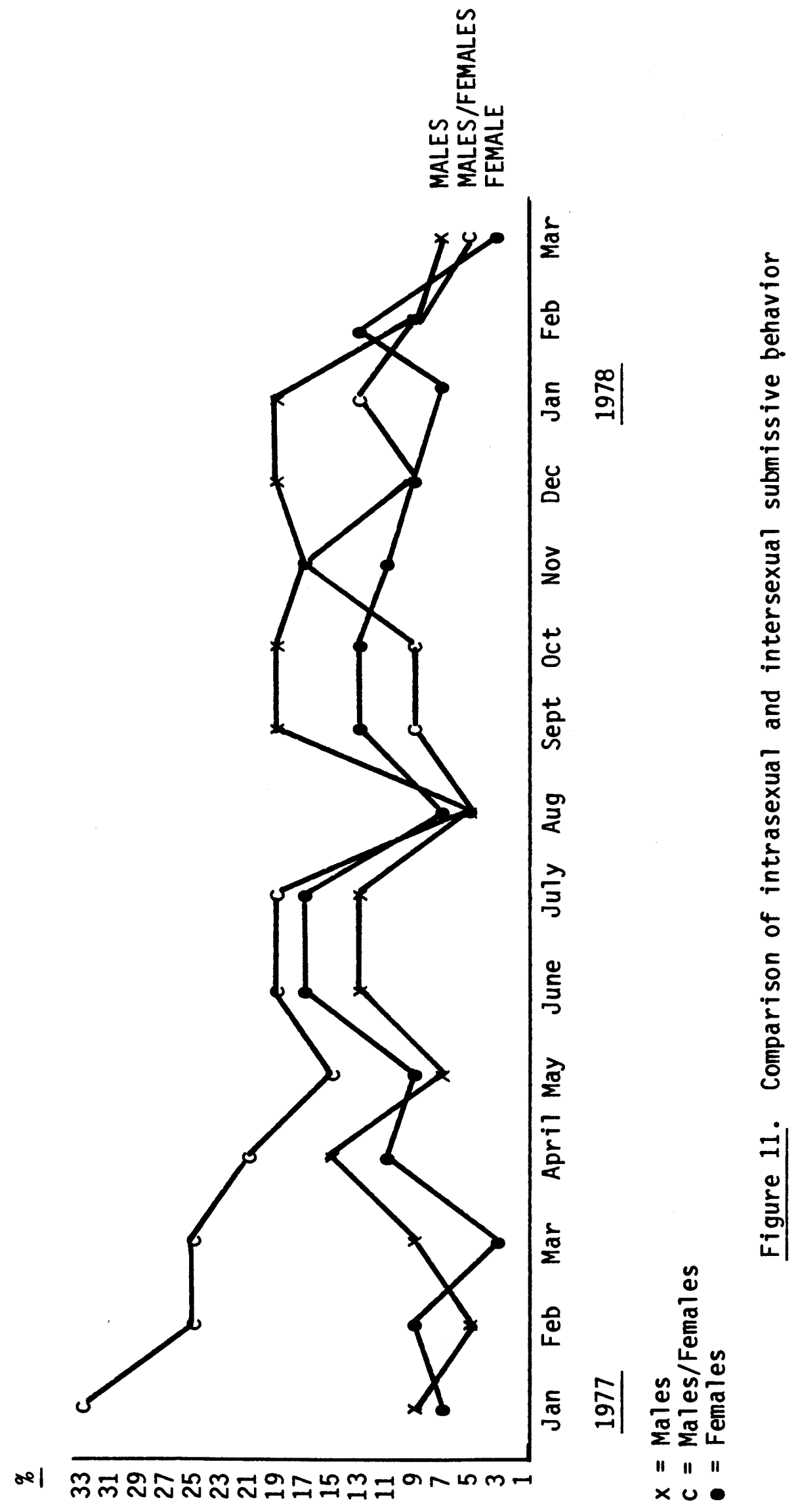


Measures of Social Rank

For the period 1 January through 5 May 1977, the Quantitative Rank Order (QRO) and the Food Rank Order (FRO) correlated closely for males and females, respectively $(r=0.97, p<.001 ; r=0.99, p<.001)$ (Figures $12,13)$. During the same period, Subjective Rank Order (SRO) corresponded with both FRO and QRO in 90 percent of the weekly ratings. QRO and FRO did not correlate in the period 24 June through 2 September 1977 for either sex ( $r=.04, p-N S[F] ; r=.40, p-N S[M])$ (Figures 14,15 ). SRO did not correspond with FRO, but was in agreement with QRO for 91 percent of weekly ratings.

FRO and QRO showed a decreased correlational value for adult males in the period 31 December through 31 March 1978 ( $r=.70, p<.01)$ (Figure 17), and SRO corresponded closely to QRO with interobserver weekly ratings of $95 \%$. FRO and SRO agreed in 70 percent of rank placements. A correlational value of $r=1.00, p<.001$ for FRO and QRO among the females during the period was equivalent to values recorded for the previous winter (Figure 16). SRO was identical to FRO and QRO with interobserver agreement of 100 percent.

Finally, wolves which initiated encounters were dominant significantly more often than those which were recipients $(t=2.96$, $p<.005)$.

Summary. Pack social activity fluctuated seasonally. It was highest during the months of October-November and lowest during JuneJuly. Friendly behavior comprised the majority of activity throughout the year and, as such, had the most profound influence on general behavior. Changes in aggressive activity began and ended later than 
changes in general activity. High levels of aggression also closely coincided with changes in the rank order. Fluctuations in submissive activity were of no apparent significance. Assessment of the social structure was conflicting, suggesting either a single social order composed of both sexes or the existence of two sexually distinct hierarchies. QRO was found to correlate with the FRO during the winter months of two consecutive years for males and females. SRO was in close agreement with QRO in all seasons, whereas FRO and SRO were comparable only in winter months. 


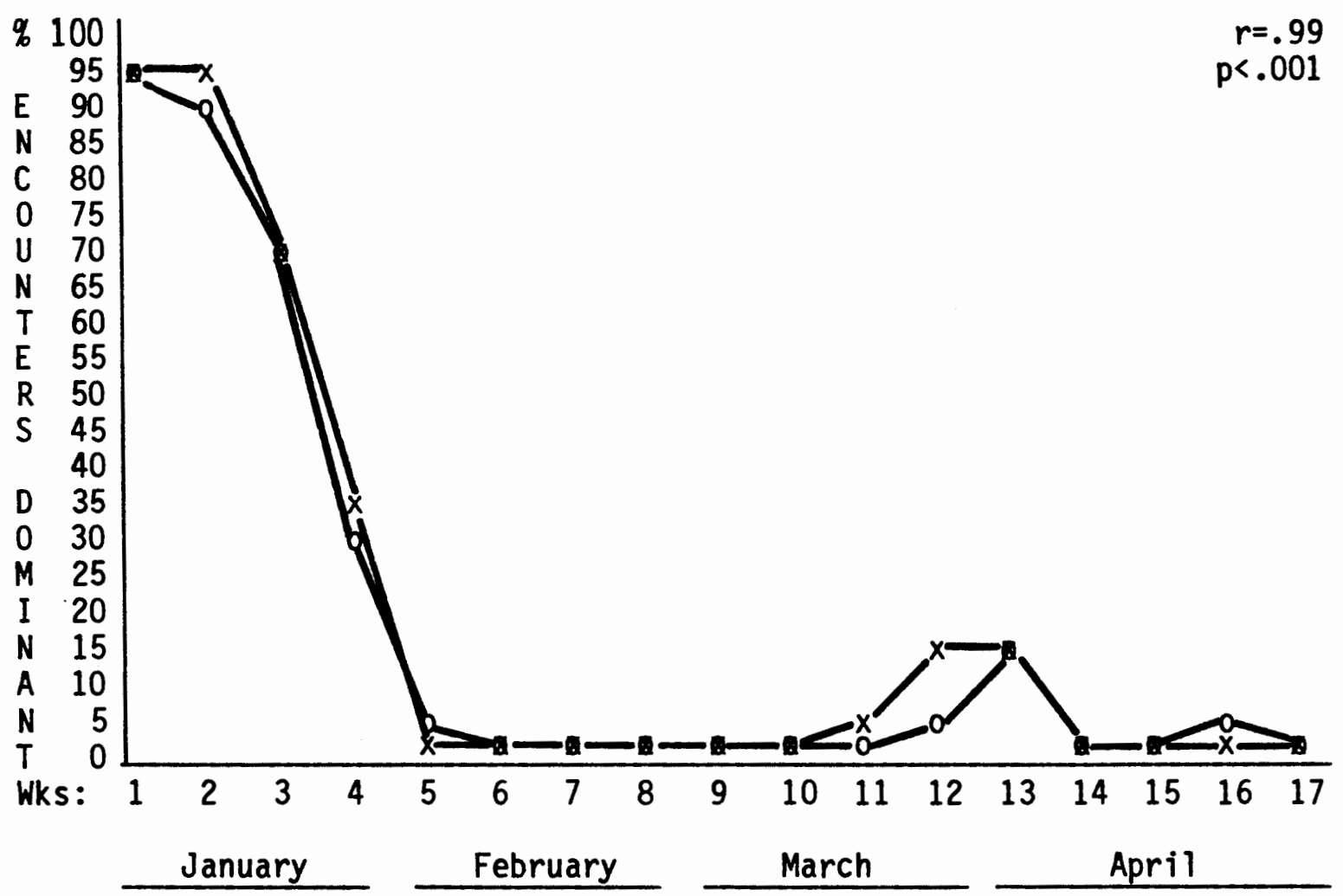

$x=Q R O$ (quantitative rank order)

$0=F R O$ (food rank order)

Figure 12. Percentage of social encounters in which Juneau dominated Sitka compared to percentage of food encounters in which Juneau dominated Sitka for the period 1 January - 5 May 1977 


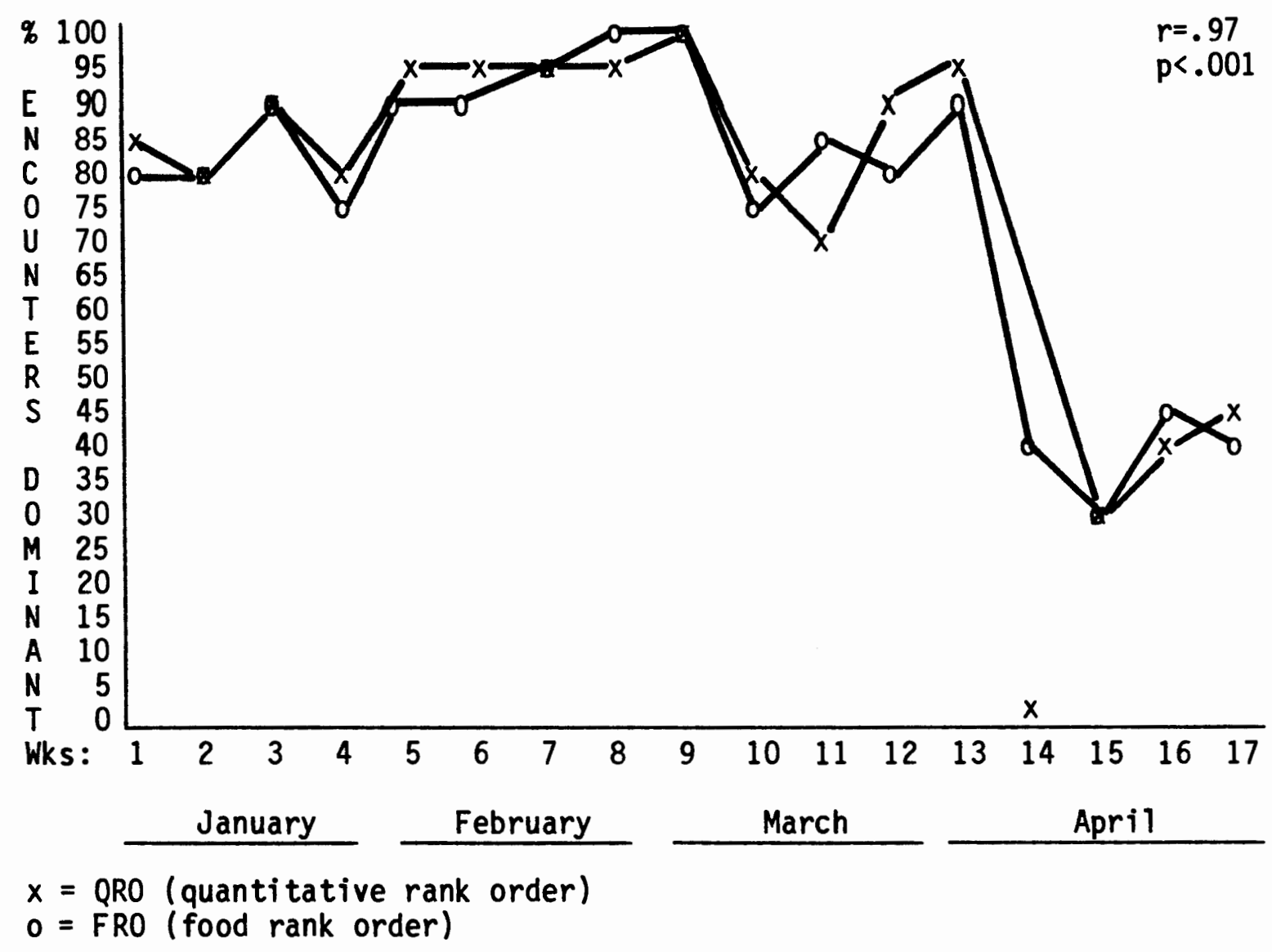

Figure 13. Percentage of social encounters in which Zane dominated Mowgli compared to percentage of food encounters in which Zane dominated Mowgli for the period 1 January - 5 May 1977 


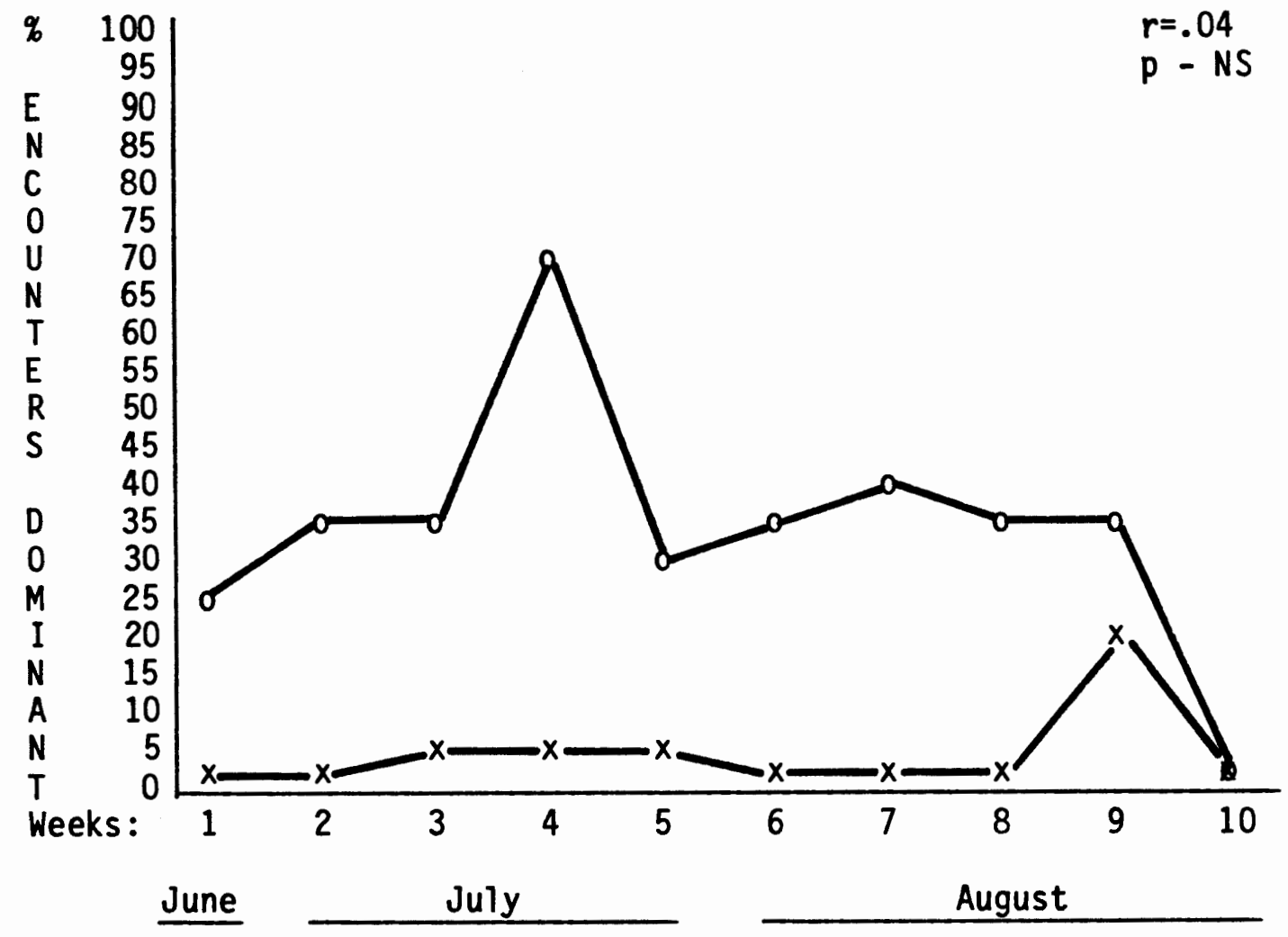

$x=Q R O$ (quantitative rank order)

$0=$ FRO (food rank order)

Figure 14. Percentage of social encounters in which Juneau dominated Sitka compared to percentage of food encounters in which Juneau dominated Sitka for the period 24 June - 2 September 1977 


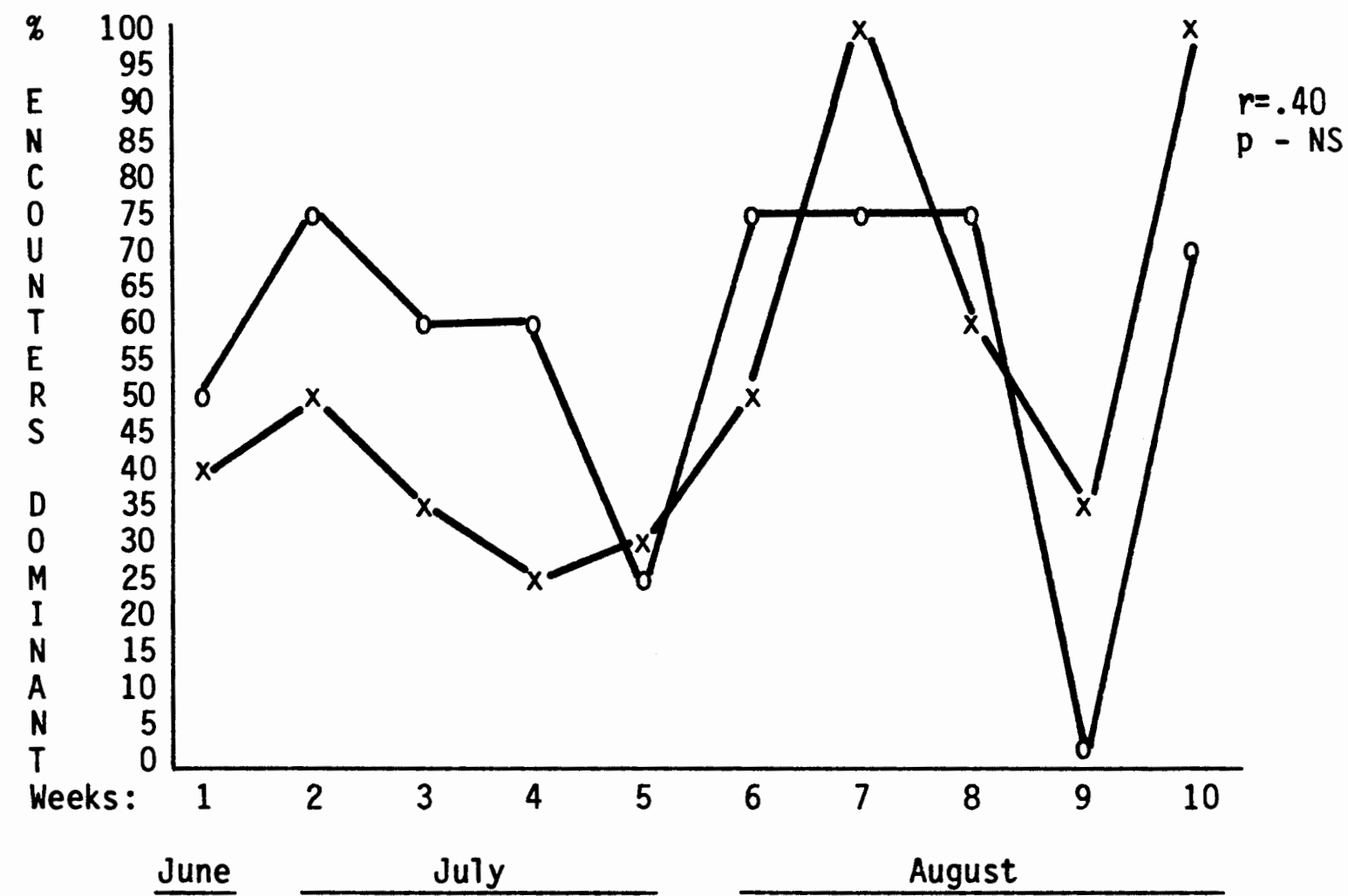

$X=Q R O$ (quantitative rank order)

$0=F R O$ (food rank order)

Figure 15. Percentage of social encounters in which Zane dominated Mowgli compared to percentage of food encounters in which Zane dominated Mowgli for the period 24 June - 2 September 1977 


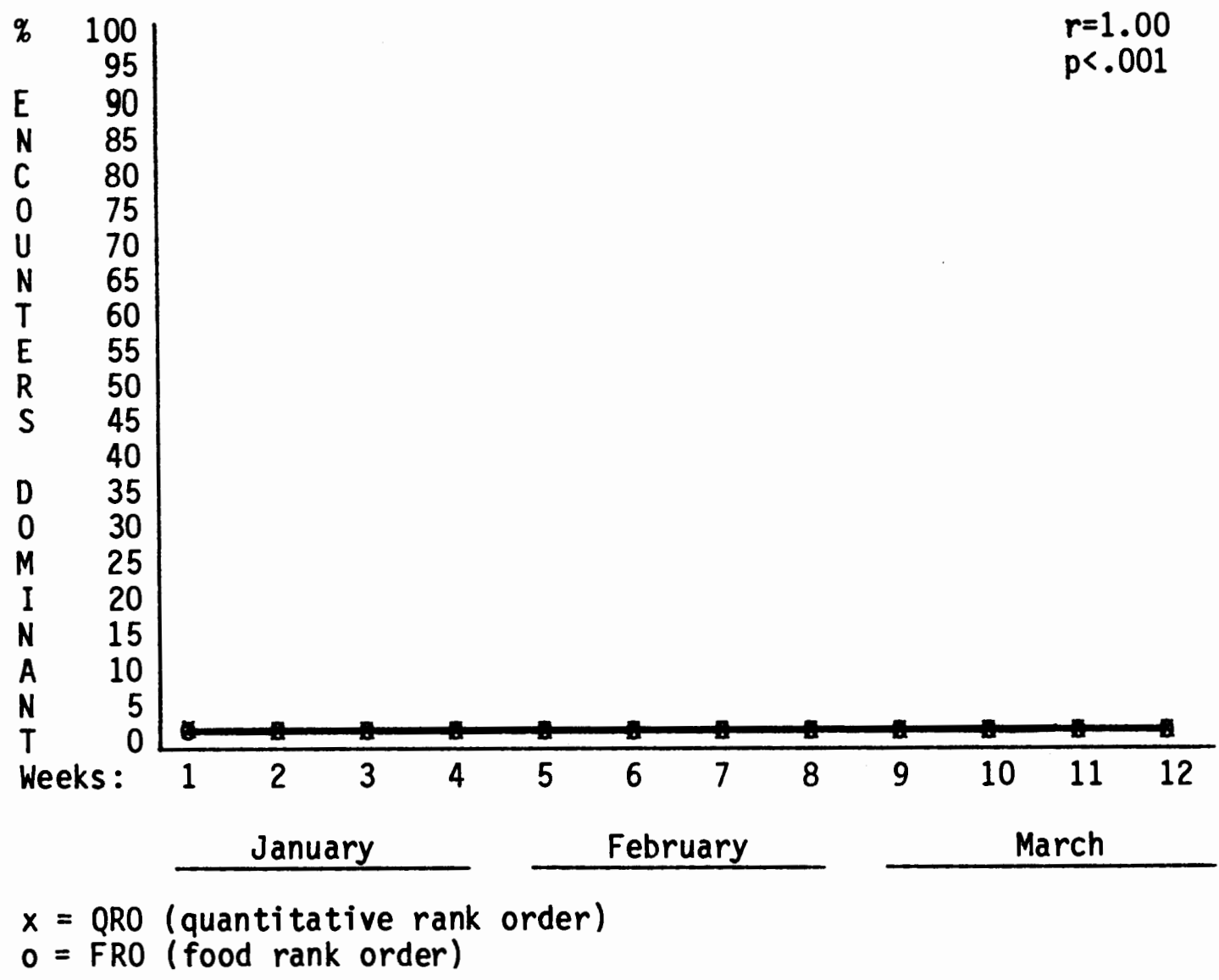

Figure 16. Percentage of social encounters in which Juneau dominated Sitka compared to percentage of food encounters in which Juneau dominated Sitka for the period 31 December - 31 March 1978 


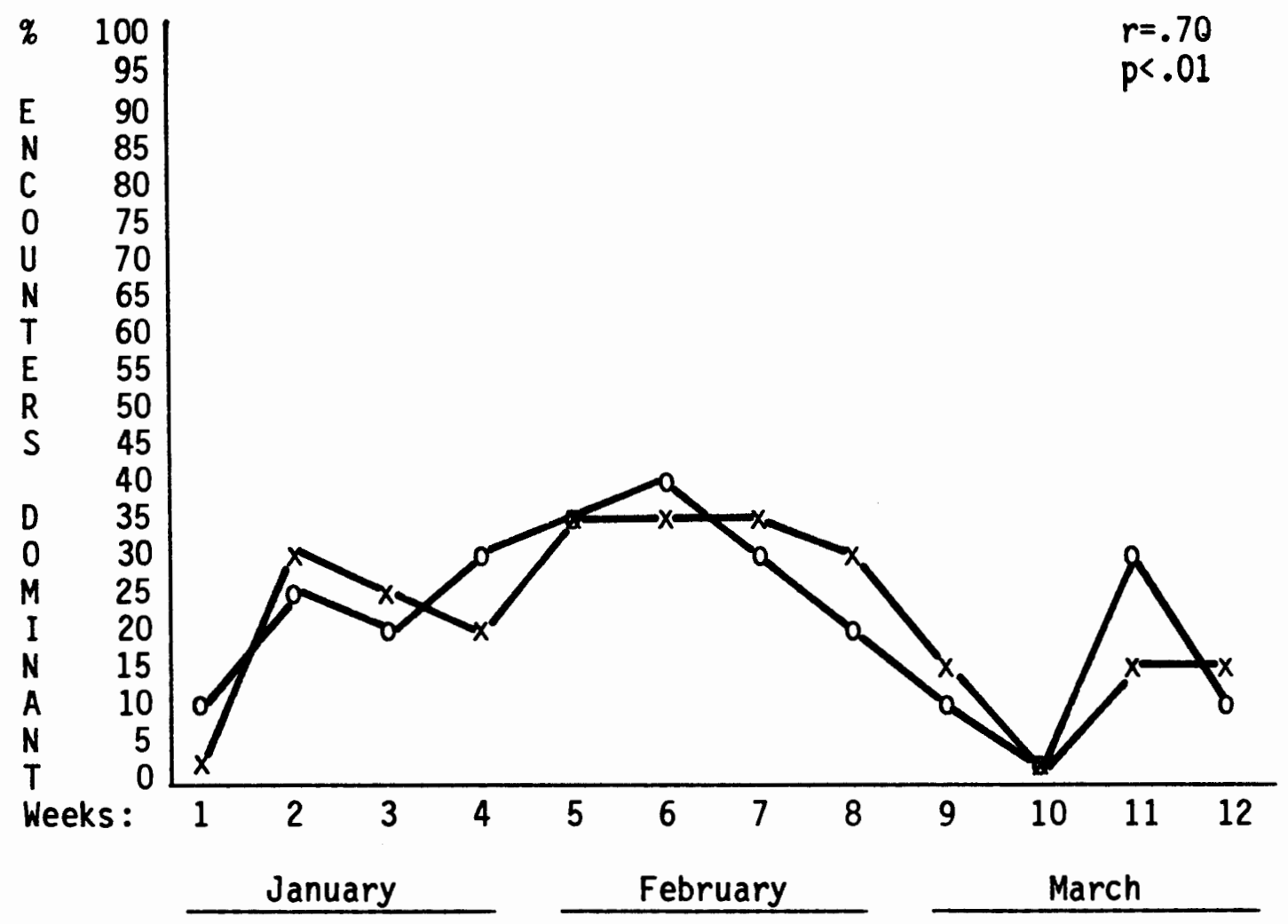

$X=Q R O$ (quantitative rank order)

$O=F R O$ (food rank order)

Figure 17. Percentage of social encounters in which Zane dominated Mowgli compared to percentage of food encounters in which Zane dominated Mowgli for the period 31 December - 31 March 1978 
Effects of Removals And Reintroductions On Aggressive Behavior

Removal of dominant females on 11 occasions during the months of December through April resulted in an average 508 percent increase in agonistic behavior upon reintroduction of these same animals. Average period of removal was nine days with a maximum time of 31 days and a minimum of one day. There was a significant, positive correlation between the length of time a wolf was isolated from the pack and the degree of aggression associated with the animal's return $(r=.714$, $p<.05)$. Reintroduction encounters were also of higher intensity, as measured by a greater frequency of injuries. There was no correlation between length of isolation and time for the pack to return to preintroduction levels of aggression $(r=-0.253, n=11)$ (Table VII). Removal of low ranking wolves which were severely harassed usually resulted in a decrease of agonistic behavior. This was due primarily to decreased aggressive activity by the dominant female.

Removal of wolves may have precipitated changes in individual relationships. For example, during December 1975, 100 percent of observed behavior between Taquish and Juneau was aggressive, while only four percent of behavior observed between Juneau and Laska was aggressive. After removal of Taquish, aggressive behavior between Juneau and Laska increased to 38 percent and then gradually decreased to the previously low level. I suspect that if the increase had been due to pre-estrus aggression rather than Taquish's removal, aggression would have remained high. 


\section{TABLE VII}

CHANGES IN AGGRESSION FOLLOWING REMOVAL AND REINTRODUCTION OF WOLVES

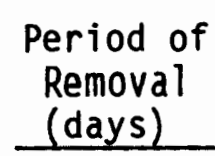

31

1

11

9

5

7

6

7

3

7

12
$\%$ Change in

Aggressive Behavior

$\underline{\text { Dates }}$

6 Jan. - 5 Feb.

9 Feb. - 10 Feb.

12 Dec. - 22 Dec.

5 March - 13 March

27 Jan. - 31 Jan.

7 April - 13 April

9 April - 14 April

16 Jan. - 22 Jan.

6 March - 8 March

15 April - 21 March

13 Feb. - 24 Feb. after Reintroduction

$+712$

$+211$

$+600$

$+627$

$+417$

$+529$

$+571$

$+491$

$+230$

$+528$

$+671$
\# Days to Return to Pre-introduction Levels of Aggression
2

7

31

11

12

5

13

7

13

14

1

Howling

Chorus howl ing fluctuated seasonally, remaining relatively constant during summer and fall, and gradually increasing in December to a peak level in February and March (Figure 18). The number of chorus howls initiated by individual wolves appeared to be related to social position. (Table VIII). Among the wolves whose status changed during the period 1976-1978, all initiated more chorus howls as dominant animals than as subordinates. 


\section{Average \# of Howls per Month}

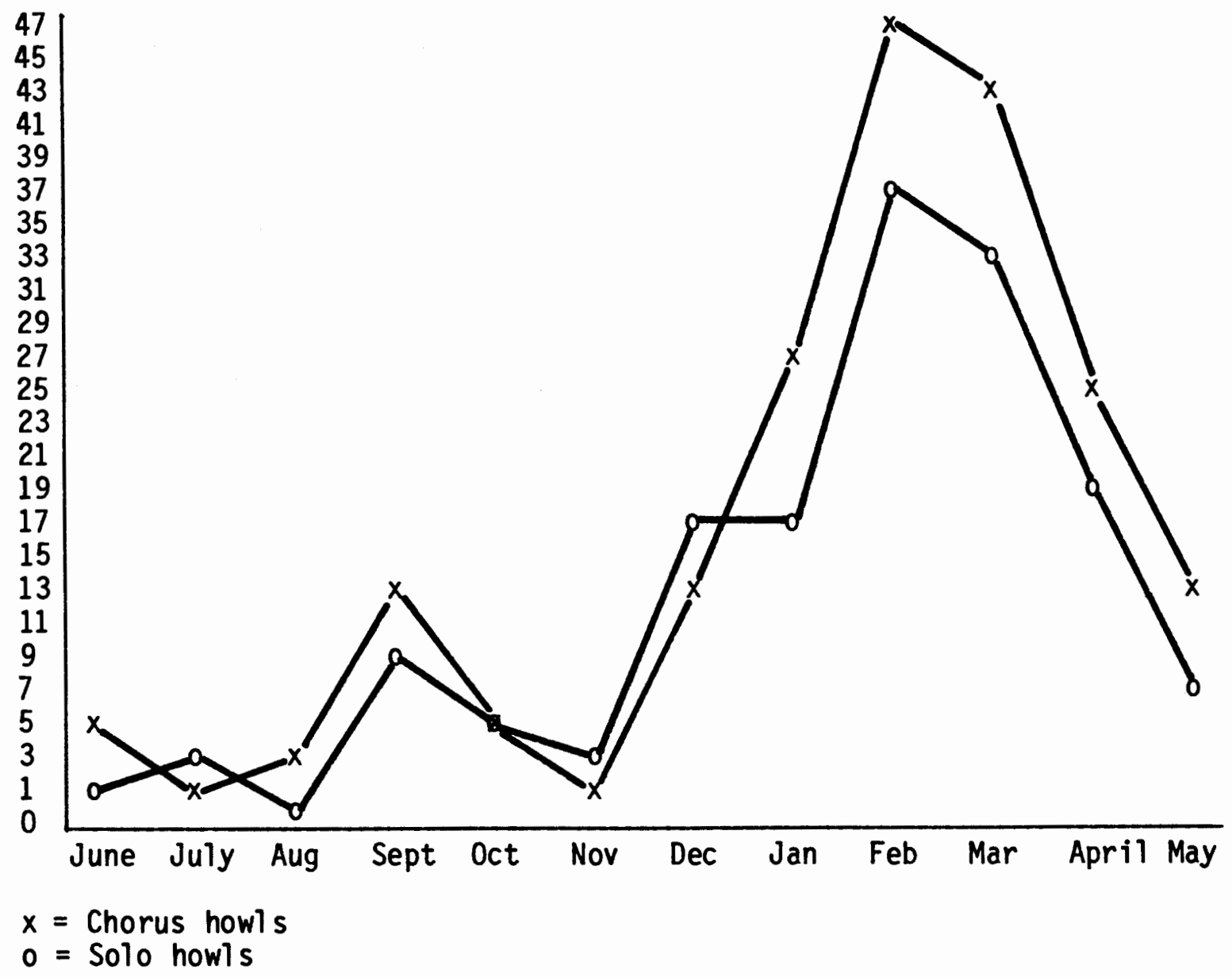

Figure 18. Seasonal frequency of chorus and solo howls expressed as the average number of howls recorded per month for the period, June 1976 through June 1977 (991 observation hours) 
Since it was not always apparent which wolf initiated a chorus, more howls were recorded (Figure 18) than indicated by Tables VIII and IX.

\section{TABLE V III}

SOLO AND CHORUS HOWLS RECORDED FROM JUNE 1976-1978

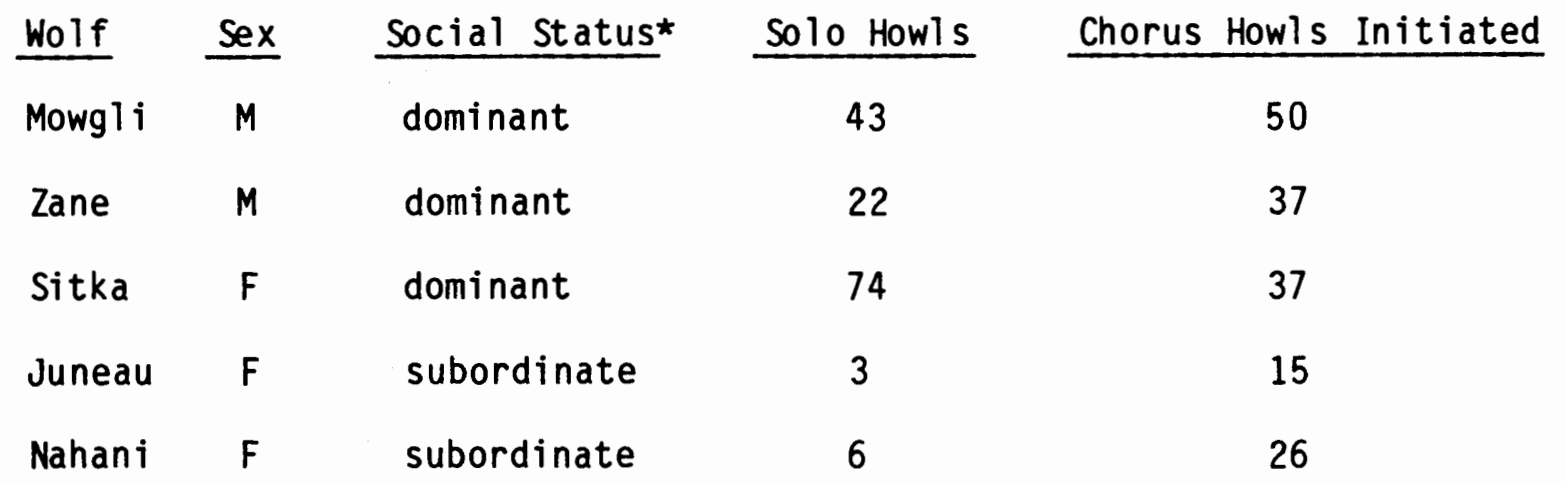

*pack ranking

TABLE IX

RELATIONSHIP BETWEEN SOCIAL STATUS

AND CHORUS HOWLS FOR THE PERIODS,

JUNE 1976-77 AND JUNE 1977-78

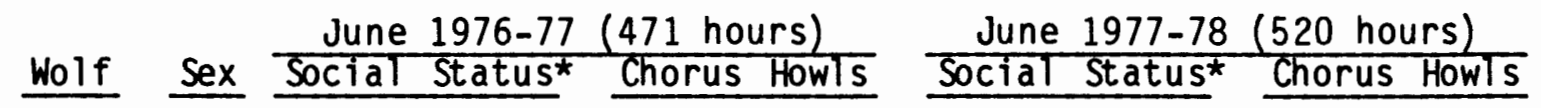

Mowgli M beta

19

alpha

31

Zane $M$

alpha

26

beta

11

Sitka $F$

beta

15

alpha

22

Juneau $F$

alpha

15

beta

0

Nahani $F$

omega

18

omega

8 
Solo howling followed a seasonal pattern similar to that observed for chorus howling (Figure 18). As with chorus howling, dominant wolves were, as a group, more likely to howl than subordinate animals (Table VIII). However, the number of solo howls recorded for Zane did not change with his decline in social status in April 1977, and actually decreased for Mowgli when he became alpha male. There was a marked increase in solo howls by Sitka once she became established as dominant female in January 1977 ( Table X).

TABLE $X$

RELATIONSHIP BETWEEN SOCIAL STATUS AND SOLO HOWLS FOR THE PERIODS JUNE 1976-77 AND JUNE 1977-78

Wolf Sex Social Status* Solo How/s $\quad \begin{gathered}\text { June } 1976-77(471 \mathrm{hrs}) \\ \text { Social Status }\end{gathered}$ Mowgli M beta 34 alpha 13 Zane $M$

alpha

13 beta 12

Sitka $\quad F$

beta

19

alpha

Juneau $F$

alpha

3

beta

0

Nahani $F$

omega

1

gamma

6

*sexual ranking

Two noteworthy observations not included in the quantified data are of interest. In December 1975, Taquish was isolated from the pack in a holding cage adjacent to the primary enclosure. She howled relentlessly for several weeks. Initially, the entire pack appeared agitated and repeatedly gathered around Zane in a "greeting ceremony" (Mech, 1970; Zimen, 1971), behavior which often precedes group howling 
and under such circumstances has been termed "rally behavior" (Klinghammer and Laidlaw, 1979). However, the pack was never observed to respond to Taquish's howls with howls of their own, although they did whine and yelp. After several days the pack appeared to totally ignore her.

During the first week of September 1977 Mowgli howled solitarily for periods of up to 14 hours. He was always oriented in an easterly direction. Other pack members appeared to pay little attention and never joined in the howling. Observers were unable to detect any unusual sounds or activities in the area.

Scent Marking

A total of 5573 urine marks were recorded during 991 hours of observation from June 1976 through June 1978. Fifty-six percent were categorized as raised leg urination (RLU) and 44 percent were listed as squat urination (SQU) (Table XI).

TABLE XI

SCENT MARKING BY INDIVIDUAL WOLVES FOR THE PERIOD JUNE 1976-78 (991 HRS)

\begin{tabular}{|c|c|c|c|c|}
\hline Wolf & Sex & Social Status* & RLU & SQU \\
\hline Mowgl i & $M$ & dominant & 760 & 171 \\
\hline Zane & $M$ & dominant & 958 & 156 \\
\hline Sitka & $F$ & dominant & 913 & 792 \\
\hline Juneau & $F$ & subordinate & 490 & \\
\hline Nahani & $F$ & subordinate & 0 & \\
\hline
\end{tabular}


The frequency of urine marking fluctuated seasonally with an increase beginning in November. Levels recorded in December, January, February, March, were more than three times those recorded during other months. A slight decrease was noted during the latter part of February, which corresponded with the period when females were sexually receptive (Figure 19). There was a proportional increase in RLUs beginning in December. This was attributable to a shift by dominant females from SQU to RLU. There was a decrease in urine marking by zane after becoming subordinate to his son Mowgli in April 1977; however, Mowgli's rate of marking also decreased following this social shift. Among individual females there was a marked change in the amount of urine marking and the method of deposit following changes in social position. The dominant female marked more frequently than subordinates and often raised her leg to urinate (Table XII). 
Mean Number of

Scent Marks per

Observation $\mathrm{hr}$.

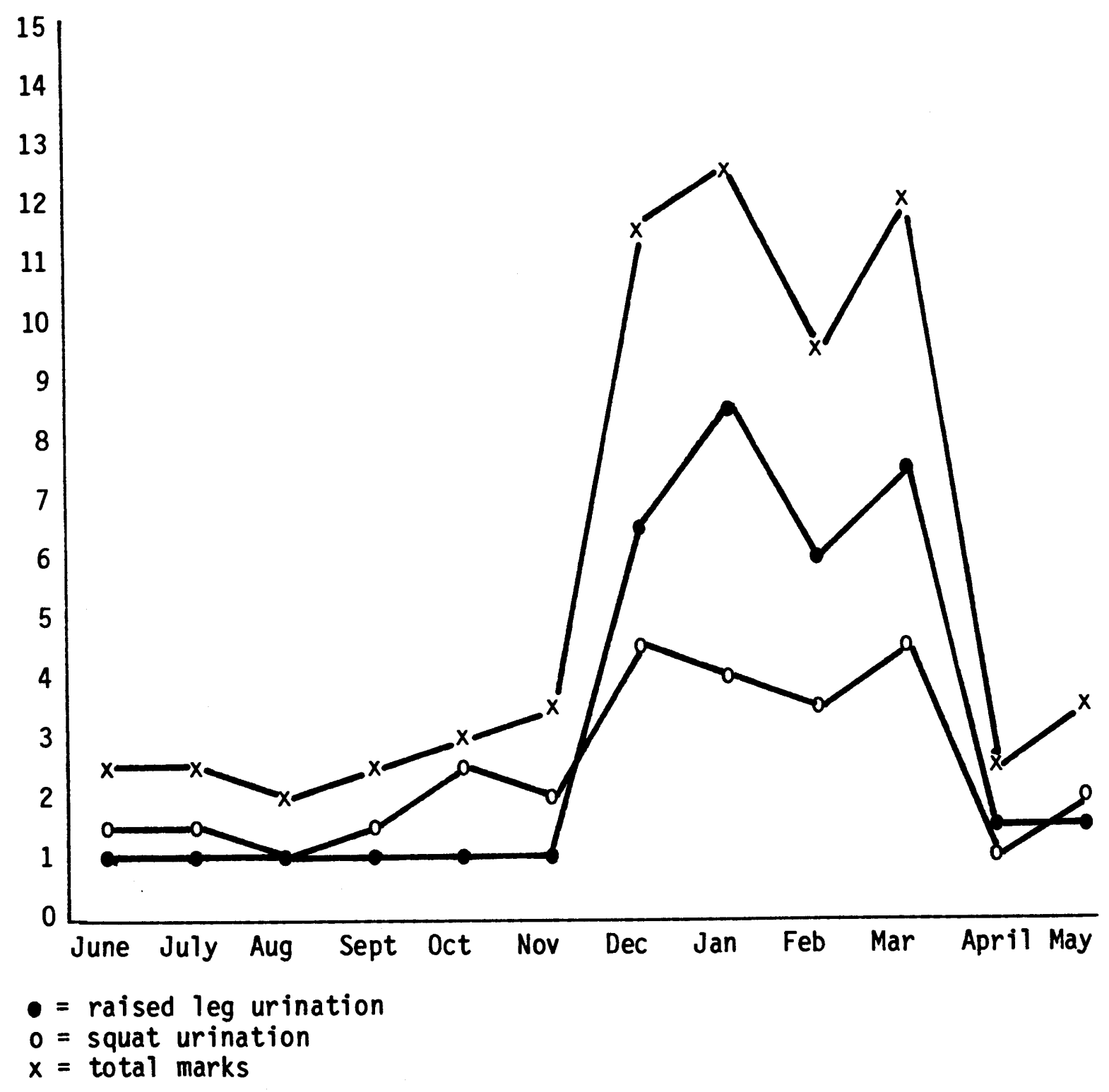

Figure 19. Seasonal frequency of urine marking, expressed as the average number of scent marks per observation hour for each one month period, June 1976 to June 1978 (991 observation hours) 
TABLE XII

SOCIAL STATUS AND URINE MARKING FOR

THE PERIODS JUNE 1976-77

AND JUNE 1977-78

\begin{tabular}{|c|c|c|c|c|c|c|c|}
\hline & & June 1976-77 ( & $\$ 71$ hol & s) & June 1977-78 & $20 \mathrm{hc}$ & s) \\
\hline Wolves & Sex & Social Status* & RLU & SQU & Social Status* & $R L U$ & SQU \\
\hline Mowgl i & $M$ & beta & 462 & 115 & alpha & 298 & 56 \\
\hline Zane & M & alpha & 593 & 97 & beta & 365 & 59 \\
\hline Sitka & $F$ & beta & 312 & 307 & alpha & 601 & 485 \\
\hline Juneau & $F$ & alpha & 469 & 243 & beta & 21 & 329 \\
\hline Nahani & $\mathrm{F}$ & omega & 0 & 302 & omega & 0 & 459 \\
\hline
\end{tabular}

*sexual ranking

Beginning in December of each year, males sampled urine deposited by females. They slowly licked the urine, frequently stopping to sniff. They exhibited an expression similar to a consumatory face: the lips were drawn forward, the eyes narrowed, and ears laid back. They salivated profusely to the point of lathering. This behavior was observed regularly, well into March. Similar observations were made during other times of the year, but these were infrequent and inconsistent from year to year. This behavior corresponded closely with seasonal changes in scent marking (Figure 19).

Mating Behavior

Courtship and breeding involved only the wolves 22 months and older. Ten month old animals showed no physical or behavioral signs of mating activity. Although the litters sired by Zane in 1975 and 1976 did not have the same mothers all observed mating during each breeding 
season was restricted to single pairs. In 1975 Zane was observed mounting Taquish 19 times and tying with her once (25 Feb.). In 1976 he was observed mounting Juneau 48 times and tying three times (27 Feb.). In 1977, although solicited by his daughter Sitka, Zane was only observed courting and breeding Juneau, his mate of the previous year. He aggressively rebuffed Sitka's courtship attempts. He was observed mounting Juneau 71 times, and tying with her successfully five times (910 March 1977). Mowgli was initially unsuccessful in attempts to court his sister Sitka as she exhibited a strong preference for her father Zane. Sitka eventually became receptive to Mowgli, who was observed mounting her 47 times and tying with her three times (4-6 March 1977) (Table XIII). With the exception of 1977, all matings were between alpha animals. In 1977, Zane was alpha male when he mated with Juneau who, at the time, was beta female.

\section{TABLE XIII}

MATING BEHAVIOR

\begin{tabular}{|c|c|c|c|c|c|}
\hline & Pairs & & & & \\
\hline Year & Male FemaTe & Mountings & Ties & Observation & Hours \\
\hline 1975 & Zane + Taquish & 19 & 1 (25 Feb) & 42 & \\
\hline 1976 & Zane + Juneau & 48 & 3 (27 Feb) & 38 & \\
\hline 1977 & Zane + Juneau & 71 & $5(9-10 \mathrm{Mar})$ & 57 & \\
\hline 1977 & Mowgli + Sitka & 47 & $3(4-6 \operatorname{Mar})$ & 57 & \\
\hline
\end{tabular}

In Utero Mortality

On 13 May 1977, Juneau delivered three pups (1 male, 2 female). She was observed during the delivery and for 18 hours afterward. Pregnancy was prevented the following year by isolating her and 
administering intramuscularly $200 \mathrm{mg}$ Deproprovira (Upjohn Co.), a commercial canine contraceptive. On 23 October 1978, Juneau died. The uterus was removed to evaluate reproductive performance. Placental scars persist for at least two years in the coyote (C. latrans) (Gier, 1968). I assume similar persistence for the wolf (Rausch, 1967). Seven placental scars were counted. Six were distinctive with definitive borders. One was ill-defined and difficult to discern. The six distinctive scars were determined to be the result of the immediate past pregnancy of 13 May 1977. The less obvious scar represented either a scar of resorption or a site of implantation from an earlier pregnancy (Rausch, 1967; Gier, 1968). The discrepancy between fetuses implanted and young produced is evidence of in utero mortality, most likely due to embryonic resorption (Packard, pers. comm.).

\section{Pup Care}

Only single litters were born in 1975 and 1976. Pup care during those years is compared with care of two concurrent litters born during 1977.

In 1977, the offspring were successfully cared for in a communal den, and were nursed without regard to relatedness by both mothers. Four days prior to the appearance of the first litter zoo management isolated the pregnant females. Sitka delivered five pups (2 males, 3 females) on 9 May 1977. Three hours after delivering she was reunited with Juneau. With the exception of occasional sniffing there was little interaction between the two females. Juneau was never observed to approach the pups although Sitka made no apparent attempts to prevent her from doing so. 
Within 24 hours of parturition it was observed that one noticeably smaller pup, crowded out by its four littermates, was unable to nurse. Sitka repeatedly carried it to the rear of the denning area and nursed it separately. This pup later disappeared and apparently died and was consumed by one of the adult wolves.

Juneau delivered three pups (1 male, 2 females) on 13 May. All pups were cleaned and nursed and then carried one at a time to Sitka, the dominant female. No signs of submissiveness were observed as she presented the pups to Sitka. Sitka received the pups and immediately commenced to clean, groom and nurse the new pups together with her own litter. Later the same morning Juneau was observed nursing both litters while Sitka slept nearby.

Both females delivered their pups in the same area of the den, constructing a ring with a raised perimeter from the straw covering the floor. One day prior to Juneau's delivery, Sitka moved her pups to the rear of a more isolated den.

Division of Maternal Care

Both litters displayed a preference for Sitka, based on the speed with which the pups approached Sitka, without apparent prompting, after a period of absence. Conversely, Juneau always had to physically retrieve individual pups and place them in a position to nurse. This pattern became evident three days after Juneau delivered.

In 1977, Sitka spent significantly more time in the den nursing, than did Juneau ( $t=1.99, p<.05)$ (Table XIV). Although nursing was defined as total suckling time, it was impossible to be certain that each pup was constantly suckling. I therefore may have miscalculated 
active milk exchange. However, because sitka typically nursed a greater number of pups ( 5 versus 3 ), I am confident her total contribution to nutrition was greater than Juneau's. Juneau spent significantly more time in care and grooming of the pups ( $t=2.52, p<.05)$ (Table XIV). In 1976 when Juneau alone littered ( 1 male, 2 females), neither percentage time nursing nor percentage time in care and grooming of pups differed significantly from her figures in $1977(t=.77, d . f .=47$ and $t=.89$, d.f. $=47)$. Due to den configuration in 1975 , we were unable to observe Taquish with her pups.

\section{TABLE XIV}

A COMPARISON OF CARE BEHAVIOR OF DENNING MOTHERS

\begin{tabular}{lcccc}
$\quad \begin{array}{c}\text { Percent } \\
\text { Time Spent: }\end{array}$ & $\frac{1976}{\text { Juneau }}$ & & \multicolumn{2}{c}{1977} \\
\cline { 2 - 2 } Nursing & $14.0 \%$ & & $33.0 \%$ & Juneau \\
Care and grooming & $3.2 \%$ & $14.0 \%$ & $4.9 \%$ \\
Total hours & 22 & 53.4 & 52.2 \\
observed in den & & &
\end{tabular}

Time Budget

In 1977, a regular periodicity in the mothers' care of the pups was established within two days after communal denning and was maintained until approximately the 14th day after Sitka whelped. The mothers were seldom with the pups between 1900-2000 hours but, during all other times, one was in regular attendance. Both mothers had preferred hours. There was a weak inverse relationship between the periods when the two mothers were in attendance $(r=-.436, p<.05)$ (Figure 20). 


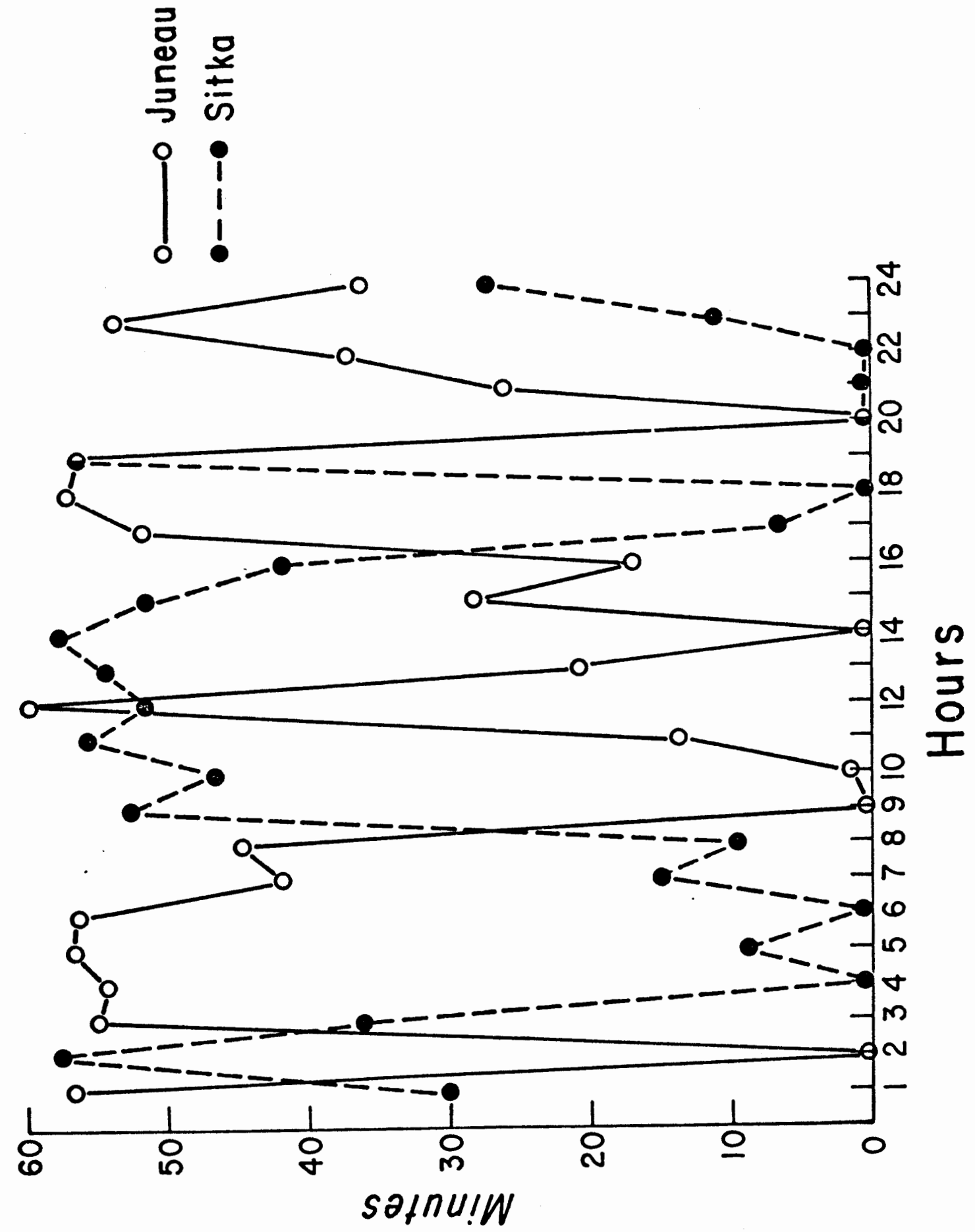

Figure 20: This graph depicts the time periods when communatTy denning mothers were in attendance (1977) 
To obtain an independent estimate of the care schedule, zoo staff made spot checks and recordings at random times. To avoid bias the observations were done when regular data collectors were absent. The checks corresponded well with the time schedule generated from observer data (Sitka; $r=.737, p<.001$ and Juneau; $r=.931, p<.001$ ). Although preferred hours of attendance had been evident in both 1975 and 1976, no verifiable patterns were established.

In 1977, Sitka and Juneau each spent about half of the total observed time with the pups (Table XV). These data do not accurately reflect real time because the 24 one-hour observation periods were biased towards Sitka's preferred hours. I compensated for this bias by calculating mean time each female was with the pups during each one hour period. This method revealed that al though Juneau spent more time with the pups than did Sitka (Table XV) the difference was not significant $(t=.979, d . f .=98)$.

Time each female was alone with the pups was equal using both the raw data (Sitka $34.6 \%$ versus Juneau 33.5\%) and the adjusted data (Sitka $28.3 \%$ versus Juneau $40.19 \% ; t=.801$, d.f. $=98$ ). Data from the other two females in 1975 and 1976 were similar (Table XV). 
TABLE XV

PERCENTAGE OF TIME FEMALES PRESENT IN DEN WITH PUPS (INCLUDES OBSERVED

TIME AND ADJUSTED TIME)

\begin{tabular}{|c|c|c|c|c|}
\hline \multirow[b]{2}{*}{ Percentage Time } & \multirow{2}{*}{$\frac{1975}{\text { Taquish }}$} & \multirow{2}{*}{$\frac{1976}{\text { Juneau }}$} & \multicolumn{2}{|c|}{1977} \\
\hline & & & sitka & Juneau \\
\hline With pups & $51.0 \%$ & $47.3 \%$ & $53.9 \%$ & $52.7 \%$ \\
\hline (adjusted time) & & & $(46.5 \%)$ & $(57.4 \%)$ \\
\hline Al one with pups & $51.0 \%$ & $47.3 \%$ & $34.6 \%$ & $33.5 \%$ \\
\hline (adjusted time) & & & $(28.3 \%)$ & $(40.1 \%)$ \\
\hline Total hours observed & 51 & 47 & 99 & 99 \\
\hline
\end{tabular}

The pups were alone significantly less often in 1977 than in either $1975(t=14.7, p<.001)$ or $1976(t=15.1, p<.001)$ (Table XVI). There was no difference between 1975 and $1976\left(t=.66, d_{. f .}=47\right)$. In 1975, Taquish did not allow other wolves into the den, so the pups were always alone whenever she was away. In 1976, Juneau allowed one other female access to her pups and that female "pup-sat" 14.8 percent of the time Juneau was absent. During 1977 Sitka would not allow other pack members to approach the pups. Therefore, the pups were cared for by only the two mothers. However, even without additional help, communal care minimized the time pups were alone. 
TABLE XVI

TIME PUPS LEFT ALONE

Dates

Taquish

Juneau

Sitka

Juneau \& Sitka
14 April - 29 April 1975

23 April - 6 May 1976

10 May - 12 May 1977

12 May - 24 May 1977
Percent Total Percent Total Observed Time Observed Time Pups Alone With Pups

* In 1976, a second nonparous female was in attendance $14.8 \%$ of the time Juneau was absent

**Sitka's high attendance rate is due to the fact that the time frame displayed in the chart represents only the first three days after parturition. The other females showed a similar high attendance rate for equivalent periods. However, none of the females alone exceeded the attendance rate of the two parous females caring for pups cooperatively.

Cooperative Feeding During Denning

Juneau was the only mother observed to cache food in 1977. She also frequently regurgitated food for Sitka. Sitka was never seen to reciprocate. The only aggressive encounter recorded while the mothers denned together occurred when Sitka attacked Juneau, pinned her to the ground and secured food from her mouth. Mowgli provided whole and regurgitated food to both mothers and the pups. When access to the den was restricted, Mowgli forced food under the door which separated him 
from the mothers. Zane and Nahani both brought food to Juneau but not to Sitka. Nahani begged food from Zane and Juneau but neither were observed to respond (Table XVII).

\section{TABLE XVII}

FEEDING DISTR IBUTION DUR ING DENNING

- 9 MAY-14 JUNE, 1977 (154

OBSERVATION HOURS)

\begin{tabular}{|c|c|c|c|c|c|c|}
\hline \multirow[b]{2}{*}{ Provisioners } & \multicolumn{6}{|c|}{ Recipients } \\
\hline & Zane & Juneau & Mowgli & Sitka & Nahani* & Pups \\
\hline Zane & & 4 & 0 & 0 & 0 & 3 \\
\hline Juneau & 0 & & 0 & 19 & 0 & 5 \\
\hline Mowgli & 0 & 3 & & 7 & 0 & 1 \\
\hline Sitka & 0 & 0 & 0 & & 0 & 7 \\
\hline Nahan j* & 0 & 4 & 0 & 0 & & 1 \\
\hline
\end{tabular}

In 1976, when Juneau produced the only litter, both Juneau and Laska were observed caching food and regurgitating food for one another and the pups. The yearling female, Sitka, never provided food or begged for food from other wolves. Her brother Mowgli never regurgitated food but brought whole pieces of food to both Juneau and Laska. Zane, the father of the litter, deposited regurgitated food near the entrance of the den, which was consumed by both Juneau and Laska. He also regurgitated food for Mowgli (Table XVIII). 
TABLE XVIII

FEEDING DISTRIBUTION DUR ING DENNING

- 23 APRIL-7 JUNE, 1976 (107

OBSERVATION HOURS)

Provisioners

Zane

Juneau

Laska

Mowgl $i *$

Sitka*

Zane June

0

0

0

0

Recipients

\begin{tabular}{|c|c|c|c|c|}
\hline & & & & \\
\hline Juneau & Laska & Mowglix & Sitka* & Pups \\
\hline 9 & 3 & 6 & 0 & 2 \\
\hline
\end{tabular}

6

3

0
5

0

0

5

0

0

$0 \quad 7$

0

2

0

1

0

*Yearlings

In 1975, Taquish only accepted food regurgitated by Zane. Both Juneau and Laska regurgitated food at the den entrance but it was ignored by Taquish and usually eaten by Zane. Zane was never observed feeding the yearling females, nor were the females observed feeding one another. After seven weeks of age the pups were recipients of whole and regurgitated food provided by Zane, but not the yearling females (Table $X I X)$. 
TABLE XIX

FEEDING DISTRIBUTION DURING DENNING -

14 APRIL-1 JUNE 1975 (93

OBSERVATION HOURS)

\begin{tabular}{|c|c|c|c|c|c|}
\hline \multirow[b]{2}{*}{ Provisioners } & \multicolumn{5}{|c|}{ Recipients } \\
\hline & Zane & Taquish & Juneau* ${ }^{*}$ & Laska* & Pups \\
\hline Zane & & 15 & 0 & 0 & 4 \\
\hline Taquish & 0 & & 0 & 0 & 0 \\
\hline Juneau* & 0 & $3 * \star$ & & 0 & 0 \\
\hline Laska* & 0 & $7 \star \star$ & 0 & & 0 \\
\hline
\end{tabular}




\section{DISCUSSION}

Variability In Wolves

Prior to persecution by humans and an accompanying loss of habitat, distribution of the wolf was nearly cosmopolitan. In the Western hemisphere, the wolf's range extended from the arctic tundra to equatorial America, and in the Eastern hemisphere from Siberia to Iran (Young and Goldman, 1944). There are no records of wolves in Indochina or Africa (Mech, 1970). At present, the wolf's range is greatly reduced, particularly in North America and Europe. The only viable population south of Canada exists in and around the Superior National Forest in Northern Minnesota (Mech, 1970). Goldman states (1944:389): "It seems doubtful whether any species of land mammal has exceeded this geographic range, and this wolf may, therefore be regarded, as the most highly developed living representative of an extraordinarily successful mammalian family."

Mech (1970) notes that any animal with such a wide distribution could be expected to vary considerably from area to area. Accordingly, depending upon the authority, about 32 to 38 subspecies of wolves are recognized throughout the world (Pocock, 1935; Goldman, 1944; Hall and Kelson, 1959; Stains, 1975). Regional morphological variations exist in pelage, skeletal features, body size and proportion (Kolenosky and Stanfield, 1975; Jolicoeur, 1975). Some of these differences may be correlated with the prey species being utilized (Fox, 1975), while others are 
adaptive to geographic location, e.g. the long white pelage of northern wolves (Jolicoeur, 1975). Al though much of this variation can be explained by the environmental influences exerted on physiology and growth, current biological thought suggests that these differences are, at least in part, controlled by heredity (Jolicoeur, 1975).

In a computer simulation of wolf pack genetics, Woolpy and Eckstrand (1979) concluded that due to restricted systems of mating observed most commonly among wolves, genetic fixation for the average pack would occur within 20 years. Migration and emigration among packs of the same subspecies would establish still larger genomes that would be characteristically different than other similarly maintained subspecies. Polymorphism in wolves appears to be both genetically inherent and environmentally influenced.

Differences in morphology suggest the likelihood of polyethism in wolves (Sullivan, 1978 and 1979). Ginsburg (1967) notes that biological variability increases with the degree of social complexity found in a species. He states that with social species there exist behavioral nonequivalents, each biologically suited for a specific behavioral niche. He believes this diversity in behavior and temperament to be, in part, genetically determined. Several studies support the theory that individual wolves vary behaviorally, although no conclusive information is available to confirm whether these differences are genetic or environmental. Distinct individual differences in hunting behavior (Sullivan, 1978 and 1979), care giving (Paquet, in press; Fentress, in press) and temperament (Rutter and Pimlott, 1968; Mech, 1970; Fox, 1971; Mech and Van Ballenberghe, 1974) have been observed in studies of 
captive wolves. Broad variation in the behavioral attributes of wolves is also recognized by the Nunamiut Eskimos of Alaska (Stephanson and Ahgook, 1975). How much variation in social organization occurs in wolf populations under different environmental conditions is unknown (Scott, 1967; Fentress, in press). Differences in group dynamics and structure are readily apparent when contrasting various studies of social behavior. Although certain commonalities exist among findings, differences abound. Much of this may be attributed to imprecise terminology and differing methodology, making interpretation and replication difficult (Lockwood, 1976). It may also result from the many largely anecdotal and quantitatively unsubstantiated claims regarding wolf behavior. However, many of these apparent discrepancies have probably resulted from accurate descriptions of behavior observed in a highly variable and behaviorally plastic animal. If, as we believe, packs are social combinations of individually variable members with each member's behavior subject to genetic and/or environmental influences, then differences in pack social structure should be expected.

The remainder of this discussion concentrates on aspects of social behavior observed during my study which were unique or differed significantly from previous reports. It should be assumed that results not discussed were comparable to observations already in the literature.

\section{Social Behavior And Dominance Relationships}

Al though Landau's Index of Linearity reflected a single unisexual social order, all other evidence strongly suggested the presence of two sexually distinct hierarchies. It is probable that separate sexual orders were contained within a single unisexual framework (Zimen, 1975, 
1976), providing what appeared to be contradictory data. The interaction of the two sexual hierarchies appears to have provided the pack general structure, as rank position within the general structure did not appear to be determined by agonistic interaction, but rather as a consequence of social position within each sexual rank order. A wolf which was dominant in one sexual order seemed to automatically dominate all non-alpha wolves of the opposite sex. It was unclear as to how the pack alpha, whether male or female, was determined. With the exception of food competition intersexual aggression between the dominant male and female was never observed. In wild packs the alpha wolf often initiates pack activities and is first to challenge tresspassers (Mech, 1970), but I am unaware of any descriptions relating to the process by which a pack leader is decided. If initiation of pack activities and confrontation of intruders are valid criteria for designating the pack alpha, then Zane and later Sitka qualified. Both were the first to challenge outsiders and the last to retreat. Although Pulliainen (1965) claimed that pack leaders are unsually females, others maintain that an alpha male is only subordinate to a female when she is caring for young. Sitka was caring for young for only one of the twenty four months during which she was the alpha female but she initiated more activities than did Mowgli and was always the first to challenge outsiders. Conversely, Mowgli dominated Sitka in most social encounters, a relationship reflected by Landau's Index. My subjective impression was that Sitka was more assertive than Mowgli and easier to arouse. Mowgli, however, was more assertive when the situation was critical. For example, when animal keepers attempted to corral the wolves, Mowgli would confront 
them and not Sitka. During less threatening situations, such as when the enclosure was being hosed down, Sitka would initiate the challenge. Pack leadership at the Washington Park Zoo appeared to be contextual, rather than a universally constant role.

Alterartions in the frequency and intensity of social behavior correlated with seasons of the year and ontogenetic changes. These observations agree with previous reports (Schenkel, 1947; Zimen, 1975, 1976; Rabb et al., 1967), differing only in minor details. One notable exception was the total absence of severe aggressive encounters during the months of June thru October. Other researchers have recorded intense agonistic behavior during these months (Rabb et al., 1967; Zimen, 1975, 1976) which, at times, has resulted in deaths (Bayer, pers comm). The lack of summer aggression may have been due, in part, to the relatively few number of adult wolves maintained during any single summer period. Because of a combination of deaths and a policy of surplussing wolves, only in the summer of 1977 did the pack contain more than a single adult of either sex. Both the dominant male and the dominant female were newly established in the winter preceding that particular summer and challenges from subordinates could have come only from the two wolves recently displaced. Therefore, I do not believe social conditions during summer months were conducive to rank conflicts. Dominance relationships corresponded closely with descriptions from other packs (Schenke1, 1947, 1967; Rabb et al., 1967; Zimen 1975, 1976; Schotte and Ginsburg, 1978; Fentress and Ryon, in press) However, two year old animals played a more important social role than typical for their age group. Three of four females were alpha wolves by 
21 months of age. Both males also achieved alpha status in their second year. It is difficult to say why the older dominant wolves were unable to retain their social position when challanged by younger subordinates, but the pattern of rank conflict and social reversal suggest that interactions may have been influenced by genetic relatedness and/or by the manner in which the pack structure evolved. Briefly, the pack was formed with the acquisition of an unrelated male, Zane, and female, Taquish. Attempts to socialize these wolves with two unrelated female pups, Juneau and Laska, the following year proved to be difficult due to aggressive threats by Taquish. It is conceivable that Taquish viewed the pups as non-pack members and therefore intruders. She may also have recognized that both pups were females and that they could eventually constitute a threat. The unfriendly behavior of Taquish's pups toward Juneau and Laska suggests that the pups were in some manner influenced by their mother. It is noteworthy, that as a young pup of eight months Sitka seldom interacted with either of the unrelated females, and in her mother's presence, was able to dominate Laska. Rabb et al. (1967) collected data suggesting that when female pups mature they may mimic their mother by assuming a dominant attitude toward other females. Juneau was recipient of the majority of Taquish's aggression and she later displaced her as dominant female. When Taquish relinquished her position, she was faced with an alliance of Juneau and Laska, and appeard to be overwhelmed by the pair. Utimately, Juneau was replaced by Taquish's daughter, Sitka. In general, the tendency was for unrelated wolves of the same sex to be in conflict with one another, Juneau and Laska were an exception but they had been together since they 
were two weeks of age. Whether this tendency for genetic affiliations was fostered by predisposed behavior or environmental conditioning is uncertain. Certainly the close allegiance of Juneau and Laska suggests that recognition of "related animals" may have been environmentally conditioned.

Influence of Biosocial and Environmental Factors

It is apparent that a number of biosocial and environmental factors influence dominance relationships and pack structure. Most evident from this and other studies are the following.

Pack Composition. The sex ratio of reproductively capable animals, age of individual pack members, and the total number of wolves comprising a pack determine the composition. Wolves behave differently depending upon the arrangement of these components. For example, an adult male who is a member of a pack composed only of a breeding pair and young of the year is de-facto the dominant male and will behave accordingly. Similarly, a male who is one of several adult males will have several roles which might be assumed.

Seasonality. As previously noted the behavior of wolves varies seasonally. Wolves are more aggressive just prior to and during the breeding season. At such times wolves test one another by aggressive displays and occasionally by fighting. Shifts in rank order occur most often at this time. Conflict tapers off after breeding, reaching a low point with the onset of spring.

Time And Energy. Time and energy budgets are of great behavioral and ecological significance among animals in nature. Captive animals, however, tend to have adequate energy provided by their diets and have 
time available for whatever activities are possible. It is probable that much of this energy is expended in agonistic behavior and could contribute strongly to the breakdown of social order, especially under crowded conditions.

Health of Individual Pack Members. Social animals with a rank order tend to test one another from time to time (Schenkel, 1947). Sickness may be detected by a wolf's conspecifics and could stimulate a subordinate to try and improve its positon in the rank order. Currently, no information is available concerning the affects of health in determing the rank order of wolves. Sullivan and Paquet (1977) discussed what appeared to be a change in social rank as a consequence of a wolf's poor physical condition.

Genetic Relatedness. Sociobiology has become a focal point of modern biology (Wilson, 1975). Central to the sociobiological argument is the theme that the evolutionary appearance of societies of animals provides conditions under which individual fitness or "selfishness" is no longer adequate to invoke the concept of inclusive fitness. Phenomena such as altruism (one organism acting to benefit a second at cost to the first) cannot be explained by Darwinian or individual selection. Studies, based to a great extent on the social insects, show that the number of genes held in common tends to determine the proportion of altruism expressed (Wilson, 1975). The perfect society would consist of genetically identical individuals (such as certain colonial invertebrates). Conflict enters into social relationships in proportion to genetic diffences between individuals. If the wolf pack consist of an expanded family, we would expect to find increased 
cooperative behavior and reduced conflict within the pack as compared with a group of wolves which share fewer genes in common. Further, if groups of wolves differ in the degree of genetic relatedness, a direct correlation between degree of relatedness and conflict could be expected. Thus far the effects of genetic relatedness are unclear and may prove to be unimportant.

Size of The Enclosure. Crowding is correlated with the number of wolves in the enclosure and the total space available. The effects of crowding on social behavior of vertebrate animals are well known. The "General Adaptation Syndrome" or "Stress Syndrome" (Selye, 1976) leads to a breakdown in social systems. It has been hypothesized that crowding of captive wolves strongly contributes to the instability of social order (Sullivan and Paquet, 1977).

Environmental Conditions. The quality of the environment is of major import for captive (Hediger, 1950) and wild animals (Mech, 1970). In captivity an impoverished environment may contribute to abnormally high levels of aggression (Hediger, 1950). In the wild, the social structure and composition of wolf packs may be determined by the availability of resources, especially food (Packard and Mech, 1980).

Manipulation of Animals. Removal of wolves from the pack does not appear to consistently disrupt pack dynamics. Rather, it is a function of several interacting and related factors, the formemost being time of year and the social rank of the animal removed. Rabb et al (1967) recount a breakdown in social structure following the death of an alpha female and the shift in the male hierarchy following removal of an alpha male. Zimen (1975) noted an incrased frequency and intensity of 
aggressive interactions among subordinate males immediately succeeding removal of an alpha male. This study documented a decrease of aggression upon removal of dominant females during breeding season with a subsequent increase when they were reintroduced.

Mating Relationships

For complete discussion, see Appendix.

Multiple Litters

Multiple litters are believed to occur infrequently. They are thought to be limited, in part, by suppression of mating activity in low status wolves (Schenkel, 1947; Rabb et al., 1967; Mech, 1970; Fox, 1971; Zimen, 1975, 1976; Haber, 1977; Sullivan, 1978, 1979; Packard and Mech, 1980), strong mate preferences and delayed sexual maturity. (Rabb et al., 1967; Mech, 1970; Fox, 1971; Packard and Mech, 1980). As a consequence, it is held that a single litter is usually born to a pack each year, most often the result of a mating between dominant wolves.

However, evidence concerning the frequency of multiple litters suggests they are relatively common. Surveys of captive packs containing two or more adult females indicate a multiple litter rate of 28 to 39 percent (Harrington et al., in press; Packard, 1980). Several captive packs have produced only single litters, whereas others have consistently displayed a high rate of multiple litters. For example, Altmann (1974) reported multiple litters in four of five breeding seasons, and Fentress and Ryon (in press) in each of five years. In contrast, Zimen (1976) and Schotte and Ginsburg (1978) reported only single litters in each of four mating seasons. 
Multiple litters also occur in the wild. Sixteen percent of all Alaskan packs studied ( $n=62$ ) have had more than one litter (Packard, 1980). When only packs known to have at least two adult females were considered, the rate of multiple litters was between 22 and 41 percent (Harrington, et al., in press). Other observations of courtship behavior, estral bleeding and copulation by more than one female per pack (Peterson, 1977, 1979; Haber, 1977; Jordan in Packard, 1980) suggest that multiple litters may be relatively common in the wild.

Communal denning has rarely been reported in wolves and there are no published records of communal nursing. Most field records of communal denning originate in Alaska. Several reports are the result of direct observation, whereas others are somewhat speculative, based primarily upon observations of abnormally large litters presumed to be the progeny of more than one female. Stephenson (pers. comm.) discovered a den in Alaska with a minimum of 11 pups attended by at least three adults. Another den containing 14 pups was found by Eskimo hunters in Alaska (Stephenson, pers. comm.). Although conclusive observations were lacking in both cases, it appeared that the pups were being cared for communally. In Mt. Mckinley National Park, Alaska, Murie (1944) observed two litters totalling 10 pups being brought together by their mothers. The pups were subsequently cared for by both females in a communal den. In the same area, Haber (1977) observed communal denning in one pack on three separate occasions. In addition, he recorded communal denning in other packs within the same general vicinity. 
Communal denning has also been observed in captivity (Rabb et al., 1967, pers. comm.; Fentress and Ryon, in press; Klinghammer, pers. Comm.; Packard, 1980; Traverso, unpub.). Commonly, however, the pups have not all survived, in some cases being killed by one of the mothers (Fentress and Ryon, pers. comm.; Klinghammer, pers. comm.; Rabb et al., 1967; Packard, 1980). Pups were killed in 54 percent of the multiple litters $(n=13)$ reviewed by Packard (1980). However, not all of these pups were being cared for in a communal den.

There are no records of wolf pups being voluntarily nursed by mothers other than their own. This is possibly due to a lack of den viewing opportunities rather than the uniqueness of the phenomenon. In one case, three litters and their mothers were placed together and a one-week-old pup was observed attempting to nurse from another litter's mother (Fox, 1971). In another captive pack, both the beta and gamma females nursed the alpha female's pups whenever she was absent from the den al though they had no pups of their own ( $K l$ inghammer, pers. comm.).

It is conceivable that a breakdown in social structure could disrupt restrictive mechanisms which limit breeding, thus resulting in an increased litter rate.

One common factor prior to the births of 21 captive-born multiple litters I reviewed was an inability on the part of established breeding females to effectively restrict the mating activity of subordinates.* This appeared to be associated with one or both of the following

*This information is based upon my interpretation of data collected from personal communication with researchers and a review of pertinent pupblished reports (Rabb et al., 1967, pers. comm.; Lentfer and Sanders, 1973; Packard, 1980; Fentress and Ryon, pers. comm.; Al tmann, 1975). 
conditions: 1) social changes resulting from loss of status, death or removal of the dominant female, either prior to or immediately following estrus, and 2) large packs containing several sexually mature females. In several instances, the removal or displacement of a key pack member appeared to have contributed to an increase in pregnancies (Rabb et al., 1967; Traverso, pers. comm.). For example, Rabb et al. (1967) noted that removal of an alpha male and the death of an alpha female promoted changes in pack social order, which they believe resulted in multiple matings and, ultimately, several pregnancies. Similar social changes preceded the double litters at the Washington Park Zoo, Portland, Oregon. Dominance shifts occurred among the females in the three consecutive years preceding the births, and the male hierarchy changed immediately following estrus the year the litters were born. In contrast to previous years, social inhibition of mating was absent throughout the breeding period. The new alpha female made no apparent attempt to prevent subordinate females from breeding. Similarly, there was no attempt by the dominant male to prevent the subordinate male from mating. The only social restrictions to mating were imposed by the alpha male, who aggressively rebuffed sexual solicitations by the new alpha female. Although changes in the rank order occurred in each of the study years, the shifts in 1975 and 1976 preceded the breeding season by several months. Possibly this permitted the dominant female to become firmly established, allowing the pack to stabilize prior to mating. Woolpy (1968) has suggested that similar social changes could be produced by human exploitation of wolves (i.e. removal by hunting, trapping, poisoning), an idea which has been reiterated by Haber (1977). 
In large packs with several sexually capable females, it may simply be beyond the capacity of one female to effectively restrict all breeding. Fentress and Ryon (pers. comm.) have observed that low ranking females will atttempt to mate whenever out of contact with the dominant female. With several sexually mature females and topography allowing for easy concealment, a single female would find it difficult to suppress all mating activity. In wild packs, which may temporarily separate into subunits during the fall and winter (Wolfe and Allen, 1973; Peterson, 1977; Harrington and Mech, 1979), females may breed prior to later regrouping. When reunited, the pack might contain several pregnant females, each from a different subgroup.

\section{Evolutionary Aspects of Multiple Litters}

offspring are an evolutionarily important resource. Their survival increases the probability of future genetic representation for all related individuals. If wolf packs are "expanded family units" (Mech, 1970), cooperative rearing of the young would be expected, as members share a portion of the same genetic complement (Hamilton, 1963). Offspring require a costly investment which individuals must balance with the potential benefits to be derived from the offsprings survival (Alexander, 1974). Consequently, individuals should behave toward pups in a manner which maximizes their own inclusive fitness, even if it results in lowered survival of the young (Bertram, 1976). Individuals cooperating in pup care would most likely be closely related (Bertram, 1976; Hamilton, 1963, 1971). However, the degree of cooperative behavior which they exhibit might vary with changing environmental constraints, social conditions, and pack size (Packard and Mech, 1980). 
The probability of more than one litter surviving in a pack would likely depend upon acceptance by the dominant breeding female of the "extra pups." Survival would be enhanced if all the offspring were closely related and were not competing for limited resources. Based on relatedness, curent resource availability, and social climate, the dominant female could "determine" whether to permit extra pups to survive and whether she should directly contribute to their care. Field evidence of mothers sharing the same den prior to parturition is not available. However, in two cases (Murie, 1944; Clark, 1971) where pups were born at seperate den sites, and subsequently integrated, the mothers shared the den of the dominant female. In one case (Clark, 1971) interactions of the subordinate female with the pups declined following repeated threats by the dominant mother.

When circumstances are favorable, the dominant female might permit subordinate females to raise their litters cooperatively with her own. A cooperative arrangement potentially offers benefits for both mothers. Obviously, it would be advantageous for a subordinate to participate in the care of another litter, as long as it would guarantee her own pups survival. Energetically, the mothers would probably expend no more energy caring for two litters cooperatively, than caring for one alone, yet the litters would profit from the increased atttention of two mothers. If one mother stopped lactating or died, the pups would still be able to obtain milk, although younger pups would be at a competitive disadvantage if there was a shortage of milk. Overall, both mothers could help insure the survival of their own offspring while gaining the added advantage of increased genetic representation via related young. 
In Utero Mortality

Al though direct evidence of in-utero mortality has not been previously reported its likelihood has been suggested (Mech, 1970, pers. comm.; Rausch, 1967). I cannot, at this time, identify the mechanisms responsible for the apparent in utero loss of pups. I can, however, provide an interpretation based upon the available evidence.

Prior to the 1977 breeding season, Juneau was the dominant of three females residing at the Washington Park Zoo. She attained alpha status spring 1977 after a rank fight in which the previous alpha female, Taquish, was killed (Sullivan and Paquet, 1977). She relinquished this position January 1977 to Taquish's two-year-old daughter, Sitka (Sullivan and Paquet, 1977). Despite loss of status, Juneau mated and conceived in mid-February. Throughout the term of her pregnancy, she was restricted in social activity and physically harassed by Sitka. In utero loss of pups may have resulted from the effects of intense social suppression.

Several studies have suggested that reproductive performance may be suppressed due to social and nutritional stress (Rausch, 1967; Pimlott et al., 1969; Packard and Mech, 1978, 1980). Similarly, intensification of agonistic interations associated with pregnancy may constitute a stressful situation resulting in embryonic resorption or abortion of fetuses. Reports of reduced litter sizes in environmentally stressed populations could be attributed to density-dependent sociobehavioral factors which reduce ovulation, affect implantation and promote in utero mortality. 


\section{Pup Preferences}

Although wolf pups are thought to be blind, deaf and have little, if any sense of smell during the neonatal period (Scott and Fuller, in Mech, 1970) the pups observed at the Washington Park Zoo displayed a remarkable ability to discriminate between females at distances of up to two meters. It seems unlikely that this could have been accomplished exclusively with taste and tacticle senses. Klinghammer (pers. comm.) has tentatively noted that neonatal wolf pups respond positively to auditory stimulus, and I believe the pups may have been reacting to auditory cues.

The onset of auditory function in domestic dogs (C. familiaris) begins four to five days after birth, but is only measurable with intense stimulation. At seven to eight days, action potentials are recognizable at the round window and the entire auditory system responds to normal acoustic stimuli (Pujol and Hilding, 1973). If I presume similar physiological development in wolves, a plausible explanation for the pups' discriminatory behavior is that the older litter responded to auditory signals from Sitka, and the younger pups simply followed their movement. The quality and quantity of Sitka's milk, as a result of an earlier littering time, may have been superior to Juneau's. Thus, the pups would have been positively rewarded by selecting sitka.

Implications of Multiple Litters For Wild Populations

The social behavior of wild wolves is determined, in part, by additional constraints not associated with life in captivity (Kleiman, 1977). It is believed that wolf density and resource availability influence territory size, and that territoriality limits the number of 
packs per unit area (Packard and Mech, 1980). Pack size is thought to vary with population density, prey biomass, size of prey, and the capacity for social attachment by individual pack members (Mech, 1970; Rausch, 1967; Zimen, 1976).

Where wolf numbers have been seriously reduced for reasons other than resource limitation (e.g. catastrophic disease, excessive human exploitation), wolves could accelerate reproduction by breeding at younger ages (Medjo and Mech, 1976), increasing litter sizes, increasing the number of females per litter (Mech, 1970; Zimen, 1976), and increasing the number of litters per pack. All of these changes are probably influenced by an interaction of social and ecological factors (Packard and Mech, 1980). The proximate regulating factor is most likely nutrition, which subsequently affects pack size and possibly social structure. Normally, packs which are not nutritionally stressed would exhibit little intrapack strife (Zimen, 1976; Packard and Mech, 1980), resulting in lower mortality among dominant females, less chance for social disruption and therefore low frequency of multiple litters. Packs which are nutritionally stressed but nevertheless retain a stable dominance hierarchy should likewise produce multiple litters at a low frequency. However, packs which have been randomly reduced may not retain an intact social structure, thus creating favorable conditions for multiple matings. Therefore, we would expect multiple litters to occur more frequently in populations which are not resource limited but have been reduced because of a catastrophic event, such as disease or excessive human hunting. 


\section{BIBLIOGRAPHY}

Al exander, R.D. 1974. The evolution of social behavior. Annual Review of Ecological Systems 5:325-383.

Al len, D.L. 1979. The Wolves of Minong: Their Vital Role in a Wild Community. Houghton Mifflin Co., Boston.

Altmann, D. 1974. Beziehungen zwischen sozialer Rangordnung und Jungen autzucht bei (Canis lupus L) Zoologisher Garten N.F. Jena 44:235236 .

Atkins, D.L. and Dillon, L.S. 1971. Evolution of the cerebellum in the genus Canis. J Mammal 52:96-107.

Bekoff, M. 1975. Social behavior and ecology of African canidae: a review. In M.W. Fox (ed.), The Wild Canids, Van Nostrand Reinhold Co., New York, Cincinnati, Toronto, London, Melbourne, p.120-142.

Bekoff, M. 1977. Quantitative studies of three areas of classical ethology: social dominance, behavioral taxonomy, and behavioral vaiability. In B. Hazlett (ed.), Quantitative Methods in the Study of Animal Behavior. Academic Press, New York, p.1-46. Bertram, B.C.R. 1976. Kin selection in lions and in evolution. In P.P.G. Bateson and R.A. Hinde (eds.), Growing Points in Ethology. Cambridge University Press, London. Brown, J.L. 1975. The Evolution of Behavior. W.W. Norton, New York, $761 \mathrm{pp}$. 
Burkholder, B.L. 1959. Movements and behavior of a wolf pack in Alaska. Journal of Wildlife Management 23:1-11. Carbyn, L.N. 1974. Wolf predation and behavioural interactions with elk and other ungulates in an area of high prey diversity. Ph.D. Thesis, University of Toronto. Canadian Wildlife Service Report, Edmonton.

Chance, M.R.A. 1962. Social behaviour and primate evolution. In M.F. Ashley Montagu (ed.), Culture and the Evolution of Man, Oxford, New York.

Chase, I.D. 1974. Models of hierarchy formation in animal societies. Behav Sci $19: 374-382$.

Clark, K.R.F. 1971. Food habits and behavior of the tundra wolf on central Baffin Island. Ph.D. Thesis, University of Toronto. Fentress, J. and Ryon, J. In press. A long-term study of distributed pup feeding in captive wolves. In F.H. Harrington and P.C. Paquet (eds.), A Worldwide Perspective of the Ecology, Behavior and Conservation of Wolves, Noyes, New Jersey.

Fox, M.W. 1971. The Behavior of Wolves, Dogs and Related Canids. Harper and Row, New York.

Fox, M.W. (ed.). 1975. The Wild Canids: Their Systematics, Behavioral Ecology and Evolution. Van Nostrand Reinhold Company, New York.

Gier, H.T. 1968. Coyotes in Kansas. Agricultural Experiment Station, Kansas State College of Agriculture \& Applied Science (Bulletin 393). 
Haber, G.C. 1973. Eight years of wolf research at McKinley Park.

Al aska Mag, April-May.

Haber, G.C. 1974. Wolves and the Endangered Species Concept. Proc.

Symp. Endang. \& Threat. Spec. N. Am., Washington D.C., pp.110-119. Haber, G.C. 1977. Socio-ecological dynamics of wolves and prey in a subarctic ecosystem. Ph.D. Thesis, University of British

Columbia, Vancouver. Published by the Joint Federal-State Land Use Planning Commission for Alaska, Anchorage.

Haber, G.C. 1978. Dynamics of the Alaska-Yukon caribou herds

(summary). In D.R. Klein and R.G. White (eds.), Parameters of Caribou Population Ecology in Alaska, 27-29, Biological papers, University of Alaska, Special Report No. 3.

Hall, E.R. and Kelson, K.R. 1959. The Mammals of North America, Vol. II, The Ronald Press, New York, p.547-1083. Hamilton, W.D. 1963. The evolution of altruistic behavior. American Naturalist $97: 354-356$.

Hamilton, W.D. 1964. The genetical evolution of social behaviour: I and II. Journal of Theoretical Biology 7:1-52. Hamilton, W.D. 1971. Selection of selfish and altruistic behavior in some extreme models. In J.F. Eisenberg and W.S. Dillion (ed.), Man and Beast: Comparative Social Behavior. Smithsonian Institution Press, Washington, D.C., p.57-91. Harrington, F.H. 1975. Response parameters of elicited wolf howling. Ph.D. Thesis, State University of New York, Stony Brook. Harrington, F.H. and Mech, L.D. 1978. Howling at two Minnesota wolf pack summer homesites. Canadian Journal of Zoology 56:2024-2028. 
Harrington, F.H. and Mech, L.D. 1979. Wolf howling and its role in territory maintenance. Behaviour 68:207-249. Harrington, F.H. and Mech, L.D. In press. Patterns of homesite attendance in two Minnesota wolf packs. In F.H. Harrington and P.C. Paquet (eds.), A Worldwide Perspect ive of the Ecology, Behavior and Conservation of Wolves, Noyes, New Jersey. Harrington, F.H., Paquet, P.C., Ryon, J. and Fentress, J. In press. Monogamy in wolves. In F.H. Harrington and P.C. Paquet (eds.), $\underline{A}$ Worldwide Perspective of the Ecology, Behavior and Conservation of Wolves, Noyes, New Jersey.

Hediger, H. 1950. Wild Animals in Captivity, Butterworths, London, Dover, New York, 1964. Huber. 1802. Jolicoeur, P. 1959. Multivariate geographical variation in the wolf Canis lupus L. Evolution 13:283-299. Jolicoeur, P. 1975. Sexual dimorphism and geographical distance as factors of skull variation in the wolf Canis lupus L. In M.W. Fox (ed.), The Wild Canids, Van Nostrand Reinhold, New York, 54-61. Joslin, P.W.B. 1966. Summer activities of two timber wolf (Canis lupus) packs in Algonquin Park. M.S. Thesis, University of Toronto.

Joslin, P.W.B. 1967. Movements and homesites of timber wolves in Algonquin Park. American Zoologist 7:279-288. Keith, L.B. 1978. Population ecology of game species. Kelsall, J.P. 1968. The migratory barren-ground caribou of Canada. Canadian Wildlife Service Monograph No. 3, Ottawa. 
Kleiman, D.G. 1967. Some aspects of social behavior in the Canidae. Aner Zool 7:365-372.

Kleiman, D.G. 1977. Monogamy in mammals. Quarterly Review of Biology $52: 39-69$.

Kl inghammer, E. and Laidlaw L. 1979. Analysis of 23 months of daily howl records in a captive grey wolf pack (Canis lupus): In Kl inghammer E. (ed.), The Behavior and Ecology of Wolves. Garland Publishing Inc., New York, p153-182.

Kolenosky, G.B. and Stanfield, R.0. 1975. Morphological and ecological variation among gray wolves (Canis lupus) of Ontario, Canada. In M.W. Fox (ed.), The Wild Canids, Van Nostrand Reinhold, New York, $62-72$.

Kuyt, E. 1962. Movements of young wolves in the Northwest Territories of Canada. Journal of Mammalogy $43: 270-271$.

Kuyt, E. 1972. Food habits of wolves on barren-ground caribou range. Can Wildl. Serv. Rpt., Ser. No. 21, 36p.

Lehner, P.N. 1979. Handbook of Ethological Methods. Garland STPM Press, New York.

Lockwood, R. 1976. An ethnological analysis of social structure and affiliation in captive wolves (Canis lupus). Ph.D. Thesis, Washington University, St. Louis.

Mech, L.D. 1966. The Wolves of Isle Royale. U.S. National Park Service, Fauna Series 7, Washington D.C. Mech, L.D. 1970. The Wolf: The Ecology and Behavior of an Endangered Species. Natural History Press, Garden City, New York. 
Mech, L.D. 1975. Disproportionate sex ratios of wolf pups. Journal of Wildl ife Management 39:737-740.

Mech, L.D. 1977. Productivity, mortality and population trends of wolves in northeastern Minnesota. Journal of Mammalogy 58:559574.

Medjo, D.C. and Mech, L.D. 1976. Reproductive activity in nine- and ten-month old wolves. Journal of Mammalogy $57: 406-408$.

Moran, G. and Fentress, J.C. A search for order in wolf social

behavior. In E. Klinghammer (ed.), The Behavior and Ecology of Wolves. Garland Publish Inc., New York.

Murie, A. 1944. The Wolves of Mt. McKinley. U.S. National Park

Service, Fauna Series 5, Washington D.C.

Ognev, S.I. 1962. Mammals of Eastern Europe and Northern Asia, Vol.

II, Carnivora (Fissipedia), pp.141-266 (Israel Program for

Scientific Translations, Jerusalem).

01 son, S.F. 1938. Organization and range of the pack. Ecology 19:168170.

Packard, J., L.D. Mech. 1978. Northwest Wildlife Society meetings, Natural Regulation of Populations Sessions, Vancouver, B.C., Canada.

Packard, J.M. 1980. Deferred reproduction in wolves (Canis lupus). Ph.D. Thesis. University of Minnesota, Minneapolis, Minnesota. Packard, J.M. and Mech, D.M. 1980. Population regulation in wolves. In M.N. Cohen, R.S. Malpasse and H.G. Klein (eds.), Biosocial Mechanisms of Population Regulation. Yale University Press, New Haven, Connecticut. 
Peters, R.P. and Mech, L.D. 1975. Scent-marking in wolves. American Scientist $63: 628-637$.

Peterson, R.0. 1974. Wolf Ecology and Prey Relationships on Isle Royale. Ph.D. Thesis, Purdue University, Lafayette, Indiana. Peterson, R.0. 1977. Wolf ecology and prey relationships on Isle Royale. U.S. National Park Service, Fauna Series 11, Washington, D.C.

Peterson, R.0. and Scheidler, J.M. 1978. Ecological studies of wolves on Isle Royale: Annual Report covering 20th year of the Isle Royale studies, $14 p p$.

Pimlott, D.H., J.A. Shannon and G.B. Kolenovsky. 1969. The ecology of the timber wolf in Algonguin Provincial Park. Ont. Dept. Lands \& Forests Res. Rep. (Wildl.), No. 87, 92p.

Pocock, R.I. 1935. The races of Canis lupus. Proc Zool Soc London, Part 3, Sept. :647-686.

Pujol, R. and Hilding, D. 1973. Anatomy and physiology of the onset of auditory function. Acta Otolaryng 76:1-10.

Rabb, G.B., Woolpy, J.H. and Ginsburg, B.E. 1967. Social relationships in a group of captive wolves. American Zoologist 7:305-311. Rausch, R.A. 1967. Some aspects of the population ecology of wolves in Alaska. American Zoologist $7: 253-265$.

Rothman, R. and Mech, L. 1979. Scent-marking in lone wolves and newly formed pairs. Animal Behavior 27:750-760. Rutter, R.J. and Pimlott, D.H. 1968. The World of the Wolf. J.B. Lippincott Company, Philadelphia. 
Schenkel, R. 1947. Expression studies of wolves. Behaviour 1:81-129 (translation).

Schenkel, R. 1967. Submission: Its feature and functions in the wolf and dog. American Zoologist $7: 319-329$.

Schjelderup-Ebbe, T. 1922. Beitrage zur sozialpsychologie des haushuns. Zeit. f. Psych. $88: 225-252$.

Schjelderup-Ebbe, T. 1935. Social behavior in birds. In C. Murchison (ed.), A Handbook of Social Psychology. Worcester, Mass. Clark U Press.

Schotté, C.S. and Ginsburg, B.E. 1978. Continuing development of social organization and mating in a captive wolf pack. Presented at annual meeting, Animal Behavior Society, Seattle, Washington. Scott, J.P. 1967. The evolution of social behavior in dogs and wolves. Amer Zool 7:373-381.

Selye, H. 1976. Forty years of stress-related research: Principal remaining problems and misconceptions. Can Med Assoc J 115.

Sharp, H.S. Some problems in wolf sociology. In press. In F.H. Harrington and P.C. Paquet (eds.), A Worldwide Perspective of the Ecology, Behavior and Conservation of Wolves, Noyes, New Jersey. Stains, H.J. 1975. Distribution and taxonomy of the canidae. In M.W. Fox (ed.), The Wild Canids, Van Nostrand Reinhold Co., New York, Cincinnati, Toronto, London, Melbourne, p.3-26.

Stenlund, M.H. 1955. A field study of the timber wolf (Canis lupus) on the Superior National Forest, Minnesota. Minnesota Department of Conservation, Technical Bulletin No. 4, 55pp. 
Stephanson, R. and Ahgook, B. 1975. The Eskimo hunter's view of wolf ecology and behavior. In M.W. Fox (ed.), The Wild Canids, Van Nostrand Reinhold Co., New York, Cincinnati, Toronto, London, Melbourne, p.286-291.

Sullivan, J.0. 1978. Variability in the wolf, a group hunter. In R.L. Hall and H.S. Sharp (eds.), Wolf and Man: Evolution in Parallel. Academic Press, New York, 31-40.

Sullivan, J.0. 1979. Individual variability in hunting behavior of wolves. In E. Klinghammer (ed.), The Behavior and Ecology of Wolves, Garland Press, New York.

Sullivan, J.0. and Paquet, P.C. 1977. Behavior of wild canids. Proceedings of the American Association of Zoological Parks and Aquariums. Hill's, Topeka, Kansas.

Theberge, J.B. and Falls, J.B. 1967. Howling as a means of communication in timber wolves. Amer Zool 7:331-338. Van Ballenberghe, V. and Mech, L.D. 1975. Weights, growth and survival of timber wolf pups in Minnesota. Journal of Mammalogy $56: 44-63$. Voigt, D.R. 1973. Summer food habits and movements of wolves (Canis lupus 1.) in Central Ontario. M.S. Thesis, University of Guelph, $76 p$.

Wilson, E.0. 1975. Sociobiology: The New Synthesis. Belknap Press of Harvard University Press, Cambridge. Wolfe, M.L. and Allen, D.L. 1973. Continued studies of the status, socialization and relationships of Isle Royale wolves, 1969-70. Journal of Mammalogy $54: 611-635$. 
Woolpy, J.H. 1968. The social organization of wolves. Natural History $77: 46-55$.

Woolpy, J.H. and Eckstrand, I. 1979. Wolf pack genetics, a computer simulation with theory. In E. Klinghammer (ed.), The Behavior and Ecology of Wolves. Garland Publishing, Inc., New York. p.206225.

Young, S.P. and Goldman, E.A. (eds.). 1944. The Wolves of North America: Part 1. American Wildlife Institute, Washington D.C., Dover Publishers, New York.

Zimen, E. 1972. Wolfe and Konigspudel. Piper, Munich. Zimen, E. 1975. Social dynamics of the wolf pack. In M.W. Fox (ed.), The Wild Canids: Their Systematics, Behavioral Ecology and Evolution. Van Nostrand Reinhold Company, New York, 336-362. Zimen, E. 1976. On the regulation of pack size in wolves. Zeitschrift fur Tierpsychologie 40:300-341. 


\title{
APPENDIX A \\ Monogamy in Wolves: \\ A Review of the Evidence
}

\author{
Fred H. Harrington, Paul C. Paquet, Jenny Ryon \\ and John C. Fentress
}

\section{INTRODUCTION}

A species' mating system 'refers to the general behavioral strategy employed in obtaining mates. It encompasses such features as: (i) the number of mates acquired, (ii) the manner of mate acquisition, (iii) the presence and characteristics of any pair bonds, and (iv) the patterns of parental care provided by each sex" (Emlen and Oring, 1977:222). Attempts to classify mating systems are difficult due to lack of precise terminology (Fmlen and Oring, 1977), unequivocal evidence of mating patterns (Kleiman, 1977), or both. Monogamous mating systems have been characterized by the presence of exclusive sexual bonds between two individuals resulting in mating exclusivity (Kleiman, 1977). However, proof of mating exclusivity is difficult to obtain without exhaustive behavioral observations or genetic comparisons between adults and young. Thus, less rigorous evidence typically has been employed: (1) close association of a pair not limited solely to breeding periods, (2) mating preferences, (3) absence of other adults in the pair's home range, and (4) breeding by only one pair in a family group (Kleiman, 1977). None of the above is definitive proof of monogamy, although the first two criteria provide stronger circumstantial evidence than the others, especially the last.

Classification of the wolf's (Canis lupus) mating system has been hampered by the animal's elusiveness, wide-ranging movements, and tendency to live in relatively large social groups, and the frequent use of imprecise behavioral terminology by researchers. Most field studies, of necessity, have relied upon aerial observation conducted during the winter breeding season (Mech, 1966; Jordan et al., 1967; Pimlott et al., 1969; Mech and Frenzel, 1971; Wolfe and Allen, 1973; Haber, 1977; Peterson, 1977). However, under these condi- 
tions, (1) wolves are difficult to sex, age or individually identify, (2) packs are difficult to follow for extended periods on a daily basis, (3) even if daily contact is possible, the portion of the pack's daily activity cycle potentially observable is limited by short mid-winter days and (4) close observation of the details of behavior is normally precluded even during available observation periods. Thus, observations of mating activity are infrequent, and observations of actual copulations are fortuitous. Determining the number of females which have littered is also difficult due to lack of snow for tracking by early spring, and the seasonal increase in vegetative cover. Furthermore, when telemetry is used, lack of radio-collars on all pack members reduces the chance of locating dens. The frequent combining of litters by mothers soon after parturition (Murie, 1944; Clark, 1977) compounds these difficulties. Nevertheless, the general impression reached by many researchers is that wolves are typically monogamous, although exceptions to this rule are usually noted (Murie, 1944 ; Mech, 1970; Haber, 1977; Peterson, 1977).

The purpose of the present paper is to re-examine evidence con. cerning wolf mating systems. Data from wild and captive wolves will be examined separately. This brief review will indicate that at present the data that do exist largely contradict the notion of wolf monogamy. We will offer a classification system which appears to fit the pattern observed in wolves more closely.

\section{MATRG PATTERNS}

\section{Problems in Observing Mating Exclusivity}

The fundamental characteristic of monogamy is mating exclusivity. In wolves, this can be inferred by either the pattern of courtship activity and copulations, or the number of litters produced by a pack. The former provides direct evidence; the latter is indirect and inferential. Both measures, however, depend upon pack composition, which corresponds with the number of mature individuals of each sex. For example, if packs contain only one sexually mature male and female, then mating exclusivity may be the result of demographic patterns (Mech, 1970) rather than direct behavioral strategy (sensu Emlen and Oring, 1977). Thus, the exclusive and reciprocal courtship pattern between the sole mature pair of a pack seems best described as "de facto" monogamy. Evidence for what might be termed "preference" monogamy would be obtained if a similar exclusive and reciprocal mating pattern occurred in packs with more than one mature adult of both sexes. If such exclusivity still occurred despite the potential for polygamy or promiscuity, then it would be more legitimate to conclude that monogamy accurately characterizes the mating system.

To distinguish between de facto and preference monogamy, pack compositions must be known. Unfortunately, authors often do not 
distinguish packs on the basis of their composition, largely because they lack sufficient evidence. The problem is further compounded since smaller packs are easier to characterize but are more likely to contain only a single adult pair, whereas large packs are more difficult to characterize but are more likely to contain several adult members of both sexes. Thus, data from larger packs, necessary to distinguish de facto from preference monogamy, are usually too equivocal to permit firm conclusions.

Once pack composition is known, behavioral observations in principle can establish mating patterns. However, the descriptions will necessarily be limited for many reasons. Search time, fuel capacities, weather and light conditions, and vegetation and topography will jointly determine the quantity and quality of observa. tions. Only a small portion of the breeding season can be covered effectively. Copulations have been observed during only 17 of 52 pack-years of study in Isle Royale and Mt. McKinley National Parks (Mech, 1966; Jordan et al., 1967; Wolfe and Allen, 1973; Peterson and Allen, 1976; Haber, 1977; Peterson, 1977; Peterson and Scheidler, 1977, 1978, 1979). In addition, pack splitting during the breeding season (Jordan et al., 1967; Wolfe and Allen, 1973; Haber, 1977; Peterson, 1977; Harrington and Mech, 1979) further dilutes observational effectiveness, especially on a per-pack-basis. Finally, intrasexual interference (summarized by Rabb et al., 1967; Mech, 1970; Zimen, 1975, 1976; Packard, 1980; Packard and Mech, 1980) may reduce mating activity by subordinate animals in the presence of more dominant ones. Subordinates may restrict overt courtship and mating behavior to periods when dominant animals are otherwise occupied (see below), or visually isolated, making observations of courtship and mating among subordinates unlikely. These factors must be considered in any attempt to clarify wolf mating patterns.

Finally, it should be noted that summary terms such as "courtship", "subordinance", etc. employed by most researchers, and used by us below, are useful precisely because they classify into single categories a range of behavioral details that appear to form common sets of action. This can also be a danger when: (1) different investigators combine different details into categories with the same name, (2) the heterogeneity of actual performance details is forgotten through the use of unitary higher-order labels, and (3) terms are used as if they are descriptors when in fact they involve inferences about either (a) causal antecedents to behavioral performance or (b) consequences (functions) of that performance (e.g. Hinde, 1970; Moran et al., in press). However, in this review we must often take terms used by investigators at face value since the precise criteria used to define them are rarely available for independent scrutiny. Sometimes we have also found it necessary to use qualifiers such as "appeared to", "apparently", etc. when the data (observations) leading to conclusions by various authors are not published in detail. 


\section{Observations of Courtship and Mating in the Wild}

The following observations are based solely on packs known or suspected to have two or more adults of both sexes, although in some instances definitive proof is lacking for certain years.

Isle Royale: Mech (1970) reported a minimum of three adult females in a pack of 15 to 16 wolves between 1959 and 1961 . However, only one female closely associated with a male during the breeding season. Attempted copulations between this pair were noted in 1959 and 1960 . One copulation observed in 1959 apparently did not involve this pair. Other copulations were observed in 1959 and 1960, but identity of the pairs was not known. At least three different pairs were observed in mating activity, typically in. volving attempted copulations by the male that were thwarted when the female sat with tail between her legs. In both 1959 and 1960 , several males courted the three known females, although no apparent courtship patterns were established. Few observations were reported in 1961.

In 1962,1963 and 1965 , little mating activity was observed. This was interpreted as being due to the wolves' wariness of the spotting aircraft (Jordan et al., 1967).

There was apparently only one breeding pack (Big Pack) on the Island from 1968 to 1970 (Wolfe and Allen, 1973) following changes in the population structure during 1967 and 1968. Courtship was observed between a single pair all three years, and copulation by this same pair was seen in 1968. During all three years, a second male remained in close physical proximity to the courting pair.

Peterson (1977) found that courtship (primarily greeting, mounting, play-soliciting, genital examination) was confined to either the dominant (alpha) pair ( $n=49$; as measured by courtship behaviors) or to subordinates (pairs?) within the pack $(n=20)$ between 1971 and 1974; only twice did subordinate males direct courtship behavior to the alpha female. For both main packs (East Pack, West Pack) courtship (and in some years, copulations) was observed for the alpha pairs. However, the East Pack probably contained only one adult pair in 1971 and 1972 . In 1972 and 1974, a "subordinate pair" was also observed copulating in the West Pack. In addition to the mutual courtship activity of the alpha pair and the one subordinate pair, "one-sided" courtship was frequently observed, typically involving males attempting to copulate with females which rebuffed the mating attempts.

In 1976, two females reportedly came into estrus in two of the four packs followed (Peterson and Allen, 1976). The East Pack alpha male courted both females, although the subordinate female was un. receptive. No copulations were observed in any of the packs.

In 1977, the alpha male of a pack of four wolves copulated with a subordinate female. During the tie, the male defended his partner from attack by the alpha female. After mating, the subordinate 
female was chased by the pack for several kilometers over the ice between Isle Royale and Ontario, Canada. However, within two days the subordinate female returned to the pack and the alpha male con. tinued to court her. It was not determined whether the alpha male also mated with the alpha female, or which of the females produced pups, although at least one litter was suspected (Peterson and Scheidler, 1977; Peterson, 1979).

A limited number of recognizable wolves made observations of courtship difficult in 1978, although at least one female came into estrus in each of the four packs (Peterson and Scheidler, 1978). In the East Pack, a subordinate female also came into estrus and was courted by a subordinate male. This pair was frequently "punished" by the alpha pair following courtship activity. No copulations were observed in this pack.

There were apparent changes in the East Pack in 1979, which had the same dominant female since its inception in 1971. During that period, the alpha female had three different mates of two, one and five years' duration, respectively (Peterson and Scheidler, 1979). These mate changes were apparently necessitated by the disappearance of the previous male, although the circumstances surrounding these losses are unknown (Peterson, 1977). Until 1979, mating activity was observed only in the dominant female (although the alpha male courted an apparently unreceptive subordinate female in 1976). In 1979, however, two females were seen urine marking ${ }^{1}$ behavior usually associated only with the dominant female (Woolpy, 1968; Peters and Mech, 1975; Packard, 1980; Harrington, 1981), and the alpha male courted the subordinate female more "actively" than he did the alpha female. Relations between the two females were described as "amicable" (Peterson and Scheidler, 1979). The only copulation observed was between the alpha male and the subordinate female.

Mt. McKinley National Park: Haber (1977) reported that court. ship and mating in the Savage Pack occurred predominantly between the same alpha pair in 1970 and 1971. However, a second male (beta male) remained in close proximity to the pair both years and occasionally attempted to mount the alpha female, although he was usually prevented from approaching the alpha female by the alpha male, which often attacked and pinned the beta male to the ground. On one occasion in 1971 , the beta male mounted the alpha female twice while the alpha male was feeding 6-12 $\mathrm{m}$ away. The alpha female stood receptively both times, and the second attempt was interrupted after 20-30 seconds when the alpha male returned and stood between the two. Two days later the alpha pair copulated.

During 1972, both males showed interest in the new alpha female. The alpha male was usually close by and often physically "Urine marking is usually distinguished from other urinations based on several of the following criteria: frequent occurrence, deposition on conspicuous targets, brief duration, and use of raised leg posture. 
touching the female; the beta male remained 3-5 m away. The alpha male was aggressive to the beta male, especially on those occasions when the beta approached closer to the female. Copulation was observed between the alpha pair. In addition, a second female conceived and gave birth that year. Her mate was assumed to be another subordinate male since courtship activity between the two had been observed. Their mating activity was often interrupted by both highranking males.

In 1973 the beta male was absent, and the only overt courtship behavior observed was between the same pair as in 1972, which were seen to copulate once. No courtship activity was noted in 1974 , when the alpha male disappeared from the pack prior to the breeding season.

Between 1970 and 1973, the same alpha male mated with two different females. Each female was judged to occupy the alpha rank at the time of mating.

Few observations of mating activity were collected for the larger Toklat Pack, although it was known that two females mated in 1973. Unfortunately, the identity of only one of the females' mates was known. Several females evidently mated during a number of years, as judged by the prevalence of multiple litters in this pack (see section on multiple litters, below).

Summary: Few other field observations of comparable detail exist for free ranging wolves. The present evidence suggests the following: (1) Courtship activity frequently appears to be confined to pairs (usually the dominant or "alpha pair"). The second ranking male (commonly termed "beta") sometimes associates closely with the primary pair and is evidently sexually interested in the female. During all, or most, of the female's estrus, however, the beta male is kept away from her by the alpha male, which also prevents approaches by all other males. Thus, the number of mates for the alpha female ap. pears to be partly limited by male-male aggression. In one case where an alpha male relaxed his vigilance briefly to feed, the beta male mounted the alpha female twice; her receptiveness to this male's advances suggests she would have readily mated with him (Haber, 1977). In these instances, male-male aggression may be more important in producing exclusive mating patterns than female preference. (2) Alpha males have sometimes courted and copulated with subordinate females while still courting the alpha female. The alpha female usually is aggressive toward other females during the breeding season, although in one case the relationship seemed amicable. Here, restricted or exclusive mating by the alpha male may be determined more by the alpha female's suppression of mating activities in other females thail by the alpha male's commitment to monogamy. (3) More than one male and female in a pack may copulate.

Observations of Courtship and Mating in Captivity

Although it has been argued reasonably that captive observations 
are "more likely... anomalous, reflecting the greater stress of captivity" (Haber, 1977:240), the precise influence of various environmental conditions upon courtship, mating, and other patterns of behavior in wolves has not been examined systematically at the present time. Certainly the close observations permitted by captive studies on groups of animals (1) with individual histories that are known in detail and (2) that live under environmental conditions that can be controlled, are potential advantages. Ideally, of course, data obtained in captivity should be compared with that found in the field, for in this way the strengths of various constraints on behavior can be assessed directly.

Our survey of the literature does suggest two areas of contrast between most captive and wild conditions that need to be accounted for. (1) The manner of establishing a captive pack (e.g. from a same. age group of siblings [Rabb et al., 1967]) may differ from that of most wild packs (e.g. from a pair of unrelated lone wolves [Mech, 1970]), introducing a confound which may bias the expression of behavior within the captive group. For example, incest avoidance mechanisms (if such exist) could influence mating patterns in the group, possibly for many years. However, it is also important to maintain the distinction between evolutionary (genetic) biases in behavior and individual developmental histories-an area where captive studies can be most useful. (2) The normal expression of some forms of behavior (e.g. foraging, dispersal) is limited, possibly distorted, or even eliminated. This may have effects on the "normal" expression of various other forms of behavior. The potential influence of any given variable upon entire networks of behavior, both directly and indirectly, is again most readily assessed through close and controlled observations such as permitted by captivity. These detailed observations can then be compared to data available in the wild as a test of their generality. Until this is done, it is dangerous to assume either similarities or differences of behavior under different circumstances.

In this survey we necessarily omit some of the desirable refinements of captive/field comparisons, and focus upon those data that do exist which are relevant to the broad theme of observed monogamy (and its limitations). While captive and field studies cannot be simply superimposed we do find apparent similarities in mating that invite more detailed comparisons in the future.

Brookfield Pack: Rabb et al. (1967) observed a pack in a 0.3 ha enclosure. The group initially consisted of five pups from two litters sired by a common father. Between 1960 and 1963, courtship patterns were fairly restricted: each of three females primarily courted a single male while one male courted a single female and the other courted all three, although with unequal frequency. Only the dominant female copulated, except once when a subordinate female mated while the dominant female was tied.

Mating was not as restricted in later years. The dominant female 
had two and three mates in 1963 and 1964, respectively. Another female had two mates in 1965. In 1966, individual females had three, two, two and no mates, while males had three, two, one, one and no mates, respectively. Throughout the study, individuals demonstrated long-term sexual preferences for certain other individuais. However, these individual preferences were not always predictive of copulation patterns. For example, the original dominant female courted and solicited the dominant male preferentially, but he did not reciprocate and they never mated. In addition, these preferences were usually not exclusive. For example, one female courted two, two, four and two males between 1963 and 1966. In turn, two, three, five and three males courted her in the same years. Her only observed copulations were with two males in 1966.

Bavarian Forest Pack: Zimen $(1975,1976)$ observed a group in a much larger enclosure (approximately 6 ha). The only adult female in the original group of four littermates did not mate with her brothers in 1971 or 1972 , although she was courted by two lower ranking brothers. An unrelated female pup, introduced in 1971, became the dominant female in 1973. She was courted by all the males except a littermate and the alpha male (the same as in 1971 and 1972). She courted the alpha male, which did not reciprocate. She eventually copulated with the beta male.

In 1974, the same alpha female was courted by several males. For a period of 12 days, she mated with her mate of the previous year who, at that time, was the dominant male. She then copulated for three days with a two year old male who, based on the date of parturition, evidently sired the litter.

In 1975, the alpha female maintained her status. Early in estrus, she mated with her original mate from 1974. She then copulated with another. two year old male. Finally, during the last portion of her estrus, she mated with her second mate from 1974, who apparently once again fathered the litter. No other females mated during the study because (1) most were excluded from the pack by the dominant female, (2) those that remained with the group were not courted by males, or ( 3 ) their courtship activities were obstructed by the dominant female.

Shubenacadie Pack: Fentress and co-workers (Fentress and Ryon, this volume, and unpublished data) have observed a group of wolves in a heavily-wooded 3.4 ha enclosure since 1974. Initially, there was an adult pair, their six pups (two male/four female), and two female yearlings (unrelated to the other animals). Two pups (male/female) were removed at 11 days of age and reunited with the pack six months later. The female pup was killed the following mating season, several months after reintroduction.

Prior to the pups' reintroduction, the 11 year old adult male died. In 1975 , no mating activity was observed. Mating resumed in 1976 when the pups were 22 months old. From then until 1980 , the reintroduced male was observed to copulate, although he was socially 
mubordinate to his brother as determined by outcome of aggressive interactions between the two males. He copulated with his mother in 1976, 1978, and 1979, and with at least two of his sisters in 1978, 1979, and 1980. In addition, several other females also mated and produced pups each year, but their mates were unknown. Other males in the group were not observed to copulate until 1980, when the dominant male from the 1974 litter, and another born in 1976 , mated with the two females born in 1977.

All six females which mated and whelped between 1976 and 1980 , courted the reintroduced male more frequently than any of the other males. Aspects of female courtship included initiation of body contact (T-formation [Golani and Mendelssohn, 1971], muzzling, body rubbing) and tail aversion.

Connecticut Pack: Schotte et al. (1977) and Schotté and Ginsburg (1978) detailed the mating patterns of a pack of wolves descended from an unrelated pair, placed together in a $<0.1$ ha enclosure. In the second breeding season, several of the 10 month old males exhibited interest in their mother (e.g., investigated genital area, or placed chin or feet on her back), but all observed mounting and copulation was done by the dominant adult male. The following season, one of the then 22 month old males courted his mother more persistently than did the adult male, and both males copulated with her. The other 22 month old males also showed interest in the female although, evidently, none mated with her. In the next breeding seacon, three of five males actively courted the dominant female atthough only the original, dominant male was seen to copulate with her. The dominant female did not appear actively to discourage courtship by her offepring, although she was less likely to stand during their attempted copulations (12\% of offspring's mounts versus $84 \%$ of the alpha male's). High ranking males interfered with mating attempts by subordinate males. Less interest was exhibited by the males toward the subordinate females $(\bar{x}=116$ courtship actions to subordinate females versus 925 to the dominant female). It was suggested that these younger females (two and three years old) may not have reached behavioral sexual maturity, "perhaps due to the presence of an older dominant female who is their mother" (Schotté and Ginsburg, 1978:12).

Summary: Captive studies indicate that mating patterns can involve a complex web of interaction among many individuals. Common to these studies is a low incidence of mating exclusivity. Mating preferences do occur, as measured by the direction and frequency of courtship between various individuals, but these preferences are relative rather than absolute. Females and males that mate often have two or more mates during the same breeding season. In cases where mating is restricted to a single pair, intrasexual aggression appears to be a common factor limiting breeding opportunities. When sociallyimposed restrictions are absent, a pattern of polygamy/promiscuity occurs. Since promiscuity implies the lack of long-term inter- 
individual bonds and indiscriminate mating (Selander, 1972), polygamy better characterizes captive wolf mating systems, with its often long-term individual preferences.

\section{NUMBER OF LITTERS PER PACK}

A further characteristic of a mating system is the number of individuals producing each year's young. Not all females that breed necessarily produce young. Wild packs are typically characterized as producing single litters (Van Ballenberghe and Mech, 1975; Haber, 1977; Peterson, 1977); multiple litters (Murie, 1944; Clark, 1971) are thought to be exceptional. However, since pack compositions are often poorly known, single litters might indicate, in at least certain cases, that packs contain only a single breeding female. Thus, pack composition must be considered when calculating the ratio of multiple to single litters in packs.

When only data from packs known to have at least two adult females are considered, the frequency of multiple litters is substantial (Table 2.1).

Table 2.1: The Prevalence of Multiple Litters in Wild and Captive Wolf Packs Containing at Least Two Adult Females

\begin{tabular}{|c|c|c|c|c|}
\hline Lecation & $\begin{array}{l}\text { ONe No } \\
\text { Single } \\
\text { Ltther }\end{array}$ & $\begin{array}{l}\text { Me of Pact- } \\
\text { Multiple } \\
\text { Liturs }\end{array}$ & $\begin{array}{l}\text { With... } \\
\text { Unknown }\end{array}$ & Reference \\
\hline \multicolumn{5}{|l|}{ wild Peks } \\
\hline $\begin{array}{l}\text { Nogk } \\
\text { Me. Mekinley Nutional Park } \\
\text { Me. MeKiniey Nitional Park }\end{array}$ & 3 & $3^{3 *}$ & $\begin{array}{l}1 \\
0\end{array}$ & $\begin{array}{l}\text { Reunch, } 1967 \\
\text { Nurie, } 1944\end{array}$ \\
\hline 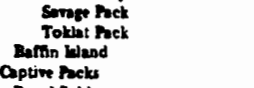 & $\stackrel{4}{3-8}$ & $0_{1}^{1}$ & $\begin{array}{l}1 \\
1 \\
0\end{array}$ & $\begin{array}{l}\text { Haber, } 1977 \\
\text { Habet, } 1977 \\
\text { Cark, } 1971\end{array}$ \\
\hline $\begin{array}{l}\text { Optive Prekts } \\
\text { Brookfield }\end{array}$ & 14 & 8 & 0 & $\begin{array}{l}\text { Rebbet al., } \\
1967, \text { perm. } \\
\text { comm. }\end{array}$ \\
\hline Bonrian Forest & 3 & 0 & 0 & $\begin{array}{l}2 \text { Lmen, } 1975, \\
1976\end{array}$ \\
\hline Subenucadie & 0 & 5 & 0 & $\begin{array}{l}\text { Fentres \& Ryon } \\
\text { (this volume) }\end{array}$ \\
\hline $\begin{array}{l}\text { Crtos Avery } \\
\text { Woif Purk }\end{array}$ & ? & $\begin{array}{l}1 \\
1\end{array}$ & $\begin{array}{l}0 \\
0\end{array}$ & $\begin{array}{l}\text { Pelard, } 1980 \\
\text { Dinghammes, } \\
\text { per. comm. }\end{array}$ \\
\hline $\begin{array}{l}\text { Nemead ' Puck } \\
\text { Derrow Colony }\end{array}$ & $\frac{1}{2}$ & 2 & $\begin{array}{l}0 \\
0\end{array}$ & $\begin{array}{l}\text { Alumand, } 1974 \\
\text { Lentfer \& } \\
\text { Sagders, } 1973\end{array}$ \\
\hline Connereticut & 2 & 0 & 0 & $\begin{array}{l}\text { Schotle und } \\
\text { Gimebert. } 1978\end{array}$ \\
\hline Weatimpton Park & 2 & 1 & o & $\begin{array}{l}\text { Pequet of al., } \\
\text { this volume }\end{array}$ \\
\hline \multicolumn{5}{|c|}{ 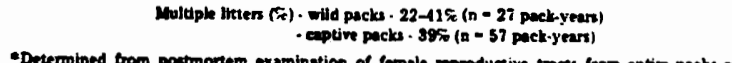 } \\
\hline \multicolumn{5}{|c|}{ 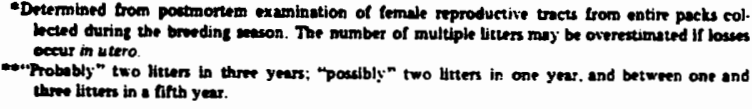 } \\
\hline
\end{tabular}


In the wild, frequency of multiple litters may range between 20 and 40 percent. These estimates are probably minimal figures since early mortality, combining of litters (Murie, 1944; Clark, 1971), and observational difficulties reduce the chances of locating all litters. All the wild data come from relatively open habitats. Finding dens and observing litters in forested habitats is extremely difficult and rarely accomplished (Mech, 1966; Peterson, 1977). Thus, whether forest dwelling wolves have multiple litters at rates comparable to tundra wolves is unknown.

The frequency of multiple litters is as high in wild packs as it is in captivity (Table 2.1), suggesting that the patterns of mating behavior observed in captivity have their counterparts in the wild.

\section{DISCUSSION}

This review of wolf mating systems was not intended to be ex haustive. Rather, we have selected representative long-term and detailed field and captive studies to examine two primary questions: (1) can wolf mating patterns be legitimately termed monogamous, and (2) do packs typically produce only one litter per year? We focused on these aspects because both scientific and popular writing frequently allude to them, and because, as we have shown, both appear to be erroneous.

The frequency of multiole litters in the wild is much greater than a cursory reading of the literature might suggest. Therefore, rather than dismissing multiple litters as exceptional, or attempting to place statistical limits on their frequency, we suggest that future studies concentrate on identifying factors which influence their expression. Neither multiple nor single litters should be viewed as anomalies; both should eventually become predictable results of a definable set of interacting social and ecological factors. It will, however, be im portant that these factors, as well as the rules by which they interact, be specified with as much clarity as possible.

Several factors leading to multiple litters have been suggested. Temporary pack splitting (Mech, 1966; Jordan et al., 1967; Haber, 1977) during the breeding season is thought to facilitate multiple litters by freeing subordinate wolves of social suppression by dominant pack members (Zimen, 1975; Haber, 1977), although subordinate females have mated in the presence of the alpha female (Peterson, 1979; Peterson and Scheidler, 1977, 1979). In one pack, a subordinate female came into estrus and mated with no apparent antagonism from the dominant female, which at the time was at least nine years old (Peterson and Scheidler, 1979). The loss of the former alpha female may also facilitate multiple litters; the only case of multiple litters observed in one Alaskan pack occurred after the alpha female disappeared prior to the breeding season (Haber, 1977). Kinship patterns (which apparently can influence mating patterns in 
a pack (Zimen, 1976]), female reproductive value and various ecological factiors (prey type, abundance, etc.) might also influence the number of litters in a pack.

One issue that has confronted us in our attempts to evaluate critically the existing behavioral data related to monogamy is that details of behavioral performance which might help clarify both phenomenology and mechanism are frequently lacking. It is not always clear, for example, whether one investigator's use of a term such as "courtship" corresponds in detail with the observations similarly classified by another (or even by the same observer on a different occasion, for a different animal, etc.). Certainly it is important to bear in mind that summary terms such as courtship reflect a diversity of particular actions that may fluctuate more or less independently. The problem is compounded when terms that imply description also incorporate inferences about either causation or function (see Hinde, 1970).

Even apparently straightforward measures of "amount of", "intensity", etc. applied to a single measure of behavior must be viewed cautiously if the details of measurement are not provided. Thus, frequency, duration, bout composition, persistence, and the like are often taken as equivalent measures of behavioral tendencies when they can in fact vary independently (Fentress, 1973). Two additional considerations limit the precision of conclusions available at the present time. The first is the frequent use of terms of intention (e.g. this wolf meant to do that) with no clear reference to overt action. The second is a common tendency to treat individually defined actions (behavioral classes) as if they are totally independent in their expression when in fact tendencies to perform one set of activities almost invariably influence tendencies to express descriptively quite different action classes. This, combined with the nonunitary nature of behavioral categories (above), makes the interpretation of direct versus indirect influences of any given variable in behavior a problem for analysis rather than assumption. Here future comparisons between field and captive studies, if pursued rigorously, could make a substantial contribution to our knowledge.

Resolving the question of monogamy also depends, in part, upon how it is defined. True or "preference" monogamy implies that a pair develops a social bond which precludes the formation of similar bonds with other individuals, thus limiting courtship and mating to one partner. By these criteria, wolves are not monogamous, since exceptions to mate exclusivity have been observed in many captive packs and have been indicated in several wild studies. It could be argued that relative, rather than absolute preference should be used to characterize monogamy; as long as one partner is "typically" preferred, the label of monogamy can still be employed. Loosening the criteria, however, introduces the necessity of establishing limits. At what point does "monogamy" cease and "polygamy" begin? In addition, social constraints limiting courtship must be considered. 
How much of the observed pattern reflects preferences of $A$ for $B$, and what proportion reflects restriction imposed upon both $A$ and $B$ by intrasexual competition.

Additional qualifications such as "de facto" or "forced" monogamy may be useful as they indicate the dependence of mating systems on the availability of mates in both a spatial and social context. Both reflect situations commonly encountered by wolf packs. De facto monogamy occurs whenever packs contain only one adult pair, which typically would occur for several years after the founding of a pack. In later years, de facto monogamy will recur whenever mortality or emigration again reduces the pack to a single adult pair. "Forced" monogamy occurs when there is a potential for polygamy in the pack which is not realized because of intrasexual dominance and aggression. With both de facto and forced monogamy, an individual has no choice as to a mating partner. Because options for mating are limited by factors other than choice, it may not be appropriate to label these patterns monogamous.

Kleiman (1977:39) distinguished two general forms of monogamy. Type I, or facultative monogamy, with "males and females being so spaced that only a single member of the opposite sex is available for mating," is analogous to de facto monogamy. Type II, or obligate monogamy, in which "a solitary female cannot rear a litter without aid from conspecifics," encompasses both de facto and forced monogamy and, if it occurs, preference monogamy. However, it must be emphasized that the aid given the female need not depend on a monogamous bond. The wolf may be an obligate social species, but its mating system need not be obligate monogamy. Type I and II monogamy characterize only a subset of mating patterns found in wolves, and are thus inadequate for characterizing wolf mating systems.

A classification scheme more relevant to wolves has been provided by Emlen and Oring (1977:217). Monogamy, where "neither sex has the opportunity of monopolizing additional members of the opposite sex," fits most, or all, new and many smaller packs characterized by de facto monogamy. Larger packs, containing more than one adult of each sex, would be characterized by two forms of polygamy. The male mating patterns resemble those of female defense polygyny in which "males control access to females directly, usually by virtue of female gregariousness" (Emlen and Oring, 1977: 217). But unlike many mammalian systems in which dominant males have many mates and subordinates few or none, dominant male wolves may have only one mate while subordinates have none. The results are nevertheless similar: dominant males have greater genetic representation because of their apparent ability to restrict subordinates' access to females. The female mating patterns resemble those of female access polyandry, in which "females do not defend resources essential to males but, through interactions among themselves, may limit access to males" (Emlen and Oring, 1977:217). 
Again, some females have greater genetic representation because they prevent other females from mating. This classification not only appears to fit most observations of wolf mating activity, but also has the advantage of being dynamically tied to the composition of adults in a pack. Changes in adult composition, or operational sex ratios (Emlen and Oring, 1977) will have important effects on courtship and mating patterns. Finally, because packs are normally composed of related individuals (Mech, 1970), kinship relationships should influence the pattern and frequency of intrasexual and intersexual reproductive activity. Here, of course, it is important to retain the distinction between evolutionary (genetic) and developmental (ontogenetic) precursors to behavior-a point where both field and captive studies offer potentially important, but incompletely explored, perspectives.

\section{SUMMARY}

A review of mating activity in wild and captive packs indicates monogamy is only one form that wolf mating systems will follow. Three forms of monogamy are distinguished. De facto monogamy occurs when only one adult pair is present, as in new and some small packs. Forced monogamy occurs when intrasexual aggression limits courtship and mating to one partner, despite the presence of other potential mates. Preference monogamy occurs when individuals, by choice, limit their courtship and mating to one partner. Unequivocal evidence for the latter form does not exist at present, and the former two forms characterize only a subset of observed mating patterns. Other evidence suggests that wolf mating systems are often polygamous, with courtship and mating patterns influenced strongly by intrasexual competition and aggression. Males exhibit a female defense polygyny and females exhibit a female access polyandry. The need for more precise measures of behavioral profiles as well as their distal and proximal antecedents is emphasized. 


\section{APPENDIX B}

\section{A SHORT DESCRIPTION OF BEHAVIOR PATTERNS OBSERVED}

$$
\text { ADOPTED FROM ZIMEN (pers. comm.) }
$$

Behavior Pattern

NEUTRAL SOCIAL CONTACTS

Muzzle to muzzle contact Muzzle sniffing, seldom licking

Muzzle to fur contact

Fur biting

Fur licking

Genital sniffing

Genital licking

Anal sniffing

Anal licking

Standing over partner SUBMISSIVE BEHAVIOR

Crowding

Active submission

Passive submission

\section{Short Description}

Fur sniffing

Biting or pulling of fur

Often licking of wounds

Standing transversely over lying partner
Friendly jostle around dominant

Face licking, etc.

Falling and/or lying on back with slightly raised hind leg in front of dominant

AGONISTIC BEHAVIOR

AGGRESSIVE BEHAVIOR, GENERALLY WITHOUT BODY CONTACT

offensive threat

Snarling with raised lips; many combinations with other inhibited aggressive behaviors possible 
Behavior Pattern

Ambush

Following

Mobbing

Attack

Chasing
Short Description

Sudden threat attack

Walking or running behind opponent, often in imposing posture, without trying to catch up

One, but more often two or more, wolves encircling defensive opponent

Sudden real attack from some distance

Full speed chase in order to catch opponent

AGGRESSIVE BEHAVIOR GENERALLY WITH BODY CONTACT, BUT BITING NOT INVOLVED

Imposing

Impose-shoving

Front feet on back

Pinning down with head

Pinning down with body

Jump on

Standing over opponent

Shoving

Hip slam
St iff-legged walk toward, parallel or perpendicular to opponent, with raised hackles

Lateral body shoving of opponent, often with neck display

Standing with stiff front feet on back of opponent

Lying opponent is pinned to the ground by dominant, keeping head or wide-open muzzle over head, neck or throat

Opponent is pressed to ground by dominant lying on top of it

Sudden jump on opponent, who normally rolls onto back

Standing stiff-legged over, or with one or two feet on lying opponent

Tactic to ward off bites when closing in on opponent

Full lateral body slam when running past opponent

AGGRESSIVE BEHAVIOR INVOLVING INHIBITED BITING

Biting over muzzle

Highly inhibited aggression toward pups or low ranking pack members, sometimes a friendly social contact 
Behavior Pattern

Lunge and snap

Inhibited body biting
Jumping forward, directing snaps;

sometimes more severe bites, mostly toward hind quarter of opponent

More or less inhibited biting, mainly toward front parts of opponent; loud vocalizations

AGGRESSIVE BEHAVIOR WITH UNINHIBITED BITING

Severe biting

Head shake

\section{DEFENSIVE BEHAVIOR}

Defensive threat

Defensive lunge and snap

Snap clatter

Keeping distance

Flight

Defensive circling

Defensive bite

\section{PLAY BEHAVIOR}

Initiating play

Play with body contact

Play running

SEXUAL BEHAVIOR

Presentation
Getting a strong hold of any part of opponent's body; biting with full strength

While biting, vigorous lateral head shaking

Full snarl, ears back

Short jumps forward, directing snaps mostly toward face of attacker, mobber

When snapping in the air, a noisy beat made by the teeth when jaws hit together

Walking or running away from follower without trying to enlarge distance

Full speed run away from attacker, chaser When mobbed on the spot, circling, trying to avoid being attacked from behind Full power bite when severely attacked

Play bow, playful approach, playful run away, etc.

Wrestle, play biting, etc.

Playful chase

Females walking or standing in front of male, holding tail sideways 
Behavior Pattern

Mounting

Pelvic thrusts
Short Description

Almost exclusively males mounting females from behind

While mounting 